Paulo Ricardo Ilha Jiquiriçá

\title{
Efeitos letais e subletais da poluição por nitrogênio em larvas de anuros
}

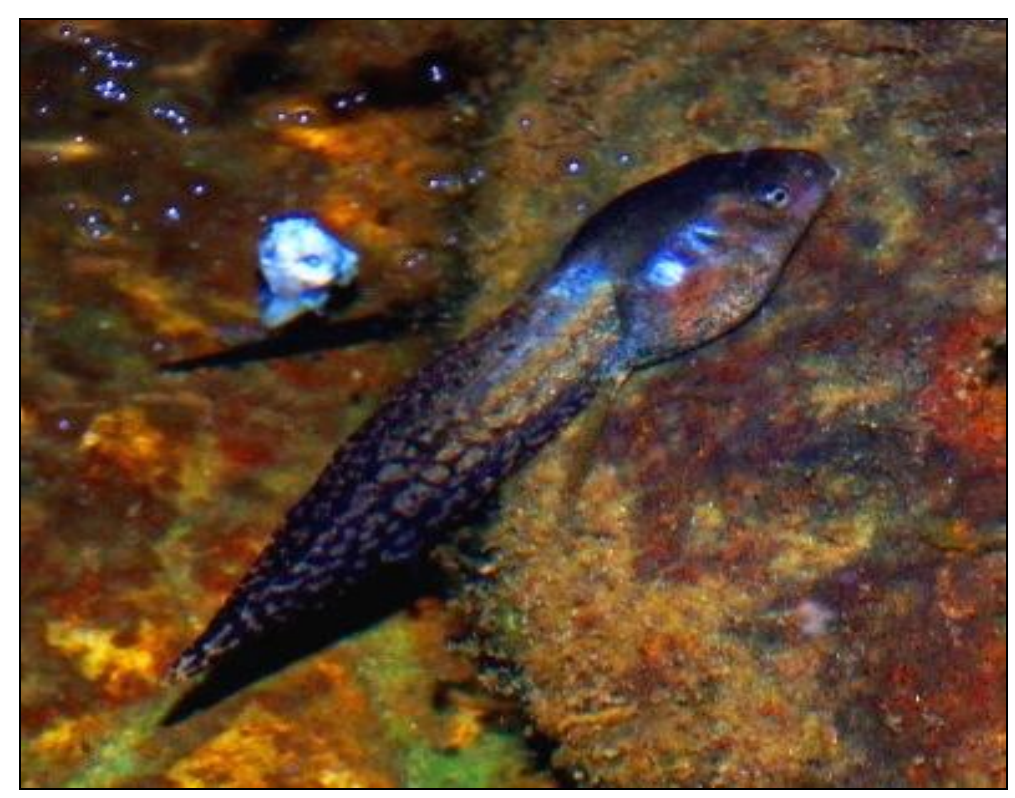

Lethal and sublethal effects of nitrogen pollution on anuran larvae 
Paulo Ricardo Ilha Jiquiriçá

\section{Efeitos letais e subletais da poluição por nitrogênio em larvas de anuros}

Lethal and sublethal effects of nitrogen pollution on anuran larvae

Dissertação apresentada ao Instituto de Biociências da Universidade de São Paulo, para a obtenção de Título de Mestre em Ciências, na Área de Ecologia.

Orientador: Luis Cesar Schiesari

São Paulo 
Ficha Catalográfica

Ilha, Paulo

Efeitos letais e subletais da poluição por nitrogênio em larvas de anuros Número de páginas

Dissertação (Mestrado) - Instituto de Biociências da Universidade de São Paulo. Departamento de Ecologia.

Palavras-chave: 1.Nitrato 2.Nitrito 3.Amônio 4.Toxicidade 5.Anfíbios

Universidade de São Paulo Instituto de Biociências Departamento de Ecologia

Comissão Julgadora:

$\operatorname{Prof}(a) . \operatorname{Dr}(a)$.

$\operatorname{Prof}(\mathrm{a}) . \operatorname{Dr}(\mathrm{a})$.

Prof. Dr. Luis Cesar Schiesari

Orientador 
À Maria Cláudia, minha mãe, por me ensinar a sonhar alto com os pés no chão 
"Todas as doenças têm seu princípio em uma das três substâncias:

Sal, Enxofre ou Mercúrio.

Isto quer dizer que podem ter sua origem no domínio da matéria,

na esfera da alma, ou no reino do espírito.

Se o corpo, a alma e a mente estão em perfeita harmonia uns com os outros,

não existe nenhuma discordância.

Mas se uma causa de discordância em um destes três planos se origina,

isto se comunica aos demais."

(Paracelso) 


\section{Agradecimentos}

Sou profundamente grato ao Professor Luis Schiesari por todos os seus ensinamentos e pela dedicada orientação; a André Gulfier, Antonio Carlos da Silva, Mariana Fekete Moutinho e Arthur llha (meu irmão) pela enorme ajuda prestada no laboratório; aos Professores Britta Grillitsch, Glauco Machado e Paulo Inácio Prado pelas sugestões feitas no decorrer deste trabalho; à Escola de Artes, Ciências e Humanidades da Universidade de São Paulo, ao Museu de Zoologia da Universidade de São Paulo e à Estação Biológica de Boracéia pelo apoio logístico; à Coordenação de Aperfeiçoamento de Pessoal de Nível Superior (CAPES) pela bolsa de estudo concedida; ao CNPq (Edital Universal Projeto 483801/2007-0) e à FAPESP (Projeto 2008/57939-9) pelo financiamento; e a Deus pelas oportunidades e condições que me foram confiadas. 


\section{Índice}

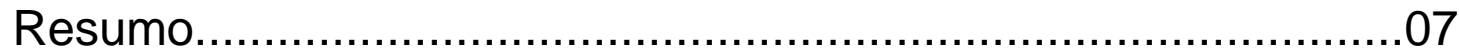

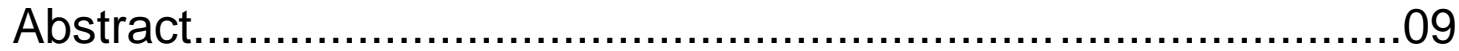

Introdução....................................................................... 11

Materiais e Métodos............................................................22

BIOENSAIOS DE EXPOSIÇÃO AGUDA....................................25

EXPERIMENTOS DE EXPOSIÇÃO CRÔNICA..............................28

Resultados

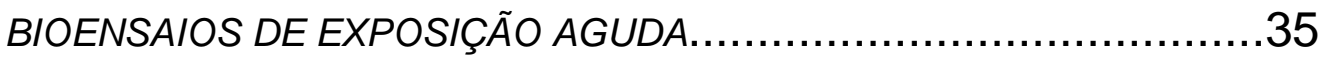

EXPERIMENTOS DE EXPOSIÇÃO CRÔNICA...............................42

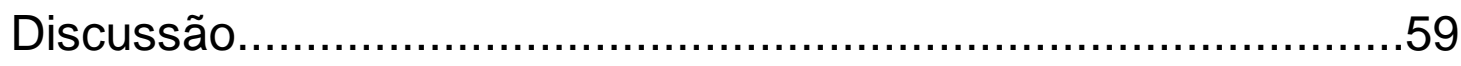

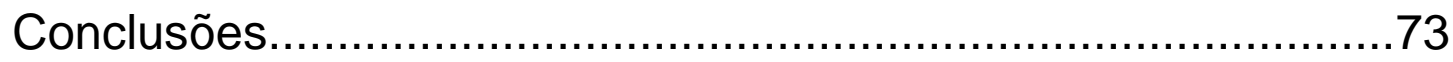

Referências Bibliográficas...................................................74 


\section{Resumo}

As atividades humanas vêm aumentando dramaticamente a quantidade de nitrogênio inorgânico liberado nos ecossistemas, seja através da aplicação de fertilizantes na agricultura, da descarga de dejetos humanos e de seus rebanhos, ou da queima de combustíveis fósseis. Os excessos de nitrogênio são eventualmente transportados para corpos d'água, onde podem, na forma de nitrato, nitrito e amônio, atingir concentrações tóxicas para organismos aquáticos. Nesta pesquisa tive dois objetivos principais. O primeiro foi testar em laboratório a toxicidade relativa dos íons nitrato, nitrito e amônio, e a variação interespecífica na sensibilidade a esses íons, em larvas de cinco espécies de anuros (Rhinella ornata, Hypsiboas faber, Hypsiboas pardalis, Physalaemus cuvieri e Physalaemus olfersii). Para isso utilizei bioensaios seguindo protocolos internacionalmente padronizados para testes de ecotoxicidade com organismos aquáticos, e que portanto permitem máximas reprodutibilidade e comparabilidade de resultados entre compostos, espécies, e laboratórios. No entanto, estes bioensaios carecem de realismo uma vez que simulam um cenário de exposição aguda a altas concentrações de contaminantes quando na natureza o cenário de exposição tende a ser crônico e prolongado a baixas concentrações. Além disso, bioensaios usam mortalidade como principal variável de resposta, quando também efeitos subletais podem influenciar a persistência de populações ao modular o sucesso dos indivíduos. Por isso, meu segundo objetivo foi testar em laboratório se concentrações relativamente baixas e ecologicamente relevantes de nitrato, nitrito e amônio podem afetar a sobrevivência, o crescimento, o desenvolvimento e o comportamento das larvas de $R$. ornata, $P$. cuvieri e H. faber. Demonstrei através dos bioensaios de exposição aguda que nitrato, a forma mais abundante na natureza, é de baixa toxicidade quando comparada a nitrito e amônio. Demonstrei também que há significativa variação interespecífica na sensibilidade ao nitrogênio inorgânico, e que o ranqueamento de 
sensibilidade das espécies ao nitrato e ao nitrito foram similares, possivelmente por conta de mecanismos comuns de ação tóxica. Através de experimentos de exposição crônica demonstrei que concentrações relativamente baixas de nitrogênio inorgânico podem causar efeitos letais e subletais às larvas de anuros se houver exposição prolongada. O nitrato causou redução no desenvolvimento larval de $P$. cuvieri e o amônio na sobrevivência e nas taxas de atividade nos girinos de $H$. faber. A exposição crônica ao nitrito também reduziu significativamente a sobrevivência das três espécies testadas, o crescimento de $H$. faber e as taxas de atividade de $R$. ornata. Contudo, é improvável que as concentrações de nitrito que manipulei em laboratório sejam comuns na natureza, especialmente em condições aeróbicas. Esta pesquisa, além de fornecer importantes informações sobre os possíveis efeitos da poluição por nitrogênio em larvas de anuros, contribui para o avanço da ecotoxicologia no Brasil ao estabelecer as bases para o emprego de espécies nativas de anfíbios como sistema-modelo experimental. Estudos futuros que almejem avaliar o risco ambiental da contaminação por nitrogênio deverão por um lado monitorar concentrações em hábitats naturais e por outro avaliar as consequências das interações sinérgicas entre nitrogênio inorgânico e outros estressores físicos, químicos ou biológicos para larvas de anfíbios. 


\section{Abstract}

Human activities dramatically increased the amount of inorganic nitrogen released in ecosystems through the application of fertilizers in agriculture, the generation of human and livestock waste, and the combustion of fossil fuels. This nitrogen eventually reaches water bodies where it can, in the form of nitrate, nitrite and ammonium, be toxic to aquatic organisms. In this study I had two main objectives. The first was to test the relative toxicity of nitrate, nitrite and ammonium, and the interspecific variation in sensitivity to these ions, in tadpoles of five anuran species (Rhinella ornata, Hypsiboas faber, Hypsiboas pardalis, Physalaemus cuvieri and Physalaemus olfersii). This objective was accomplished by laboratory bioassays following internationally standardized protocols for ecotoxicity tests with aquatic organisms, therefore allowing maximum reproducibility and comparability of results among compounds, species and laboratories. However, these bioassays lack realism for simulating a scenario of acute exposure to high concentrations of contaminants, while exposure in nature tends to be chronic and prolonged at low concentrations. Furthermore, bioassays use mortality as the main response variable, whereas sublethal effects may also influence the persistence of populations by modulating individual success. My second objective was therefore to test in the laboratory if low and environmentally relevant concentrations of nitrate, nitrite and ammonium affect survival, growth, development and behavior of $R$. ornata, $P$. cuvieri and $H$. faber larvae.

Through acute exposure bioassays I demonstrated that nitrate, the most abundant $\mathrm{N}$ form in nature, has low toxicity when compared to nitrite and ammonium. I also demonstrated that there is significant interspecific variation in the sensitivity to inorganic nitrogen, and that the ranking of species sensitivity to nitrate and nitrite were similar, possibly due to common mechanisms of toxic action. Through chronic 
exposure I demonstrated that relatively low concentrations of inorganic nitrogen can cause lethal and sublethal effects on anuran larvae if there is extended exposure. Nitrate decreased developmental rate in $P$. cuvieri and ammonia decreased survival and activity rates in $H$. faber tadpoles. Chronic exposure to nitrite also significantly reduced survival of all three species tested, growth of $H$. faber and activity rates of $R$. ornata. However, it is unlikely that the concentrations of nitrite manipulated in the laboratory are common in nature, especially in aerobic conditions. This is the first study to document deleterious effects of nitrogen pollution to Brazilian amphibian species, and contributes to the development of ecotoxicology in Brazil by establishing the basis for the employment of native amphibians as model experimental system. Future studies that aim to assess the environmental risk of nitrogen contamination should monitor concentrations in natural habitats and evaluate the effects of synergistic interactions between inorganic nitrogen and other physical, chemical or biological stressors to amphibian larvae. 


\section{Introdução}

As atividades humanas vêm dobrando a quantidade de nitrogênio reativo que é produzido no mundo, e dessa forma alterando significativamente o ciclo biogeoquímico de um dos elementos mais importantes para o metabolismo dos ecossistemas (Vitousek et al., 1997; Esteves, 1998; Galloway et al., 1998; Kalff, 2002). A importância do nitrogênio deve-se ao fato dele integrar moléculas biológicas envolvidas na estrutura, armazenamento, atividade, metabolismo, e regulação de seres vivos (Sterner \& Elser, 2002). Consequentemente, alterações na especiação molecular, disponibilidade, distribuição e abundância relativa deste elemento têm conseqüências determinantes para a performance dos indivíduos, para a dinâmica das populações e para a estrutura e composição das comunidades biológicas.

As alterações antrópicas no ciclo do nitrogênio vêm sendo dramáticas desde o século passado (Filoso et al., 2006). Estas alterações derivam principalmente da fixação de nitrogênio atmosférico através do cultivo de espécies vegetais fixadoras e de processos industriais de produção de fertilizantes para propulsionar a produtividade agrícola; dos dejetos derivados do consumo secundário desta produtividade agrícola pelo homem e seus rebanhos em atividades domésticas e industriais; e pela liberação do nitrogênio armazenado na biomassa através do desmatamento e da queima de combustíveis fósseis (Galloway, 1998; Rouse et al., 1999; Stoddard et al., 1999; Sterner \& Elser, 2002).

Tais alterações manifestam-se em múltiplas escalas espaciais: embora descargas maiores de nitrogênio concentrem-se em áreas de agricultura intensiva e em regiões industrializadas (Matthews, 1994; Townsend et al., 1996), mecanismos de transporte regionais como rios, e globais como correntes oceânicas e massas de ar, têm o potencial de redistribuir o nitrogênio de modo a atingir áreas remotas e 
aparentemente não perturbadas, onde mesmo baixas concentrações podem ter consequências biológicas importantes (Blaustein et al., 2003). Por conseguinte, a questão da alteração do ciclo do nitrogênio é um problema sério em potencialmente qualquer área ou ecossistema do planeta.

Das atividades antrópicas, a produção de alimento é responsável pelo maior aporte absoluto de nitrogênio em ecossistemas (Galloway, 1998). Até aproximadamente 1960, a maior contribuição vinha do cultivo de espécies fixadoras de nitrogênio (Young, 1992), e ainda hoje essa via contribui significativamente para o orçamento de nitrogênio (Sterner \& Elser, 2002; Filoso et al., 2006). Contudo, com o desenvolvimento do processo Haber-Bosch de fixação industrial (conversão de $\mathrm{N}_{2}$ para $\mathrm{NH}_{3}$ ) a utilização de fertilizantes à base de $\mathrm{N}$ aumentou rapidamente (cerca de 10 vezes até 1990) e este se tornou o processo dominante (Oldham et al., 1997; Galloway, 1998; Rouse et al., 1999). A injeção maciça de fertilizantes em agroecossistemas no mundo todo despeja cerca de 80 bilhões de toneladas métricas de $\mathrm{N}$ por ano, o que corresponde a mais de $57 \%$ da descarga antropogênica total (Vitousek et al., 1997).

Nos países industrializados da zona temperada, as aplicações de fertilizantes são a principal fonte de nitrogênio reativo (Filoso et al. 2006). Contudo, as aplicações nesses países estabilizaram nos últimos anos, enquanto nos países em desenvolvimento elas vêm aumentando drasticamente (Vitousek et al., 1997). Hoje os trópicos e subtrópicos já são responsáveis por 40\% das aplicações globais de fertilizantes, e projeções indicam que até 2020 mais de $60 \%$ das aplicações de fertilizantes ocorrerão nas regiões em desenvolvimento (Matthews, 1994). O Brasil ilustra bem esta tendência. Nos últimos 50 anos, o consumo de fertilizantes no país aumentou 25 vezes - de 360 mil toneladas na década de 1960 para um consumo médio anual de 7 milhões de toneladas em 2000 (ANDA, 2003) e de quase 9 milhões de toneladas em 2007 (IFA, 2008). Esta demanda coloca o Brasil como o 
quarto maior consumidor mundial de fertilizantes com $5,4 \%$ do total (IFA, 2008). E uma vez que a agroindústria é setor-chave no desempenho econômico brasileiro, acredita-se que o consumo de fertilizantes nitrogenados ainda aumentará consideravelmente no país e, possivelmente, elevará as taxas de deposição de nitrogênio reativo nos sistemas aquáticos (Filoso et al., 2006)

Os fertilizantes são utilizados na agricultura como fonte de nutrientes limitantes para o crescimento de plantas, mas as aplicações tendem a serem maiores que o necessário, e as culturas não são capazes de absorver todos os nutrientes disponíveis (Hecnar, 1995). O termo "saturação de nitrogênio" (Agren \& Bosatta, 1988) é aplicado às mudanças no funcionamento dos ecossistemas que ocorrem quando os acréscimos de nitrogênio suprem a limitação da atividade biológica causada por este elemento. Em geral, o paradigma da saturação de nitrogênio prediz que sistemas $\mathrm{N}$-limitados inicialmente retêm o $\mathrm{N}$ antropogênico acumulando-o na biomassa. Contudo, em algum momento a descarga de $\mathrm{N}$ excede a demanda biológica, e o sistema começa a perder sua capacidade de reter este elemento. O N excedente é então perdido através do fluxo de gases e em solução, sendo frequentemente depositado, lixiviado ou carreado para ambientes aquáticos (Matson et al., 1999).

Nos ecossistemas aquáticos o nitrogênio pode ocorrer em diversas formas, embora as predominantes sejam o nitrogênio molecular $\left(\mathrm{N}_{2}\right)$, A amônia não-ionizada $\left(\mathrm{NH}_{3}\right)$, o íon amônio $\left(\mathrm{NH}_{4}^{+}\right)$, nitrito $\left(\mathrm{NO}_{2}^{-}\right)$e o nitrato $\left(\mathrm{NO}_{3}^{-}\right)$, além de um grande número de compostos orgânicos dissolvidos (peptídeos, purinas, aminas, aminoácidos, etc.) e particulados (bactérias, fitoplâncton, zooplâncton, detritos, etc.) (Wetzel, 2001). A forma de nitrogênio predominante em um ambiente é dependente de vários fatores, incluindo $\mathrm{pH}$, temperatura, disponibilidade de oxigênio, assimilação vegetal e taxa de mineralização do nitrogênio orgânico (Environment Canada, 2003). 
Em solução, o nitrogênio molecular $\left(\mathrm{N}_{2}\right)$ ocorre naturalmente em concentrações próximas ao nível de saturação, o qual depende das condições locais de temperatura e pressão. Contudo, esta forma de $\mathrm{N}$ só tornar-se disponível para os organismos após ser convertido a nitrogênio reativo, que é definido como $\mathrm{N}$ ligado a carbono, oxigênio ou hidrogênio (Wetzel, 2001). Essa conversão pode ocorrer naturalmente devido a descargas elétricas na atmosfera e principalmente por meio da fixação biológica realizada por bactérias, a qual é responsável por mais de $95 \%$ da conversão natural de nitrogênio molecular em amônia $\left(\mathrm{NH}_{3}\right)$.

A amônia também é formada como produto da decomposição da parte nitrogenada da matéria orgânica, no processo chamado de amonificação, que também é realizado por microorganismos. No meio aquático a molécula da amônia é instável, e é convertida por hidratação no íon amônio $\left(\mathrm{NH}_{4}^{+}\right)$segundo o equilíbrio químico $\mathrm{NH}_{3}+\mathrm{H}_{2} \mathrm{O} \Leftrightarrow \mathrm{NH}_{4}^{+}+\mathrm{OH}^{-}$. Esse equilíbrio é fortemente influenciado pela temperatura e principalmente pelo $\mathrm{pH}$ da água: o aumento dos valores de $\mathrm{pH}$ e/ou temperatura causa o aumento da concentração relativa de $\mathrm{NH}_{3}$, mas somente em ambientes muito alcalinos a amônia é predominante (Russo, 1985). Por exemplo, em condições de temperatura de até $30^{\circ} \mathrm{C}$, o amônio representa mais de $98 \%$ quando o $\mathrm{pH}$ for menor ou igual 7,4 e mais de $92 \%$ em $\mathrm{pH} 8$.

Em sistemas com disponibilidade de oxigênio ocorre o processo de nitrificação, que também é realizado por bactérias. Esse processo envolve a oxidação das formas reduzidas de nitrogênio, primeiro de amônio para nitrito $\left(\mathrm{NH}_{4}^{+}+3 / 2 \mathrm{O}_{2} \Rightarrow \mathrm{NO}_{2}^{-}+\mathrm{H}_{2} \mathrm{O}+2 \mathrm{H}^{+}\right)$, e depois de nitrito para nitrato $\left(\mathrm{NO}_{2}^{-}+1 / 2 \mathrm{O}_{2} \Rightarrow \mathrm{NO}_{3}^{-}\right)$. Já em sistemas com baixas concentrações de oxigênio, bactérias utilizam o nitrato e o nitrito como receptor de elétrons durante a oxidação da matéria orgânica no processo chamado denitrificação:

$\mathrm{NO}_{3}^{-}+1 / 3 \mathrm{CH}_{3} \mathrm{OH} \Rightarrow \mathrm{NO}_{2}^{-}+1 / 3 \mathrm{CO}_{2}+2 / 3 \mathrm{H}_{2} \mathrm{O}$ 
$\mathrm{NO}_{2}^{-}+1 / 2 \mathrm{CH}_{3} \mathrm{OH} \Rightarrow 1 / 2 \mathrm{~N}_{2}+1 / 2 \mathrm{CO}_{2}+1 / 2 \mathrm{H}_{2} \mathrm{O}+\mathrm{OH}^{-}$

Esta redução bioquímica do nitrogênio produz a forma gasosa de nitrogênio molecular $\left(\mathrm{N}_{2}\right)$, causando perda de $\mathrm{N}$ da circulação biológica geral para a atmosfera. Portanto, a denitrificação equilibra naturalmente o orçamento global de $\mathrm{N}$ devolvendo para o sistema o $\mathrm{N}_{2}$ que havia sido fixado. Sendo assim, a forma intermediária de nitrito $\left(\mathrm{NO}_{2}^{-}\right)$raramente atinge elevadas concentrações na natureza porque é oxidada ou reduzida tão rápido quanto é formada (Halling-Sorensen \& Jorgensen, 1993). Da mesma forma, a amônio também não costuma ocorrer em altas concentrações na natureza, porque é rapidamente oxidado a nitrato ou assimilado pelas algas (Horne \& Goldman, 1994). Portanto, o nitrato constitui a forma de nitrogênio mais estável e abundante em águas superficiais com condições aeróbicas, e costuma representar de dois terços a quatro quintos do total de nitrogênio disponível nesses ambientes (Crouzet et al., 1999).

No entanto, estudos interessados nos efeitos das crescentes descargas de nitrogênio vêm observando aumentos significativos não somente nas concentrações de nitrato, as também nas de nitrito e amônio em ecossistemas aquáticos afetados pela agricultura e atividades urbanas no mundo todo (EIAFAC, 1984; Henriksen \& Brakke, 1988; Stoddard, 1994; Camargo \& Alonso, 2006). Por exemplo, na América do Norte as concentrações de nitrato em alguns rios aumentaram de 3-10 vezes desde 1900 (Turner \& Rabalais, 1991; Justie et al., 1995). As mesmas tendências são sugeridas para muitos rios na Europa desde a virada do século XX (Paces, 1982; Larsson et al., 1985; Henriksen \& Brakke, 1988) e alguns rios na Península Ibérica tiveram suas concentrações de nitrito e amônio aumentadas em mais de dez vezes (Egea-Serrano et al., 2008). Similarmente, mais de 30\% dos rios no Japão excedem o nível máximo de nitrato aceitável (44 $\left.\mathrm{mg} \mathrm{NO}_{3}^{-} / \mathrm{L}\right)$ pelas regulamentações japonesas (Babiker et al., 2004). 
Os principais efeitos negativos do aporte excessivo de nitrogênio em sistemas aquáticos são: o aumento da concentração de íons hidrogênio e a consequente acidificação do meio aquático; o aumento da produtividade primária e sua cascata de efeitos sobre a cadeia trófica; e os diversos impactos decorrentes da toxicidade dos compostos nitrogenados sobre a biota aquática (Camargo \& Alonso, 2006). A contribuição do $\mathrm{N}$ para a acidificação de rios e lagos ocorre principalmente devido à deposição atmosférica do ácido nítrico $\left(\mathrm{HNO}_{3}\right)$ produzido a partir de gases $\mathrm{NO}_{x}$ liberados na queima de combustíveis fósseis (Vitousek et al., 1990). Porém, grandes descargas de amônio também podem ser importantes porque a liberação de íons $\mathrm{H}^{+}$no processo de nitrificação contribui para a acidificação de ambientes aquáticos (Wetzel, 2001). Como muitas espécies são intolerantes a condições ácidas, geralmente as comunidades de habitats acidificados possuem menor diversidade que aqueles onde as condições de pH são próximas a neutralidade (Camargo \& Alonso, 2006).

O aumento da produtividade primária ocorre devido ao enriquecimento nutritivo dos ecossistemas aquáticos, e os efeitos desta adição são chamados de eutrofização (Thomann \& Mueller, 1987). Uma vez que a produtividade é nos ambiente é modulada principalmente pela disponibilidade de $\mathrm{N}$ e P (fósforo), o excesso de um desses nutrientes leva ao aumento da produtividade primária, e pode ter consequências para toda a comunidade biológica através de cascatas tróficas (Wootton \& Power, 1993). O aumento na disponibilidade de nutrientes também pode afetar a composição das comunidades por favorecer espécies adaptadas à abundância de nutrientes em detrimento de espécies adaptadas a condições de escassez de nutrientes (Grime, 1979; Schiesari, 2004). Além disso, o enriquecimento com $\mathrm{N}$ pode afetar os ecossistemas aquáticos através da depleção do oxigênio pela proliferação de bactérias heterotróficas que se alimentam da matéria orgânica das algas e de outros microrganismos em decomposição 
(Resende, 2002). Consequentemente, comunidades sujeitas a aportes excessivos de nutrientes geralmente sofrem diminuição da biodiversidade (Schindler, 1990).

A poluição por compostos nitrogenados também pode prejudicar a biota aquática devido à toxicidade direta das formas inorgânicas de $\mathrm{N}$, causando redução das capacidades de sobrevivência, crescimento e reprodução dos animais (Camargo \& Alonso, 2006). Estudos comprovam que a amônia, o nitrito e o nitrato são tóxicos para diversos grupos animais, como os moluscos (Alonso \& Camargo, 2003; Mummert et al., 2003), crustáceos (Muir et al., 1990; Alonso \& Camargo, 2004), insetos (Kelso et al., 1999; Camargo \& Ward, 1992), anfíbios (Hecnar, 1995; Jofre \& Karasov, 1999; Marco et al., 1999; Schuytema \& Nebeker, 1999b) e peixes (Westin, 1974; Rubin \& Elmaraghy, 1977; Tomasso \& Carmichael, 1986).

Dentre estes, merece especial atenção o grupo dos anfíbios. Anfíbios são hoje reconhecidos como excelentes bioindicadores de estresse ambiental (Blaustein \& Wake, 1995) por possuírem um conjunto de atributos morfológicos, fisiológicos e de história de vida que os tornam particularmente vulneráveis a alterações ambientais. Dentre estes pode-se mencionar a pele permeável, a presença de ovos desprovidos de casca, e o ciclo de vida tipicamente bifásico que condiciona exposição a estresses tanto no ambiente aquático quanto terrestre (Barinaga, 1990; Wake \& Morowitz, 1991). Talvez por isso, os anfíbios constituam atualmente a mais ameaçada classe de vertebrados do planeta: das quase seis mil espécies conhecidas, pelo menos $43 \%$ estão declinando, aproximadamente $32 \%$ estão ameaçadas de extinção e acredita-se que mais de 160 já tenham sido extintas (IUCN, 2006). Além disso, as larvas de anuros são sistema modelo em ecologia experimental (Wilbur, 1997) e sua utilização na pesquisa científica oferece diversas vantagens. Por exemplo, a manutenção em cativeiro de muitos indivíduos pode ser feita com relativa facilidade e permite a condução de experimentos bastante complexos com diferentes graus de controle e realismo. Por isso, importantes 
conceitos em ecologia foram desenvolvidos a partir de estudos com larvas de anfíbios (por exemplo Wilbur, 1976; Wilbur, 1987; Morin, 1983; Werner, 1992; Werner \& Peacor, 2003).

Muitas destas espécies declinaram e desapareceram por conta de perda e degradação do habitat. No entanto, a observação de que diversos declínios ocorreram em ambientes aparentemente intocados (Wake, 1991; Crump et al., 1992; Lips, 2000) sugere que fatores difusos e globalmente distribuídos , como a poluição química, possam estar envolvidos. Recentemente, a poluição foi considerada a segunda maior ameaça aos anfíbios ao redor do mundo (IUCN, 2006). A susceptibilidade dos anfíbios em paisagens rurais é conhecida em diversas localidades do mundo e há sugestões de severos declínios populacionais em decorrência da toxicidade de compostos nitrogenados (Cooke, 1972; Berger, 1987; Berger, 1989; Hecnar, 1995, Marco et al., 1999, Rouse et al., 1999). No Brasil sugere-se que a poluição industrial possa ter contribuído para o declínio de algumas populações de anfíbios no Brasil (Verdade et al., no prelo), mas nenhum trabalho relacionou a contaminação por agroquímicos com declínios de anfíbios no país.

Pesquisas demonstram que a amônia não-ioniza é a forma de nitrogênio mais tóxica para os organismos aquáticos, seguida pelo nitrito e pelo nitrato (Camargo \& Ward, 1992). Contudo, a dinâmica destes poluentes, os mecanismos que causam determinados efeitos e os fatores ambientais que influenciam a toxicidade não são bem estudados para os anfíbios (Marco \& Ortiz-Santaliestra, 2009). Acredita-se que as moléculas de $\mathrm{NO}_{3}^{-}, \mathrm{NO}_{2}^{-}, \mathrm{NH}_{3}$ e $\mathrm{NH}_{4}^{+}$presentes no ambiente penetram o corpo dos anfíbios por difusão através da pele, brânquias, pulmões e/ou por ingestão (Hecnar, 1995). Porém, os mecanismos envolvidos na toxicidade de cada uma dessas formas de nitrogênio são diferentes.

Embora o nitrito seja consideravelmente mais tóxico que o nitrato, a ação tóxica desses íons é bastante similar, pois o nitrato é reduzido a nitrito na cavidade 
digestiva devido às condições corporais internas (Camargo \& Alonso, 2006). Após entrar na corrente sanguínea, o nitrito oxida as proteínas responsáveis pelo transporte de oxigênio (hemoglobina, hemocianina) convertendo-as em formas incapazes de transportar oxigênio para a respiração celular (metahemoglobina, metahemocianina) (Huey \& Beitinger, 1980; Eckert et al., 1988). Ambos os compostos também favorecem a formação de $\mathrm{N}$-nitrosaminas secundárias, as quais são cancerígenas e mutagênicas (Nugent et al., 2001), e promovem a depressão do sistema imunológico aumentando a susceptibilidade a doenças e parasitas (Camargo \& Alonso, 2006). Além do mais, acredita-se que o nitrato e o nitrito possam atuar como disruptores endócrinos, influenciando o funcionamento da tireóide e o equilíbrio hormonal (Guillette \& Edwards, 2005). O nitrito também pode causar: depleção dos níveis intra e extracelulares de cloreto $\left(\mathrm{Cl}^{-}\right)$, causando severo desequilíbrio de eletrólitos, depleção de potássio $\left(\mathrm{K}^{+}\right)$intracelular e elevação de $\mathrm{K}^{+}$ extracelular afetando os potenciais de membrana, neurotransmissão, contração muscular e função cardíaca; e danos às mitocôndrias nas células do fígado causando suprimento deficiente de oxigênio ao tecido (Camargo \& Alonso, 2006).

A ação tóxica da amônia sobre os organismos aquáticos pode envolver os seguintes mecanismos: destruição do epitélio branquial prejudicando respiração e osmorregulação; estimulação da glicólise e inibição do ciclo de Krebs causando progressiva acidose sanguínea com conseqüente redução da capacidade transportadora de oxigênio; inibição da produção de ATP e depressão do ATP cerebral; disrupção de vasos sanguíneos e atividade osmorregulatória; e depressão do sistema imunológico aumentando a susceptibilidade a doenças e parasitas (Camargo \& Alonso, 2006). Já o íon amônio parece ser não tóxico ou consideravelmente pouco tóxico, embora seja capaz de reduzir a concentração corporal interna de sódio $\left(\mathrm{Na}^{+}\right)$para níveis possivelmente fatais (Russo, 1985). 
Por conseguinte, há fortes evidências que esses efeitos fisiológicos negativos do nitrato, do nitrito e da amônia-total podem escalonar para efeitos sobre a história de vida dos indivíduos, afetando atributos como comportamento, crescimento, desenvolvimento e sobrevivência das larvas de anfíbios (Marco \& Ortiz-Santaliestra, no prelo). Tais efeitos subletais também têm grande relevância ecológica porque, em longo prazo, podem indiretamente reduzir a sobrevivência dos girinos e dos estágios pós-metamórficos, além de afetar o sucesso reprodutivo dos adultos.

A redução do crescimento larval, e portanto o tamanho corporal menor, reduz a capacidade competitiva e locomotora dos girinos, tornando-os mais vulneráveis à predação (Berven, 1990; Newman \& Dunham, 1994). A redução do desenvolvimento larval também pode afetar negativamente os anfíbios devido à dessecação em hábitats efêmeros e ao maior período de exposição aos predadores aquáticos (Griffis-Kyle, 2007). E tanto a redução do crescimento quanto do desenvolvimento podem resultar em metamórficos com menor tamanho, o que também condiciona menor sobrevivência à predação (Xu \& Oldham, 1997), menor tolerância à desidratação, e menor sucesso reprodutivo, pois adultos menores possuem menor fertilidade e sucesso na seleção de parceiros (Smith, 1987; Goater et al., 1993). Da mesma forma, as alterações comportamentais também têm grande relevância ecológica, especialmente a redução nos níveis de atividade (Marco \& Ortiz-Santaliestra, no prelo). Isso ocorre porque a atividade media o conflito que há entre forrageamento e evitação de predadores (Werner \& Anholt, 1993) e influencia as habilidades competitivas dos girinos (Semlitsch, 1993; Dayton \& Fitzgerald, 2001).

Pesquisas também demonstram que os efeitos tóxicos letais e subletais da exposição aos compostos nitrogenados variam grandemente entre espécies de anfíbios (Hecnar 1995, Marco et al. 1999, Schuytema \& Nebeker 1999a) e até 
mesmo entre populações de uma espécie (Johansson et al. 2001). Contudo, nenhum dos mais de 2000 artigos sobre ecotoxicologia de anfíbios publicados ao longo de 40 anos no mundo todo lidou com a toxicidade de compostos nitrogenados sobre espécies brasileiras (Luis Schiesari, Britta Grillitsch e Heinz Grillitsch, dados não-publicados). E justamente no Brasil, o problema da poluição por nitrogênio é particularmente importante, pois aqui se encontra a maior riqueza de anfíbios do mundo (aproximadamente 875 espécies segundo SBH, 2010), e ao mesmo tempo o consumo de fertilizantes é enorme e a expansão da fronteira agrícola é agressiva.

Portanto, não sabemos de forma empírica o quanto as espécies brasileiras de anfíbios são sensíveis a poluição por nitrogênio. E na verdade, falta esse conhecimento para as espécies neotropicais em geral (Schiesari et al., 2007). Essa carência de dados traz implicações práticas para a conservação porque, por exemplo, faz com que os critérios aplicados no controle de qualidade da água das regiões tropicais sejam derivados de dados obtidos com espécies da zona temperada (Kwok et al., 2007). Logo, para que os critérios regulatórios nas regiões tropicais fossem mais adequados à conservação de seus ecossistemas, seria necessário então que fossem realizados bioensaios ecotoxicológicos com suas espécies nativas.

Nesta pesquisa tive dois objetivos principais. O primeiro foi testar em laboratório a toxicidade relativa dos íons nitrato, nitrito e amônio, e a variação interespecífica na sensibilidade a esses íons, em larvas de cinco espécies de anuros (Rhinella ornata, Hypsiboas faber, Hypsiboas pardalis, Physalaemus cuvieri e Physalaemus olfersii). Para isso utilizei bioensaios seguindo protocolos internacionalmente padronizados para testes de ecotoxicidade com organismos aquáticos (ASTM, 2004), e que portanto permitem máximas reprodutibilidade e comparabilidade de resultados entre compostos, espécies, e laboratórios. No entanto, estes bioensaios carecem de realismo uma vez que simulam um cenário 
de exposição aguda a altas concentrações de contaminantes quando na natureza o cenário de exposição tende a ser crônico e a baixas concentrações. Além disso, bioensaios usam mortalidade como principal variável de resposta, quando também efeitos subletais podem influenciar a persistência de populações ao modular o sucesso dos indivíduos. Por isso, meu segundo objetivo foi testar em laboratório se concentrações relativamente baixas e ecologicamente relevantes de nitrato, nitrito e amônio podem afetar a sobrevivência, o crescimento, o desenvolvimento e o comportamento das larvas de $R$. ornata, $P$. cuvieri e $H$. faber.

\section{Materiais e Métodos}

Os experimentos que realizei foram conduzidos com embriões e larvas derivados de desovas provenientes de um sítio de referência não-contaminado, a Estação Biológica de Boracéia (EBB), Salesópolis, São Paulo (23³7' 59”' S e 45 31' 59" W). A EBB compreende uma área de 96 ha e está situada dentro de uma reserva protetora de mananciais (Adutora do Rio Claro, SABESP) de 16450 ha localizada a cerca de $110 \mathrm{~km}$ da cidade de São Paulo (Ferro \& Diniz, 2007). A identidade das espécies que utilizei foi definida pela abundância e facilidade na coleta das desovas no campo, pois só foram testadas aquelas espécies que encontrei um numero de desovas igual ou maior a três. Fiz isso para evitar que as particularidades de uma determinada desova criassem vieses nos resultados experimentais devido a efeitos parentais ou do ambiente. As espécies que eu utilizei nesse trabalho foram: o bufonídeo Rhinella ornata, os hilídeos Hypsiboas faber e Hypsiboas pardalis e os leiuperideos Physalaemus cuvieri e Physalaemus olfersii. A coleta e transporte de material biológico realizados nesta pesquisa foram autorizados pelo IBAMA (Protocolo IBAMA 02027.0011085/06-48) e a condução dos 
experimentos aqui descritos foi autorizada pela Comissão de Ética em Experimentação do Instituto de Biociências-USP (Protocolo 039/2007).

Rhinella ornata é uma espécie terrestre de porte médio (adultos possuem comprimento rostro-cloacal de 63-95 mm) que ocorre em uma grande variedade de hábitats, incluindo florestas primárias e secundárias, pastos e áreas abertas (Heyer et al., 1990). Seus ovos são depositados em cordões gelatinosos na água de poças, brejos e margens de lagos (Ramos \& Gasparini, 2004) em eventos de explosão reprodutiva que ocorrem no início da estação chuvosa (Bertoluci, 1997). Uma única desova pode conter mais de 4500 ovos (Haddad, 1991). Seus girinos são negros, tem o hábito de formação de cardumes (Heyer, 1990), e são impalatáveis para alguns vertebrados, como peixes, aves e mamíferos (Wassersug, 1971; Heyer et al., 1975). Não há dados na literatura para a duração do período larval de $R$. ornata na natureza, mas em laboratório o desenvolvimento dos ovos até a metamorfose demora aproximadamente 40 dias, embora haja grande plasticidade nessa característica (Simon M.N. comunicação pessoal). A distribuição geográfica dessa espécie se estende do sul do Espírito Santo até o norte do Paraná, incluindo os estados de Rio Janeiro e São Paulo e possivelmente áreas no nordeste da Argentina (IUCN, 2009).

Hypsiboas faber é a espécie de anfíbio arborícola de maior tamanho da Mata Atlântica, atingindo cerca de 100 mm (Verdade et al., 2009). Sua reprodução ocorre em lagoas, geralmente permanentes, localizadas em áreas abertas e na borda da mata, principalmente no período de outubro até março (Bertoluci, 1997). Suas desovas são depositadas em pequenas depressões no solo construídas pelos machos nas margens de brejos e lagoas, e possuem em média 2270 ovos (Martins, 1993). O desenvolvimento larval se estende por quase 12 meses e os girinos podem atingir até $90 \mathrm{~mm}$ de comprimento total (Bertoluci, 1997). A distribuição 
geográfica dessa espécie se estende da Bahia até o Rio Grande do Sul, e inclui a província de Misiones na Argentina e a porção oriental do Paraguai (IUCN, 2009).

Hypsiboas pardalis é uma espécie arborícola de médio porte (comprimento rostro-cloacal de até $70 \mathrm{~mm}$ ) que ocorre em florestas de Mata Atlântica nos estados de São Paulo, Rio de Janeiro, Espírito Santo e na porção leste de Minas Gerais (IUCN, 2009). Seus ovos também são depositados em pequenas depressões no solo construídas pelos machos, mas ocorrem preferencialmente em poças ou charcos situados na borda da mata (Ramos \& Gasparini, 2004). Os girinos atingem comprimento total máximo de $37 \mathrm{~mm}$ e possuem coloração marrom-acinzentada com marcas transversais escuras no dorso (Bertoluci, 1997).

Physalaemus cuvieri é uma espécie terrestre de pequeno porte (comprimento rostro-cloacal de até $30 \mathrm{~mm}$ ) que ocorre em florestas, pastos e áreas abertas (Verdade et al., 2009). A reprodução dessa espécie ocorre de setembro até março em ambientes lênticos temporários e permanentes (Heyer et al., 1990). As desovas possuem em média 550 ovos e são depositadas em ninhos de espuma que ficam ancorados à vegetação (Haddad \& Sazima 1992). Os girinos são pequenos (comprimento total máximo de $26 \mathrm{~mm}$ ) e a fase larval é geralmente inferior a dois meses (Bokerman, 1962). Sua ampla distribuição geográfica abrange praticamente todo o Brasil (exceto a região norte), a província de Misiones na Argentina e a porção oriental do Paraguai (IUCN, 2009).

Physalaemus olfersii é uma espécie terrestre de pequeno porte (comprimento rostro-cloacal de até $40 \mathrm{~mm}$ ) que ocorre em florestas primárias e secundárias das regiões sul e sudeste do Brasil (IUCN, 2009). Seus ovos também são depositados em ninhos de espuma, mas frequentemente em lagoas de pequena dimensão na borda da mata (Bertoluci, 1997). Os girinos dessa espécie são morfologicamente idênticos aos girinos de $P$. cuvieri. Contudo, segundo Bertoluci (1997) a duração mínima da fase larval dessa espécie é de cinco meses. 
Após coletar as desovas na EBB eu as transportei para o laboratório da Escola de Artes, Ciências e Humanidades da Universidade de São Paulo (EACH USP). No laboratório, os ovos eclodiram e os girinos foram mantidos em tanques com 50 litros de água filtrada e declorinada. A água utilizada nas culturas e nos experimentos foi analisada em 06/08/2009 por métodos padronizados (APHAAWWA-WEF, 1995) e apresentou os valores de $56 \mathrm{mg} / \mathrm{L}$ para dureza total (SM 2340 C - EDTA Titrimetric Method), 24 mg/L para alcalinidade total (SM 2320 B Titration Method), 0,46 UT para turbidez (SM 2130 B - Turbidity Nephelometric Method) e concentração de Cloro total menor que 0,01 mg/L (SM 4500 - Cl - G DPD Colorimetric Method). Nesta fase de cultura, as larvas foram alimentadas com ração para coelhos (Purina Mills, LLC, USA; 16\% proteína) ad libitum até o início dos experimentos.

Dos compostos químicos usualmente utilizados para testar os efeitos tóxicos do nitrato, do nitrito e do amônio sobre os organismos aquáticos escolhi o nitrato de sódio, o nitrito de sódio e o sulfato de amônio (Merck KGaA, Darmstadt, Alemanha, pureza > 99\%). O nitrato de sódio $\left(\mathrm{NaNO}_{3}\right)$ e o nitrito de sódio $\left(\mathrm{NaNO}_{2}\right)$ foram escolhidos como fonte de nitrato e nitrito, respectivamente, porque estudos que compararam a toxicidade de $\mathrm{NaNO}_{3}$ e $\mathrm{NaCl}$ (cloreto de sódio) a organismos aquáticos demonstraram que a toxicidade observada é resultado da exposição ao ânion nitrato e não ao cátion $\mathrm{Na}^{+}$(Baker \& Waights, 1994). Da mesma forma, escolhi o sulfato de amônio $\left(\left(\mathrm{NH}_{4}\right)_{2} \mathrm{SO}_{4}\right)$ como fonte de amônio porque a toxicidade desse composto é atribuída essencialmente a sua fração nitrogenada (Schuytema \& Nebeker, 1999b).

Uma vez que este estudo teve por objetivo avaliar a toxicidade comparativa dos íons nitrogenados, utilizei a massa de nitrogênio como unidade de concentração dos sais manipulados. Isso permitiu que as comparações entre as formas de nitrogênio fossem baseadas no mesmo número de mols das moléculas de 
interesse, embora as frações de nitrogênio presentes nas moléculas dos sais manipulados fossem consideravelmente diferentes. Todas as operações que envolveram pesagem de material neste trabalho foram realizadas em balança semianalítica com precisão de $1 \mathrm{mg}$ (Ohaus Corporation, Pine Brook, NJ, USA). Os experimentos foram realizados nas condições ambientes de temperatura e fotoperíodo, conforme protocolo descrito abaixo.

\section{BIOENSAIOS DE EXPOSIÇÃO AGUDA}

Para comparar a toxicidade do nitrato, nitrito e amônio para as larvas de anuros e para testar a variação interespecífica na sensibilidade a estes íons eu realizei bioensaios de exposição aguda (96 horas) baseados nas diretrizes da ASTM (2004) com larvas das cinco espécies descritas anteriormente (Rhinella ornata, Hypsiboas faber, Hypsiboas pardalis, Physalaemus cuvieri e Physalaemus olfersii). Embora de forma ideal esses bioensaios devessem ter sido conduzidos simultaneamente por questões de comparabilidade, a fenologia reprodutiva das espécies e também questões de logística, como restrições de espaço e material, impediram que todas as espécies e compostos fossem testados ao mesmo tempo (Tabela 1). Além disso, alguns experimentos falharam em detectar mortalidade na faixa de concentrações manipuladas e por isso tiveram que ser refeitos. Isso aconteceu nos testes com $P$. cuvieri e $P$. olfersii em exposição ao nitrato de sódio em dezembro de 2009, e com $H$. faber e H. pardalis em exposição ao sulfato de amônio em janeiro de 2010. Portanto, fatores que não foram controlados, como a temperatura por exemplo, foram diferentes em cada teste (Tabela 1).

Nestes bioensaios, cada unidade experimental consistiu em um pote de vidro de $2.7 \mathrm{~L}$ contendo 1 litro de água pura (controle) ou uma de cinco concentrações de um dos compostos manipulados (Tabela 1). Em cada um dos recipientes experimentais eu coloquei 10 girinos. Para os testes com Rhinella ornata 
em cada réplica coloquei girinos provenientes de uma mesma desova, enquanto que para as demais espécies testadas, em cada réplica coloquei girinos

Tabela 1. Síntese do delineamento dos bioensaios de exposição aguda realizados com larvas de cinco espécies de anuros.

\begin{tabular}{crccc}
\hline ESPÉCIE & COMPOSTO & \multicolumn{1}{c}{ DATA } & CONCENTRAÇÃO NOMINAL & $\begin{array}{c}\text { TEMPERATURA } \\
\text { MÉDIA }\left({ }^{\circ} \mathbf{C}\right)\end{array}$ \\
\hline Rhinella ornata & $\mathrm{NaNO}_{3}$ & 15 -set-09 & $200,355,632,1124$ e $2000 \mathrm{mg} \mathrm{N} / \mathrm{L}$ & 19,65 \\
& $\mathrm{NaNO}_{2}$ & 15 -set-09 & $15,32,67,142$ e $300 \mathrm{mg} \mathrm{N} / \mathrm{L}$ & 19,65 \\
& $\left(\mathrm{NH}_{4}\right)_{2} \mathrm{SO}_{4}$ & 15 -set-09 & $15,32,67,142$ e $300 \mathrm{mg} \mathrm{N} / \mathrm{L}$ & 19,65 \\
\hline Physalaemus cuvieri & $\mathrm{NaNO}_{3}$ & 15 -fev-10 & $200,355,632,1124$ e $2000 \mathrm{mg} \mathrm{N} / \mathrm{L}$ & 27,66 \\
& $\mathrm{NaNO}_{2}$ & 4 -dez-09 & $15,32,67,142$ e $300 \mathrm{mg} \mathrm{N} / \mathrm{L}$ & 21,88 \\
& $\left(\mathrm{NH}_{4}\right)_{2} \mathrm{SO}_{4}$ & 4 -dez-09 & $15,32,67,142$ e $300 \mathrm{mg} \mathrm{N} / \mathrm{L}$ & 21,88 \\
\hline Physalaemus olfersii & $\mathrm{NaNO}_{3}$ & 18 -jan-10 & $200,355,632,1124$ e $2000 \mathrm{mg} \mathrm{N} / \mathrm{L}$ & 24,25 \\
& $\mathrm{NaNO}_{2}$ & 4 -dez-09 & $15,32,67,142$ e $300 \mathrm{mg} \mathrm{N} / \mathrm{L}$ & 21,88 \\
& $\left(\mathrm{NH}_{4}\right)_{2} \mathrm{SO}_{4}$ & 4 -dez-09 & $15,32,67,142$ e $300 \mathrm{mg} \mathrm{N} / \mathrm{L}$ & 21,88 \\
\hline Hypsiboas faber & $\mathrm{NaNO}_{3}$ & 18 -jan-10 & $200,355,632,1124$ e $2000 \mathrm{mg} \mathrm{N} / \mathrm{L}$ & 24,25 \\
& $\mathrm{NaNO}_{2}$ & 18 -jan-10 & $15,34,77,176$ e $400 \mathrm{mg} \mathrm{N} / \mathrm{L}$ & 24,25 \\
& $\left(\mathrm{NH}_{4}\right)_{2} \mathrm{SO}_{4}$ & 15 -fev-10 & $15,42,122,350$ e $1000 \mathrm{mg} \mathrm{N} / \mathrm{L}$ & 27,66 \\
\hline Hypsiboas pardalis & $\mathrm{NaNO}_{3}$ & 18 -jan-10 & $200,355,632,1124$ e $2000 \mathrm{mg} \mathrm{N} / \mathrm{L}$ & 24,25 \\
& $\mathrm{NaNO}_{2}$ & 18 -jan-10 & $15,34,77,176$ e $400 \mathrm{mg} \mathrm{N} / \mathrm{L}$ & 24,25 \\
& $\left(\mathrm{NH}_{4}\right)_{2} \mathrm{SO}_{4}$ & 18 -jan-10 & $15,34,77,176$ e $400 \mathrm{mg} \mathrm{N} / \mathrm{L}$ & 24,25 \\
\hline
\end{tabular}

aleatoriamente retirados de todas as desovas disponíveis para aquela espécie.

Selecionei para os experimentos indivíduos em estágios iniciais de desenvolvimento (por volta do estágio 25; Gosner, 1960) e dentro de uma faixa estreita de massas corporais. Essa padronização é importante porque o tamanho e o estágio de desenvolvimento do indivíduo são atributos que influenciam fortemente sua suscetibilidade aos compostos nitrogenados (Ortiz-Santaliestra et al., 2006). Além disso, girinos aparentemente não saudáveis, com anormalidades morfológicas e/ou comportamentais visíveis foram excluídos. Dentro de cada experimento, todos os potes foram identificados com relação à espécie, composto e concentração manipulada, e suas posições nas estantes do laboratório foram aleatorizadas para evitar vieses nos resultados. Não houve alimentação dos girinos durante os experimentos. Após 48 horas retirei os indivíduos mortos e medi a temperatura de 10 potes (escolhidos aleatoriamente) para que a média desses valores representasse a temperatura na qual o bioensaio foi conduzido. Decorridas 96 horas registrei a mortalidade total em cada pote e encerrei os testes. 
Experimentos-piloto ('range-finding tests') conduzidos com todas as espécies e compostos permitiram refinar a metodologia experimental e aproximar, para cada composto, (i) a maior concentração onde nenhum indivíduo foi afetado e (ii) a menor concentração onde todos os indivíduos foram afetados. Estas concentrações foram então usadas para definir os extremos de um gradiente de 5 concentrações (logaritmicamente espaçadas) manipuladas nos testes definitivos. Assim, para o nitrato de sódio testei as concentrações nominais de 200, 355, 632 , 1124 e 2000 mg N/L sobre as cinco espécies. Para o nitrito de sódio testei as concentrações nominais de 15, 32, 67, 142 e $300 \mathrm{mg} \mathrm{N} / \mathrm{L}$ para os girinos de $R$. ornata, $P$. cuvieri e $P$. olfersii , e para os girinos de $H$. faber e $H$. pardalis testei as concentrações nominais de 15, 34, 77, 176 e $400 \mathrm{mgN}$ / L. Para o sulfato de amônio testei as concentrações nominais de 15, 32, 67, 142 e $300 \mathrm{mg} \mathrm{N} / \mathrm{L}$ para os girinos de $R$. ornata, $P$. cuvieri e $P$. olfersii ; 15, 42, 122, 350 e $1000 \mathrm{mg} \mathrm{N} / \mathrm{L}$ para os girinos de $H$. faber e 15, 34, 77, 176 e $400 \mathrm{mg} \mathrm{N} / \mathrm{L}$ para os girinos de $H$. pardalis. Para cada tratamento e para os controles de todos os bioensaios utilizei quatro réplicas.

Os valores de mortalidade registrados para as concentrações manipuladas foram utilizados para identificar parâmetros-padrão, como a maior concentração sem efeito observado (CSEO), a menor concentração com efeito observado (MCEO) e a concentração com efeito letal para $50 \%$ da população experimental (CL50). Os valores de CL50 foram estimados estatisticamente pelo Método de Interpolação Linear (USEPA/600/4-89-001).

Para testar diferenças de toxicidade entre nitrato, nitrito e amônio os valores de CL50 obtidos para cada íon foram comparados por Análise de Variância e testados a posteriori para diferenças entre pares com ajuste de Bonferroni pelo programa SPSS 11.5 (SPSS Inc., Chicago, IL). O efeito da temperatura sobre os valores de CL50 foi testado por regressão linear também pelo programa SPSS 11.5. 
Para testar diferenças de sensibilidade entre as espécies para um mesmo íon, os valores de CL50 obtidos foram comparados pelo teste $Z$ (Zar, 1999). E finalmente, a associação entre o ranqueamento de sensibilidade das espécies ao nitrato de sódio, nitrito de sódio e sulfato de amônio foi medida através do índice de correlação de Spearman, também pelo programa SPSS 11.5. Todos os testes foram realizados com nível de significância 5\%.

\section{EXPERIMENTOS DE EXPOSIÇÃO CRÔNICA}

Para testar os efeitos letais e subletais de concentrações ecologicamente realistas do nitrogênio inorgânico expus os girinos de Rhinella ornata, Physalaemus cuvieri e Hypsiboas faber a baixas concentrações dos compostos nitrato de sódio, nitrito de sódio e sulfato de amônio. De forma a obter máximo de realismo no que diz respeito à duração da exposição, e melhor interpretação no que diz respeito às conseqüências da exposição ao nitrogênio inorgânico para a aptidão darwiniana, a meta inicial foi conduzir experimentos abrangendo todo o período embrio-larval até a metamorfose. As variáveis de resposta pré-metamórficas foram sobrevivência (em \%), massa (em mg), estágio de desenvolvimento (conforme Gosner 1960) e taxas de atividade (\% de girinos ativos - nadando ou se alimentando - em determinado momento no tempo; Schiesari 2004); por sua vez, as variáveis de resposta metamórficas foram sucesso em atingir a metamorfose (em \%), tempo para a metamorfose (em dias) e massa na metamorfose (em $\mathrm{mg}$ ). Os indivíduos foram considerados como tendo completado a metamorfose quando toda a cauda fora absorvida.

Uma vez que a quantificação de algumas variáveis pré-metamórficas (massa e estágio de desenvolvimento) implica no manuseio dos indivíduos, e que este manuseio pode influenciar seu posterior desempenho, optei por dividir cada experimento de forma a desmontar metade das réplicas (e preservar os girinos em 
solução 1:1 de etanol 70\% e formaldeído 5\%) após 21 dias de exposição, e manter a exposição na outra metade das réplicas até que a metamorfose fosse atingida. Para isso selecionei duas espécies de desenvolvimento rápido ( $R$. ornata e $P$. cuvierı) (Bokermann 1962; M.N. Simon comunicação pessoal ) para avaliação de efeitos pré-metamórficos e metamórficos, e complementei a investigação de efeitos pré-metamórficos apenas com uma espécie adicional, Hypsiboas faber, que tem desenvolvimento larval durando muitos meses (Martins 1993).

Os três compostos foram testados simultaneamente sobre cada espécie em experimentos de longa duração realizados nos períodos de 7 setembro a 17 de novembro de 2009 com $R$. ornata (Tabelas 2), 14 de janeiro a 4 de fevereiro de 2010 com P. cuvieri, e 22 de fevereiro a 15 de março de 2010 com H. faber (Tabela 3). Nestes experimentos, cada unidade experimental consistia em aquários de vidro de $40 \times 30 \times 50 \mathrm{~cm}$ contendo $20 \mathrm{~L}$ de água pura (controle) ou uma de duas concentrações (2,5 ou $10 \mathrm{mg} / \mathrm{L})$ de nitrogênio na forma de nitrato de sódio, nitrito de sódio ou sulfato de amônio (Tabelas 2 e 3). Essas concentrações estão dentro da amplitude que ocorre na natureza em casos de poluição por nitrogênio (veja por exemplo em McCoy, 1972; Bogardi et al., 1991; Wetzel, 1983; Edwards \& Daniel, 1994). Nos experimentos com $R$. ornata e $H$. faber eu coloquei 20 girinos em cada aquário, e no experimento com $P$. cuvieri coloquei 15 girinos. Todos os girinos utilizados estavam em mesmo estágio de desenvolvimento (por volta do estágio 25; Gosner, 1960), dentro de uma faixa estreita da massa corporal (massa média de 30 indivíduos igual a 12,4 mg para $R$. ornata, 5,4 mg para $P$. cuvieri e $18,3 \mathrm{mg}$ para $H$. faber) e aparentando estar saudáveis, sem anormalidades morfológicas e/ou comportamentais. Todos os aquários foram identificados com relação ao composto e concentração manipulada, e suas posições nas estantes do laboratório foram aleatorizadas para evitar vieses nos resultados. A manutenção desses experimentos (registro da sobrevivência, retirada de indivíduos mortos e 
alimentação) foi feita toda segunda, quarta e sexta-feira. Os girinos foram alimentados com uma mistura moída de ração de coelho (Purina Mills, LLC, USA; 16\% proteína) e de peixe (TetraMin, Melle, Alemanha; 45\% proteína) na proporção de $3: 1$, escalonada em uma dose diária per capita equivalente a 16\% da massa média individual no início do experimento. Estudos anteriores demonstraram que este valor excede a capacidade máxima de ingestão de alimento por espécies de girinos, permitindo crescimento ótimo, e ao mesmo tempo minimiza os restos de comida no aquário, que poderiam prejudicar a qualidade da água e alteração das concentrações reais de nitrogênio (Schiesari, 2004).

Semanalmente a solução de todos os aquários foi substituída por uma nova para que as concentrações de nitrogênio fossem mantidas. Trabalhos realizados com metodologias similares indicam que desvios significativos (>25\%) da concentração original não ocorrem em períodos de até sete dias (Marco et al., 1999). As características físico-químicas das soluções testadas a cada semana foram medidas e registradas para efeitos de controle de qualidade. Utilizei eletrodos para medir a concentração de oxigênio dissolvido (Oxímetro DM4P - Digimed, São Paulo, Brasil), o pH (pHscan - Eutech Instruments Pte Ltd, Ayer Rajah Crescent, Singapura) e também a temperatura e a condutividade (ECTestr - Eutech Instruments Pte Ltd, Ayer Rajah Crescent, Singapura) de todos os aquários. Amostras compostas de água de cada tratamento (formadas por alíquotas de mesmo volume de cada réplica) foram analisadas para determinação das concentrações reais de N com espectrofotômetro Hach DR2800 (USA Hach Company, Loveland, USA) e kits de reagentes apropriados utilizando os métodos de redução de cádmio para quantificação de nitrato (método nํ8171, Hach 2007, limite de quantificação $0,1 \mathrm{mg} / \mathrm{l} \mathrm{NO}{ }_{3}^{-}-\mathrm{N}$ ), diazotização para quantificação de nitrito (método $\mathrm{n}^{\circ}$ 8507, Hach 2007, limite de quantificação $0,002 \mathrm{mg} / \mathrm{NO}_{2}^{-}-\mathrm{N}$ ) e salicilato para quantificação de N-amônia-total (método no 8155, Hach 2007, limite de 
quantificação 0,01 mg/l N-amônia-total). Como no meio aquático a amônia nãoionizada e o amônio sempre ocorrem juntos, geralmente as concentrações dessas moléculas também são analiticamente medidas juntas nas amostras de água, e os valores de concentração são então expressos como amônia-total, mas representam a soma das concentrações dessas duas formas (Camargo e Alonso 2006). Sendo assim, após quantificar as concentrações de $\mathrm{N}$-amônia-total presentes nas soluções de sulfato de amônio, calculei as concentrações de amônio e de amônia nãoionizada conforme proposto por Emerson et al. (1975) utilizando os valores médios de $\mathrm{pH}$ e temperatura registrados durante cada experimento.

$R$. ornata foi testada ao longo de todo o desenvolvimento embrio-larval e até a metamorfose em um experimento conduzido em duas fases: numa primeira fase, um fragmento de desova com 50 ovos (estágio < 15; Gosner, 1960) foi colocado em um vidro contendo $1 \mathrm{~L}$ de água filtrada (controle) ou de uma das soluções descritas acima. Cada tratamento foi replicado três vezes, sendo cada réplica representada por uma desova. O experimento começou no dia 7 de setembro e terminou após $96 \mathrm{~h}$, quando o sucesso na eclosão foi estimado em $98 \%$ independente do tratamento experimental. Neste momento iniciei a segunda fase do experimento (11/setembro) transplantando parte dos girinos (estágio 22-23, Gosner, 1960; massa média 12,4 mg) para os aquários de vidro de 40 X 30 X $50 \mathrm{~cm}$ contendo 20L das mesmas soluções. Cada combinação de desova*réplica da primeira fase do experimento deu origem a duas réplicas na segunda fase do experimento. Por exemplo, 40 embriões da desova 1 e que eclodiram em vidros contendo solução-controle foram divididos em dois aquários contendo soluçãocontrole (20 girinos em cada aquário). Como já foi dito, este delineamento foi decidido porque uma das réplicas de cada desova*tratamento seria desmontada após 21 dias para estimativa da massa e desenvolvimento dos girinos enquanto a outra réplica seria mantida até que a maior parte dos indivíduos completasse a 
metamorfose (que ocorreu em 17/novembro). Portanto houve 3 réplicas para variáveis metamórficas e 3 réplicas para variáveis pré-metamórficas exceto para taxas de sobrevivência e taxas de atividade que puderam ser estimadas para todas as seis réplicas até o $21^{\circ}$. dia de experimento.

Devido à grande variação nos dados que obtive para $R$. ornata, optei por aumentar o número de réplicas de três (3 pré-metamórficas + 3 metamórficas) para quatro (4 pré-metamórficas +4 metamórficas) no experimento com $P$. cuvieri .Infelizmente, por conta da alta mortalidade ocorrida em todos os tratamentos e inclusive nos controles (ver em 'Resultados') optei por encerrar o experimento após 21 dias de exposição. Conforme explicado acima, o experimento com Hypsiboas faber teve como objetivo a quantificação de variáveis de resposta pré-metamórficas apenas e por isso foi conduzido com 5 réplicas e encerrado após 21 dias de exposição.

Conduzi uma Análise de Variância (ANOVA) testanto o efeito da concentração de cada íon (sendo que o controle representa a concentração $=0$ mgN/L) sobre as variáveis dependentes sobrevivência após 7, 14 e 21 dias de exposição; taxas de atividade (medidas em 20 ocasiões); massa média e estágio de desenvolvimento médio após 21 dias de exposição; e, no caso, de R. ornata, também sobrevivência até a metamorfose; tempo para completar a metamorfose; e massa na metamorfose. Quando detectado efeito significativo, diferenças entre controle e concentrações de 2,5 e $10 \mathrm{mg} \mathrm{N} / \mathrm{L}$ foram testadas a posteriori com ajuste de Bonferroni. Todos os testes de ANOVA foram realizados com nível de significância 5\% pelo programa SPSS 11.5 (SPSS Inc., Chicago, IL). 


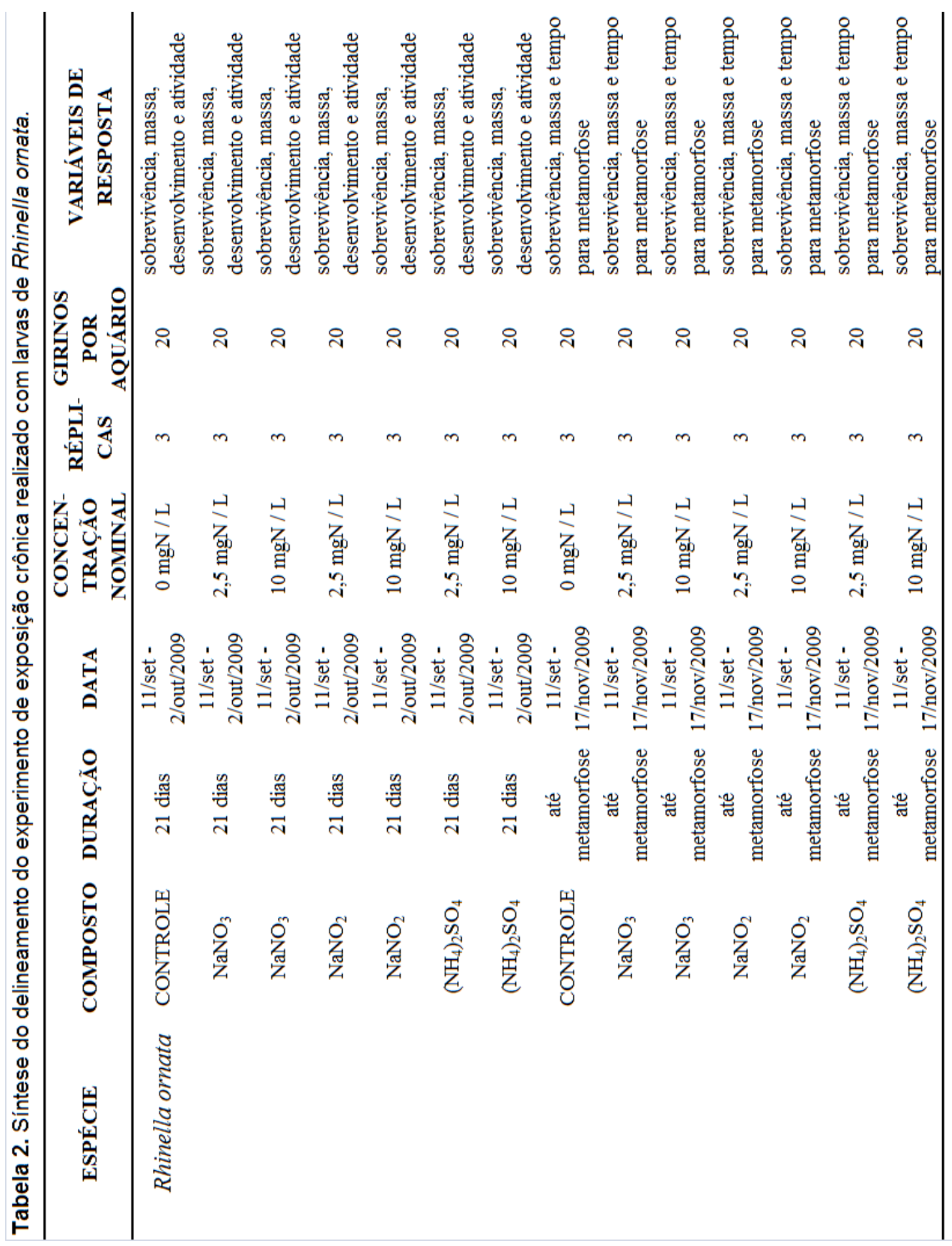




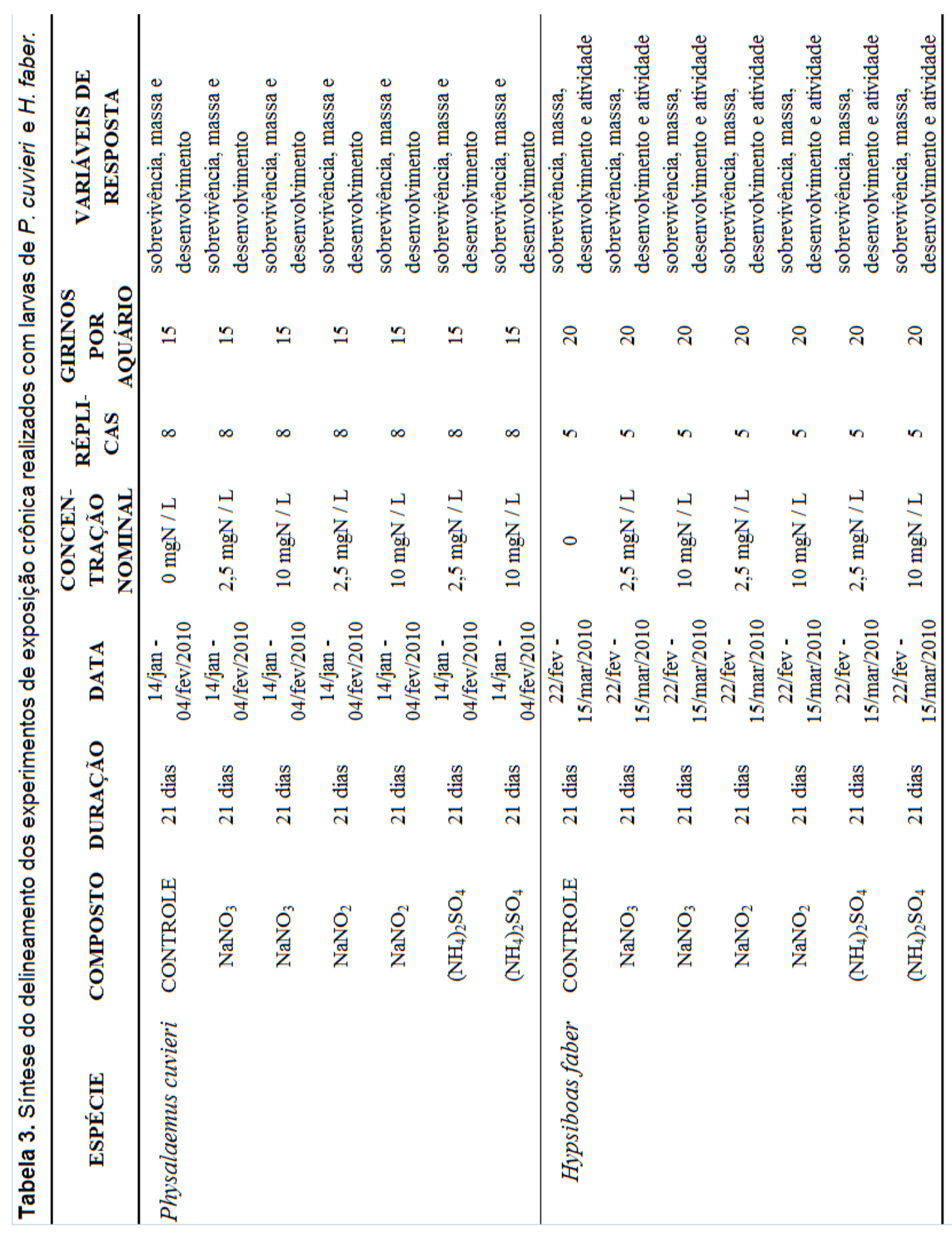




\section{Resultados}

\section{BIOENSAIOS DE EXPOSIÇÃO AGUDA}

Uma vez que a toxicidade dos sais de nitrato de sódio, nitrito de sódio e sulfato de amônio expressam a toxicidade dos íons nitrato, nitrito e amônio, então nitrato foi a forma de nitrogênio menos tóxica para as larvas das cinco espécies testadas (Figura 1; ANOVA $F_{2,13}=19,869 ; p<0,001$ ). O valor médio de CL50 para nitrato $(1116,42 \mathrm{mg} \mathrm{N} / \mathrm{L} ; \mathrm{EP}=179,34)$ foi oito vezes e meia superior ao calculado para nitrito $(130,85 \mathrm{mg} \mathrm{N} / \mathrm{L}$; EP $=34,67)$, e quase três vezes maior que o calculado para amônio $(376,25 \mathrm{mg} \mathrm{N} / \mathrm{L}$; EP = 124,75). Embora o valor médio de CL50 calculado para nitrito tenha sido quase três vezes menor que o calculado para amônio, não houve diferença estatisticamente significativa na toxicidade destes dois íons (Figura $1 ; p=0,392$ ). As análises de regressão linear que realizei demonstraram que a temperatura não influenciou significativamente os resultados que obtive para nitrato $\left(n=5 ; p=0,355 ; R^{2}=0,2843 ; y=-0,0042 x+28,745\right)$, nitrito $\left(n=5 ; p=0,43 ; R^{2}=0,0082 ; y=-0,004 x+23,585\right)$, embora aparente ter influenciado de forma marginalmente significativa os resultados para amônio $(n=4$; $\left.p=0,071 ; R^{2}=0,6412 ; y=0,006 x+19,645\right)$.

Para as larvas de Rhinella ornata nitrato foi cerca de sete vezes e meia menos tóxico (CL50 = 1452,5 mg N/L) que nitrito (CL50 = 192,46 mg N/L), e cinco vezes e meia menos tóxico que amônio (CL50 = 264,05 mg N/L; Figura 2). Por sua vez, nitrito foi cerca de $70 \%$ mais tóxico que amônio. Das concentrações manipuladas, a maior concentração sem efeito observado e a menor concentração com efeito observado foram, respectivamente, 632,45 e 1124,68 mg N/L para nitrato, 31,72 e 67,08 mg N/L para nitrito, e 67,08 e 141,86 mg N/L para amônio. Os girinos de $R$. ornata foram pouco sensíveis ao nitrato com relação a maioria das espécies testadas (Tabela 4; Figura 2), mas apresentaram sensibilidade intermediária ao nitrito e amônio. 


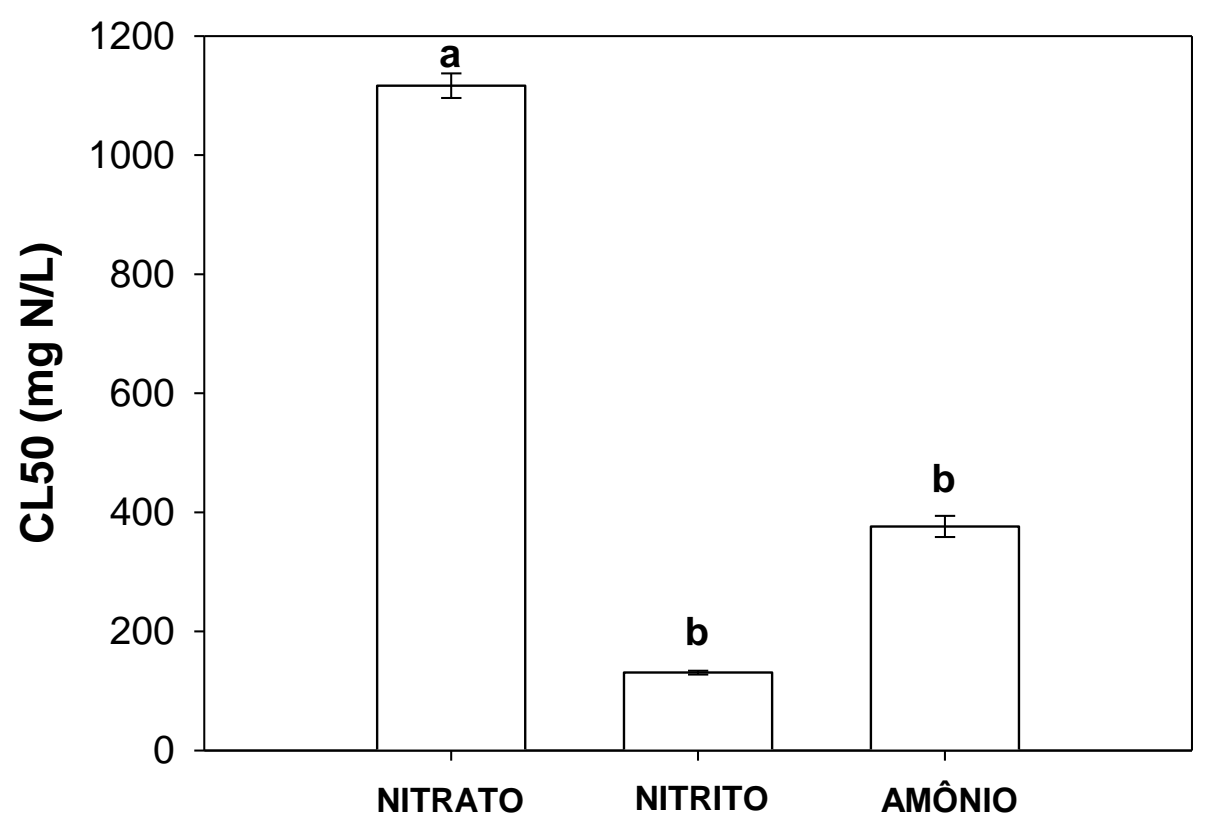

Figura 1. Comparação entre a concentração letal de nitrato, nitrito e amônio para $50 \%$ da população experimental de Rhinella ornata, Hypsiboas faber, Hypsiboas pardalis, Physalaemus cuvieri e Physalaemus olfersii em exposição aguda (96 horas). As barras representam média \pm 1 erro padrão dos valores de CL50 calculados para as cinco espécies. Para amônio, média e erro padrão foram calculados com apenas quatro espécies porque não foi possível calcular a CL50 desse íon para $H$. pardalis.

Para as larvas de Hypsiboas faber o nitrato foi cerca de oito vezes e meia menos tóxico (CL50 = 1546,63 mg N/L) que nitrito (CL50 = 181,6 mg N/L), e duas vezes menos tóxico que amônio (CL50 = 264,05 mg N/L; Figura 2). Por sua vez, nitrito foi quatro vezes mais tóxico que amônio. Das concentrações manipuladas, a maior concentração sem efeito observado e a menor concentração com efeito observado foram, respectivamente, 1124 e $2000 \mathrm{mg} \mathrm{N} / \mathrm{L}$ para nitrato, 77 e $176 \mathrm{mg}$ $\mathrm{N} / \mathrm{L}$ para nitrito, e 350 e $1000 \mathrm{mg} \mathrm{N} / \mathrm{L}$ para amônio. Dentre as espécies testadas, $H$. faber esteve entre as menos sensíveis ao nitrato e nitrito e foi a mais resistente ao amônio (Tabela 4; Figura 2). 

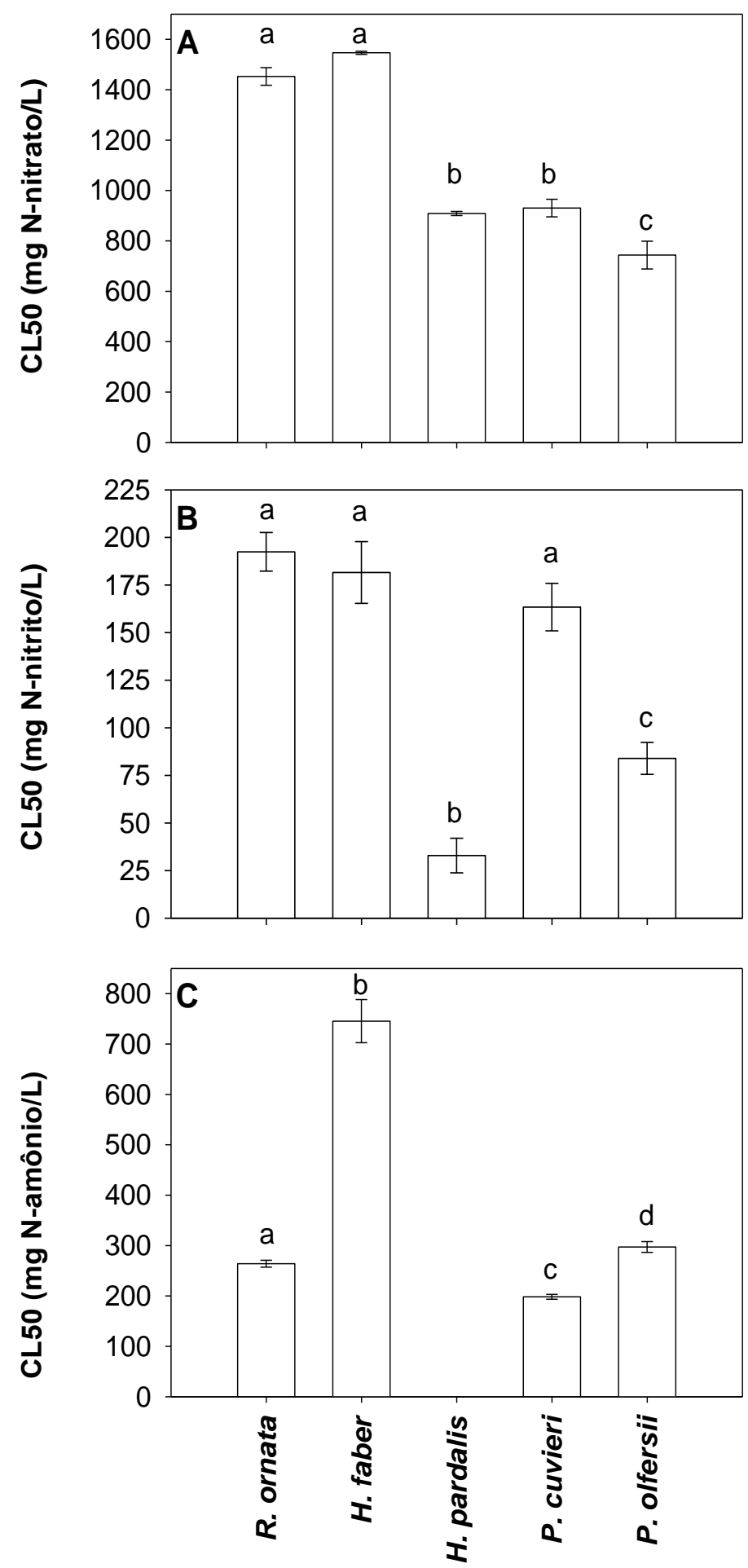

Figura 2. Comparação interespecífica na CL50 de nitrato $(A)$, nitrito $(B)$ e amônio (C) para larvas de Rhinella ornata, Hypsiboas faber, Hypsiboas pardalis, Physalaemus cuvieri e Physalaemus olfersii em exposição aguda (96 horas). As barras representam média \pm 1 erro padrão de 4 réplicas. Note que em $C$ não foi possível estimar a CL50 para $H$. pardalis porque não houve mortalidade significativa na faixa de concentrações de sulfato de amônio manipuladas (15-400 mgN / L). 
Para Hypsiboas pardalis não foi possível calcular a CL50 de amônio porque nem mesmo a maior concentração manipulada (400 mg N/L) causou mortalidade (Figura 2). Portanto, a maior concentração sem efeito observado para amônio foi $400 \mathrm{mg} \mathrm{N} / \mathrm{L}$. Presume-se então que a CL50 seja superior a esse valor, e que $H$. pardalis seja pouco sensível ao amônio. Nitrato foi cerca de 27 vezes menos tóxico (CL50 = 908,75 mg N/L) que nitrito (CL50 = 32,88 mg N/L). Das concentrações manipuladas, a maior concentração sem efeito observado e a menor concentração com efeito observado foram, respectivamente, 632 e $1124 \mathrm{mg} \mathrm{N} / \mathrm{L}$ para nitrato, e 15 e $34 \mathrm{mg} \mathrm{N} / \mathrm{L}$ para nitrito. Os girinos de $H$. pardalis apresentaram sensibilidade intermediária ao nitrato, mas foram os maios sensíveis ao nitrito dentre todas as espécies testadas (Tabela 4; Figura 2).

Para as larvas de Physalaemus cuvieri o nitrato foi cerca de cinco vezes e meia menos tóxico (CL50 = 930,39 mg N/L) que nitrito (CL50 = 163,42 mg N/L), e quatro vezes e meia menos tóxico que amônio (CL50 = 198,34 mg N/L; Figura 2). Por sua vez, nitrito foi ligeiramente mais tóxico (21\%) que amônio. Das concentrações manipuladas, a maior concentração sem efeito observado e a menor concentração com efeito observado foram, respectivamente, 632 e 1124 mg N/L para nitrato, 32 e $67 \mathrm{mg} \mathrm{N} / \mathrm{L}$ para nitrito, e 67 e $141 \mathrm{mg} \mathrm{N} / \mathrm{L}$ para amônio. Os girinos de $P$. cuvieri apresentaram sensibilidade intermediária ao nitrato, foram pouco sensíveis ao nitrito e foram os mais sensíveis ao amônio (Tabela 4; Figura 2).

Para as larvas de Physalaemus olfersii o nitrato foi quase nove vezes menos tóxico $(C L 50=743,82 \mathrm{mg} \mathrm{N} / \mathrm{L})$ que nitrito $(\mathrm{CL50}=83,9 \mathrm{mg} \mathrm{N} / \mathrm{L})$, e duas vezes e meia menos tóxico que amônio (CL50 = 297,17 mg N/L; Figura 2). Por sua vez, nitrito foi três vezes e meia mais tóxico que amônio. Das concentrações manipuladas, a maior concentração sem efeito observado e a menor concentração com efeito observado foram, respectivamente, 200 e $355 \mathrm{mg} \mathrm{N} / \mathrm{L}$ para nitrato, 32 e $67 \mathrm{mg} \mathrm{N} / \mathrm{L}$ para nitrito, e 67 e $141 \mathrm{mg} \mathrm{N} / \mathrm{L}$ para amônio. Esta espécie foi a mais 
sensível ao nitrato e a segunda mais sensível ao nitrito, embora tenha apresentado sensibilidade intermediária ao amônio com relação às outras espécies testadas (Tabela 4; Figura 2).

Dentre as formas de nitrogênio que manipulei, observei menor variação interespecífica de sensibilidade para o nitrato. $R$. ornata e $H$. faber foram as espécies menos sensíveis a esse íon, enquato $H$. pardalis e $P$. cuvieri foram cerca de $60 \%$ mais sensíveis e $P$. olfersii foi quase duas vezes mais sensível. Já o nitrito foi a forma de nitrogênio que causou maior variação interespecífica de sensibilidade. Para esse íon $R$. ornata, $H$. faber e $P$. cuvieri foram cerca de cinco vezes menos sensíveis que $H$. pardalis e duas vezes menos sensíveis que $P$. olfersii. E por fim, a variação interespecífica de sensibilidade ao amônio foi intermediária com relação ao nitrato e nitrito. A sensibilidade de $H$. faber ao amônio foi cerca de três vezes menor que a das demais espécies, enquanto $R$. ornata, $P$. cuvieri e $P$. olfersii diferiram em sensibilidade em cerca de $10-50 \%$ entre si.

A análise de correlação entre os valores de CL50 calculados para os três íons (Figura 3) demonstrou que os ranqueamentos de CL50 para nitrato e para o nitrito são fortemente correlacionados $(r=0,8 ; p=0,052)$. Ou seja, para esses dois íons a ordenação de sensibilidade das espécies foi semelhante. Já os valores de CL50 calculados para o amônio não tiveram correlação com os valores calculados para nitrito $(r=0 ; p=0,5)$, e apresentaram correlação fraca e não-significativa com os valores de CL50 para nitrato $(r=0,4 ; p=0,3)$. Para nitrato $P$. olfersii foi a espécie mais sensível, seguida por $H$. pardalis e $P$. cuvieri, e depois por $R$. ornata e $H$. faber. De forma similar, para o nitrito $H$. pardalis foi a espécie mais sensível, seguida por $P$. olfersii, e depois por $P$. cuvieri, $H$. faber e $R$. ornata. Diferentemente, para o amônio $P$. cuvieri foi a espécie mais sensível, seguida por $P$. olfersii, $R$. ornata e depois por $H$. faber. 


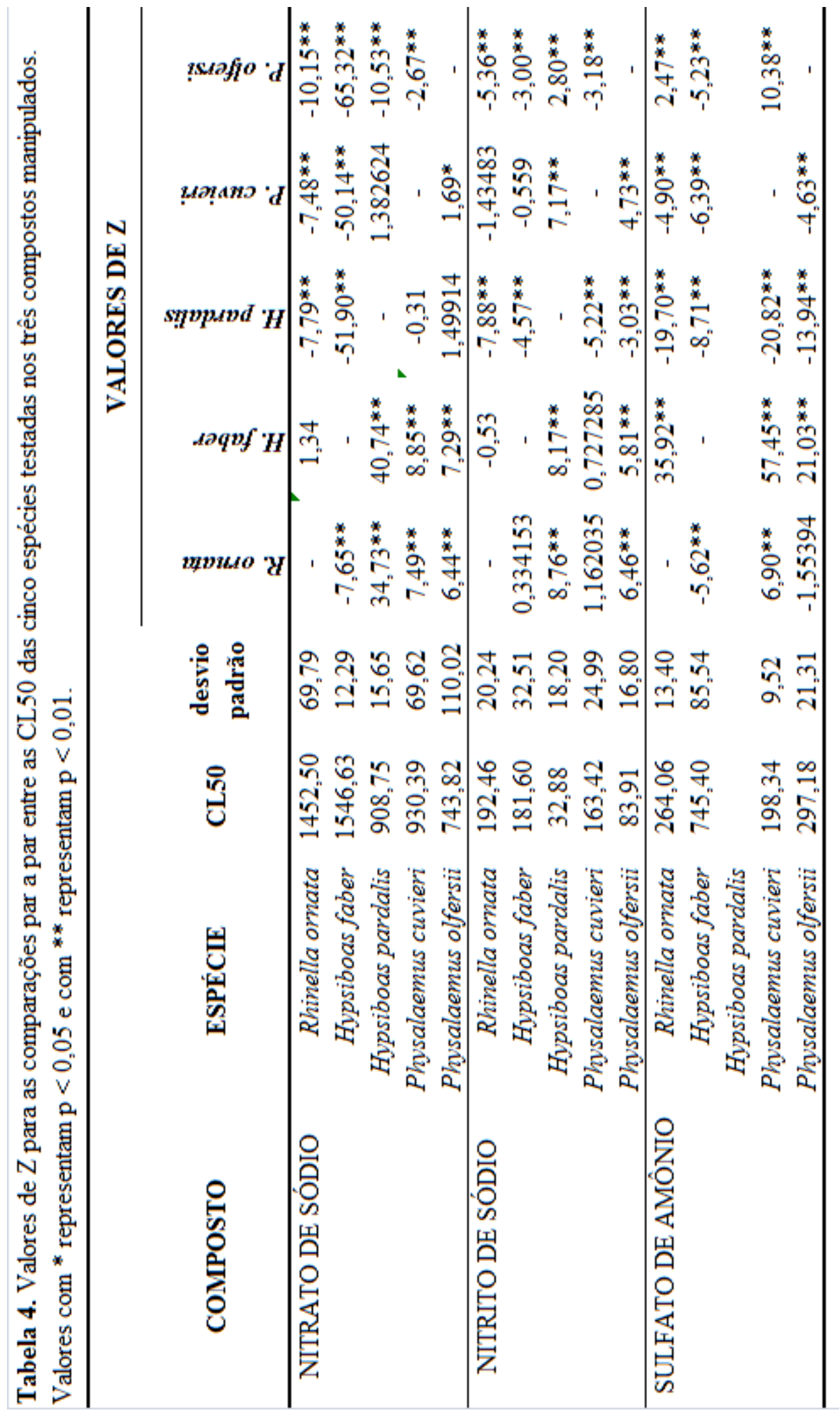



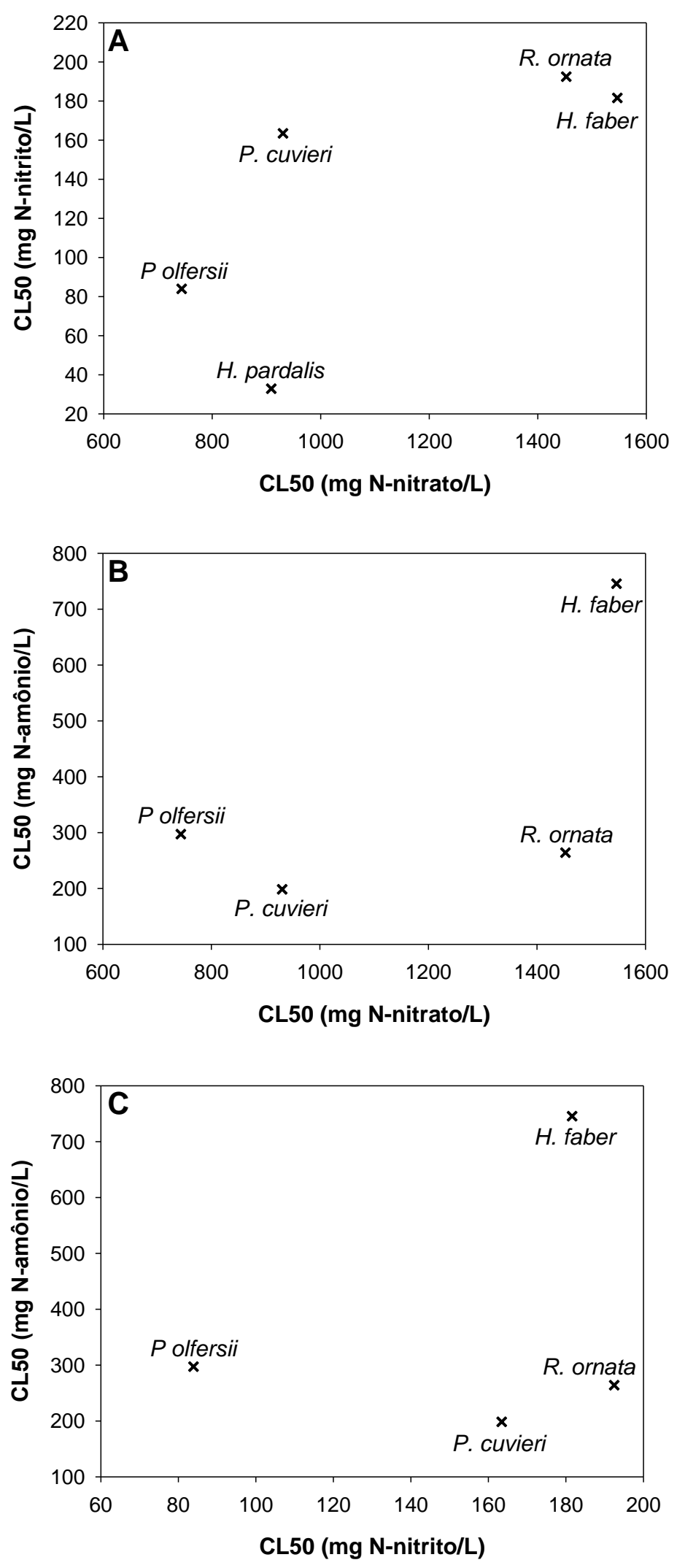

Figura 3. Correlação entre CL50 de nitrato e nitrito (A), nitrato e amônio (B) e nitrito e amônio (C) para larvas de Rhinella ornata, Hypsiboas faber, Hypsiboas pardalis, Physalaemus cuvieri e Physalaemus olfersii em exposição aguda (96 horas). 


\section{EXPERIMENTOS DE EXPOSIÇÃO CRÔNICA}

As concentrações de $\mathrm{N}$ medidas para cada tratamento mantiveram-se dentro da faixa de $20 \%$ das respectivas concentrações nominais (2,5 e $10 \mathrm{mg} \mathrm{N} / \mathrm{L})$ durante todos os experimentos, exceto em dois momentos, quando erros de diluição ocorreram (Figura 4). No experimento com P. cuvieri todas as soluções-teste da terceira semana de exposição tiveram a metade da concentração desejada (Figuras 4B, 4E e 4H), e no experimento com $H$. faber a concentração medida no tratamento de $10 \mathrm{mg} \mathrm{N} / \mathrm{L}$ como sulfato de amônio foi de 13,8 mg N/L na primeira semana (mas foi corrigida nas trocas seguintes; Figura 4I). Os valores medidos de $\mathrm{pH}$, condutividade e oxigênio dissolvido mantiveram-se dentro da amplitude esperada para essas variáveis, e também variaram pouco, tanto dentro de cada experimento como entre eles, não influenciando portanto os resultados obtidos (Tabelas 5 e 6). A temperatura média da água no experimento com $R$. ornata $\left(20,4^{\circ} \mathrm{C}\right)$ foi de dois a três graus inferior a temperatura média registrada nos experimentos com $P$. cuvieri e $H$. faber (respectivamente 23,3 e $22,7^{\circ} \mathrm{C}$ ). Nos tratamentos de manipulação de sulfato de amônio, as concentrações estimadas de amônia não-ionizada $\left(\mathrm{NH}_{3}\right)$ correspondentes as concentrações de 2,5 e $10 \mathrm{mg} \mathrm{N} / \mathrm{L}$ foram calculadas em aproximadamente 0,025 e $0,109 \mathrm{mg} \mathrm{N}-\mathrm{NH}_{3} / \mathrm{L}$ para $R$. ornata, 0,014 e 0,064 mg N$\mathrm{NH}_{3} / \mathrm{L}$ para $P$. cuvieri e em 0,011 e $0,053 \mathrm{mg} \mathrm{N}-\mathrm{NH}_{3} / \mathrm{L} H$. faber. Portanto as frações de amônia não-ionizada nunca excederam 1\% da concentração medida para amônia total. 

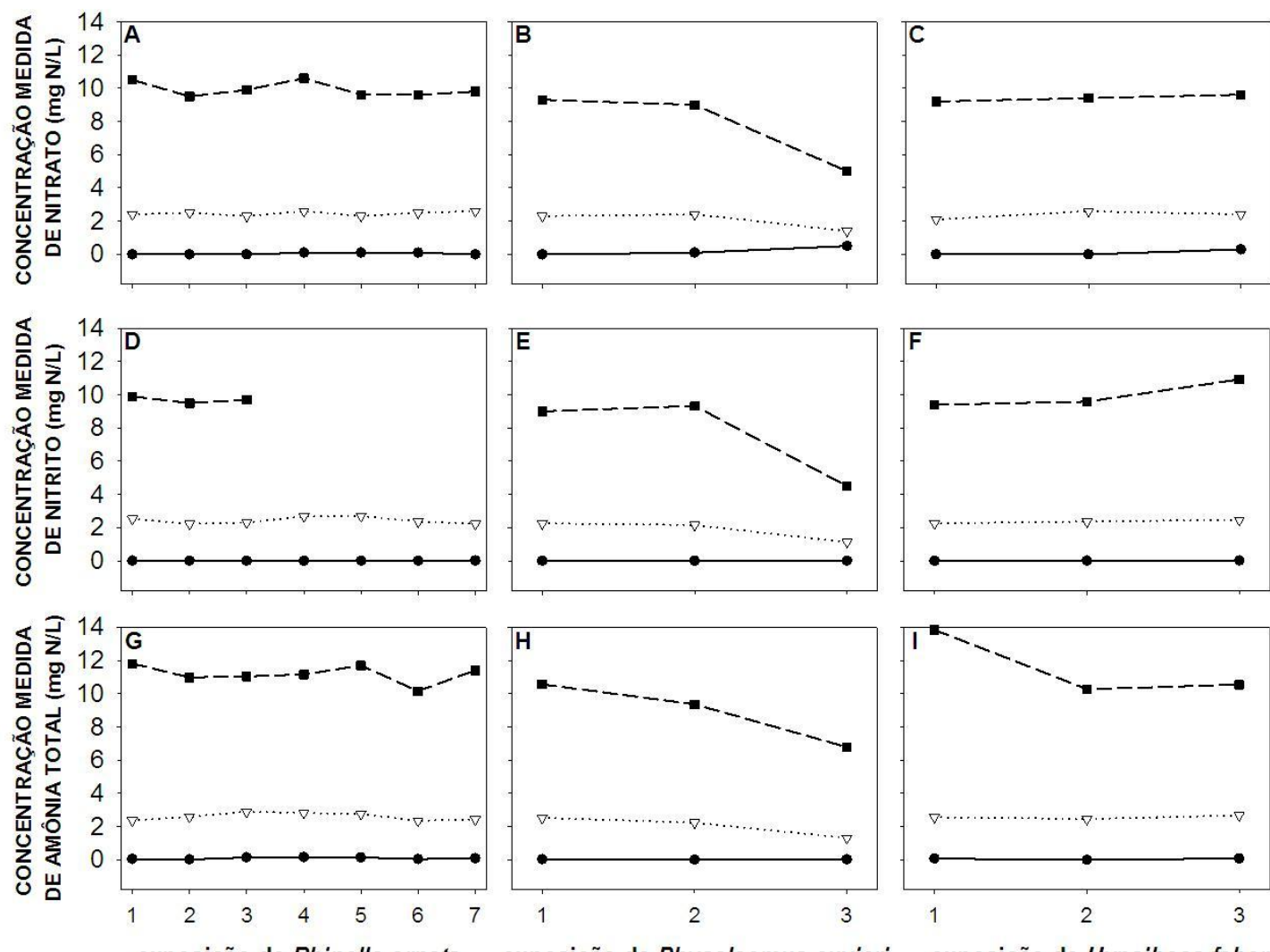

exposição de Rhinella ornata

exposição de Physalaemus cuvieri (semanas) (semanas)

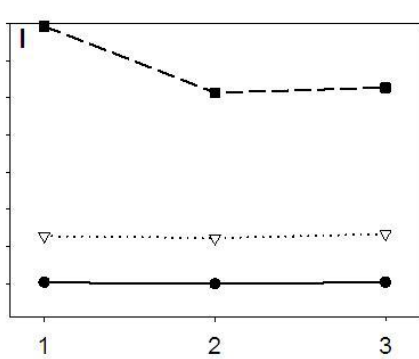

exposição de Hypsiboas faber (semanas)

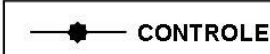

$\nabla \cdots \cdots \cdots \cdots \cdot-2,5 \mathrm{mg} \mathrm{N} / \mathrm{L}$

$--\square--10 \mathrm{mg} \mathrm{N} / \mathrm{L}$

Figura 4. Concentrações medidas de nitrogênio nas formas de nitrato $(A, B, C)$, nitrito $(D, E, F)$ e amônia total $(G, H, I)$ durante os experimentos de exposição crônica com larvas de Rhinella ornata (A, D, G), Physalaemus cuvieri (B, E, H) e Hypsiboas faber (C, F, I). 


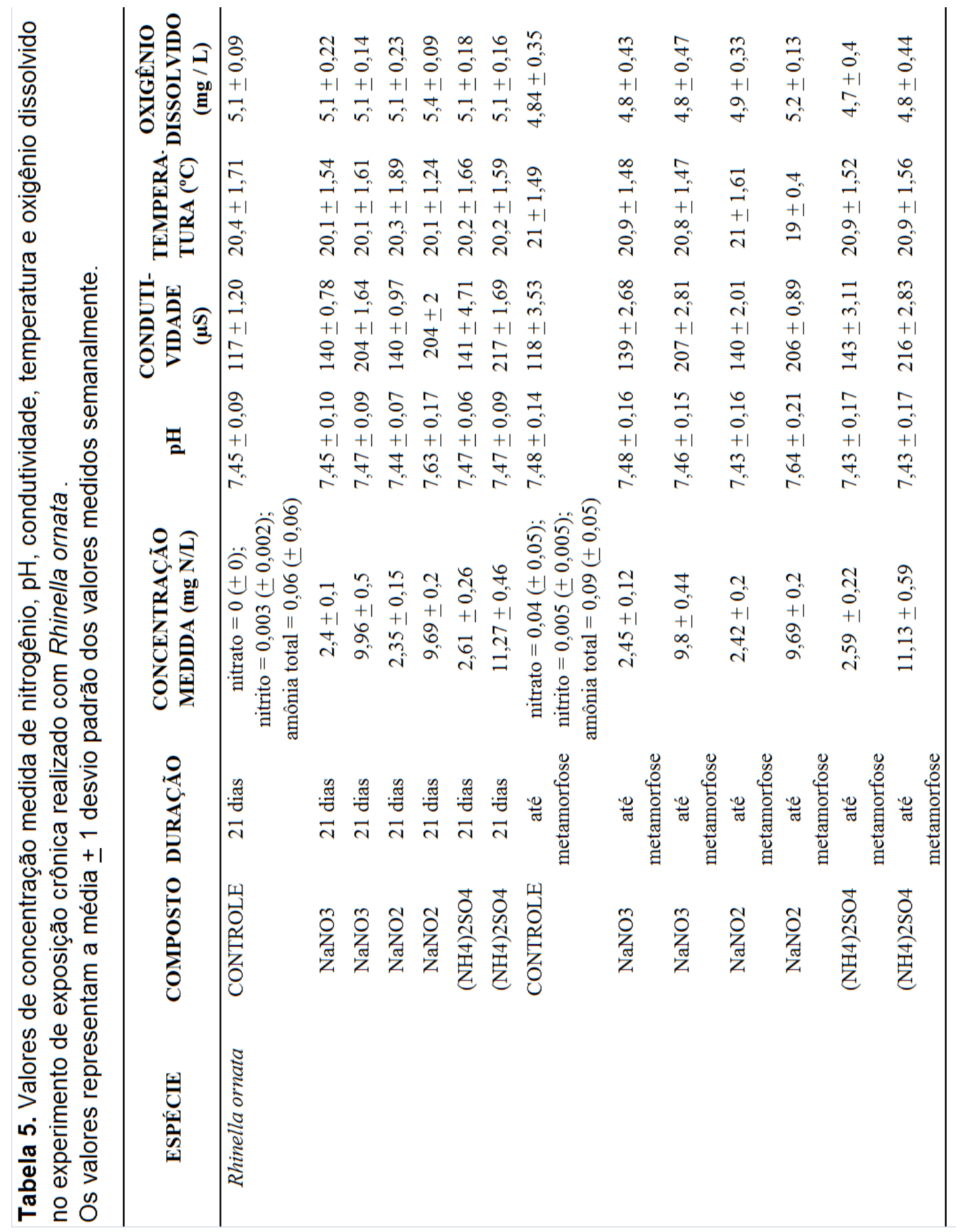




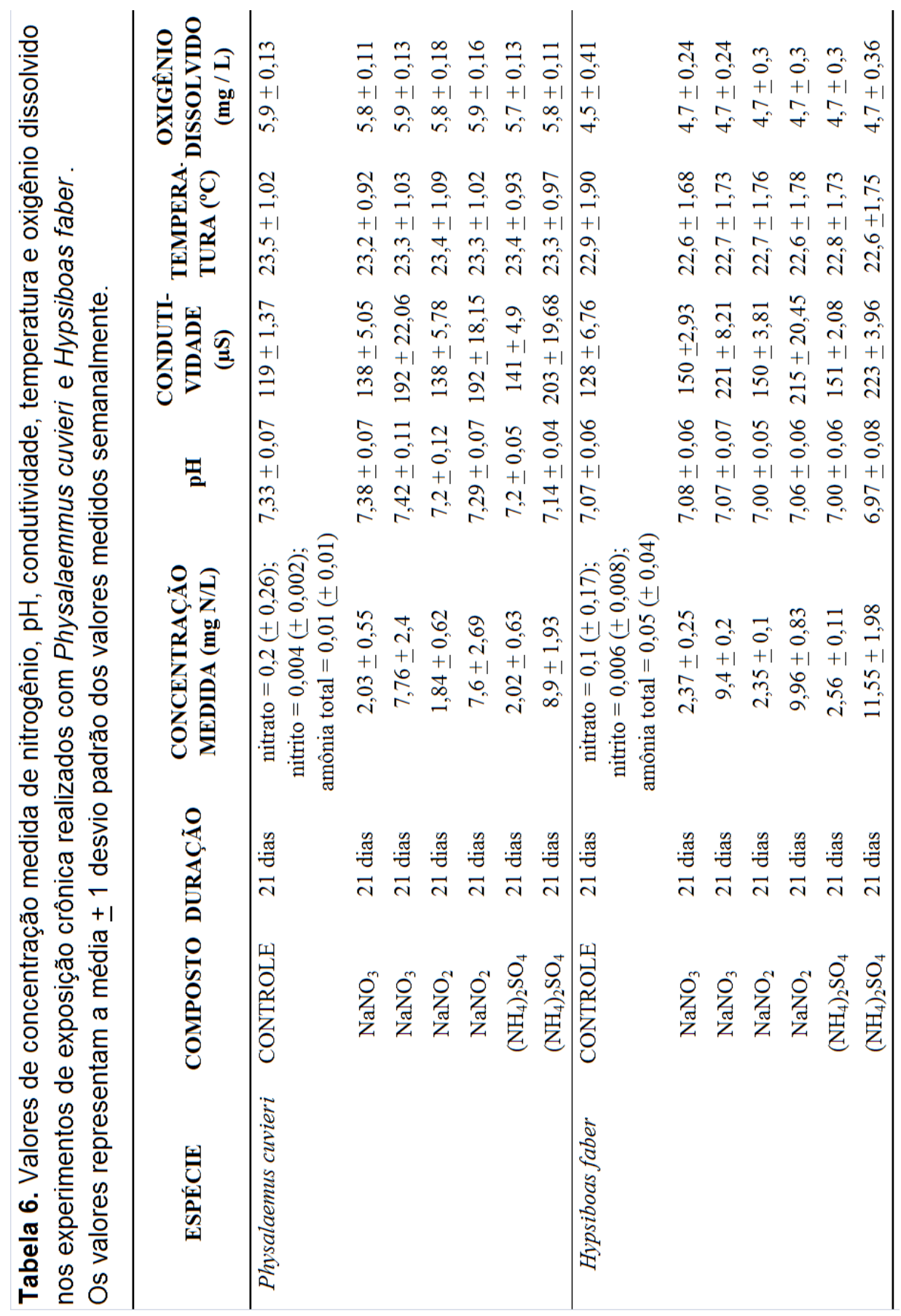


No experimento com Rhinella ornata (Figura 5), os controles apresentaram sobrevivência superior a 98\% decorridos 21 dias de experimento. Nesse momento as larvas dos controles tinham massa média de 141 mg e estavam no estágio 34 (Gosner 1960). Após aproximadamente 55 dias, mais de $90 \%$ dos girinos completaram a metamorfose nos controles, pesando em média 106 mg. Nenhum efeito letal ou subletal foi causado pela exposição ao nitrato de sódio ou sulfato de amônio nas duas concentrações manipuladas, nem pelo nitrito de sódio na concentração de 2,5 mgN / L (Tabela 7; Figuras 6, 7 e 8). Já a exposição ao nitrito de sódio na concentração de $10 \mathrm{mgN} / \mathrm{L}$ reduziu drasticamente a sobrevivência e os níveis de atividade dos girinos. A sobrevivência caiu para menos de $50 \%$ após 7 dias, 1,6 \% após 14 dias, e 0,8\% após 21 dias. Por conseguinte, a sobrevivência até a metamorfose foi zero (todos os resultados significativamente diferentes do controle; Tabela 4; Figura 7). Os girinos expostos à solução com 10 mgN-nitrito / L permaneceram imóveis no fundo dos aquários desde o início do teste, e a taxa de atividade registrada para este tratamento foi inferior a $20 \%$, quando comparada a $80 \%$ ou mais em todos os demais tratamentos e nos controles (Tabela 4; Figura 8; ANOVA $\left.F_{2,17}=407,256 ; p<0,001\right)$. Neste experimento pude realizar apenas oito observações da atividade dos girinos devido à elevada mortalidade que ocorreu no tratamento de $10 \mathrm{mgN}$-nitrito / L. 

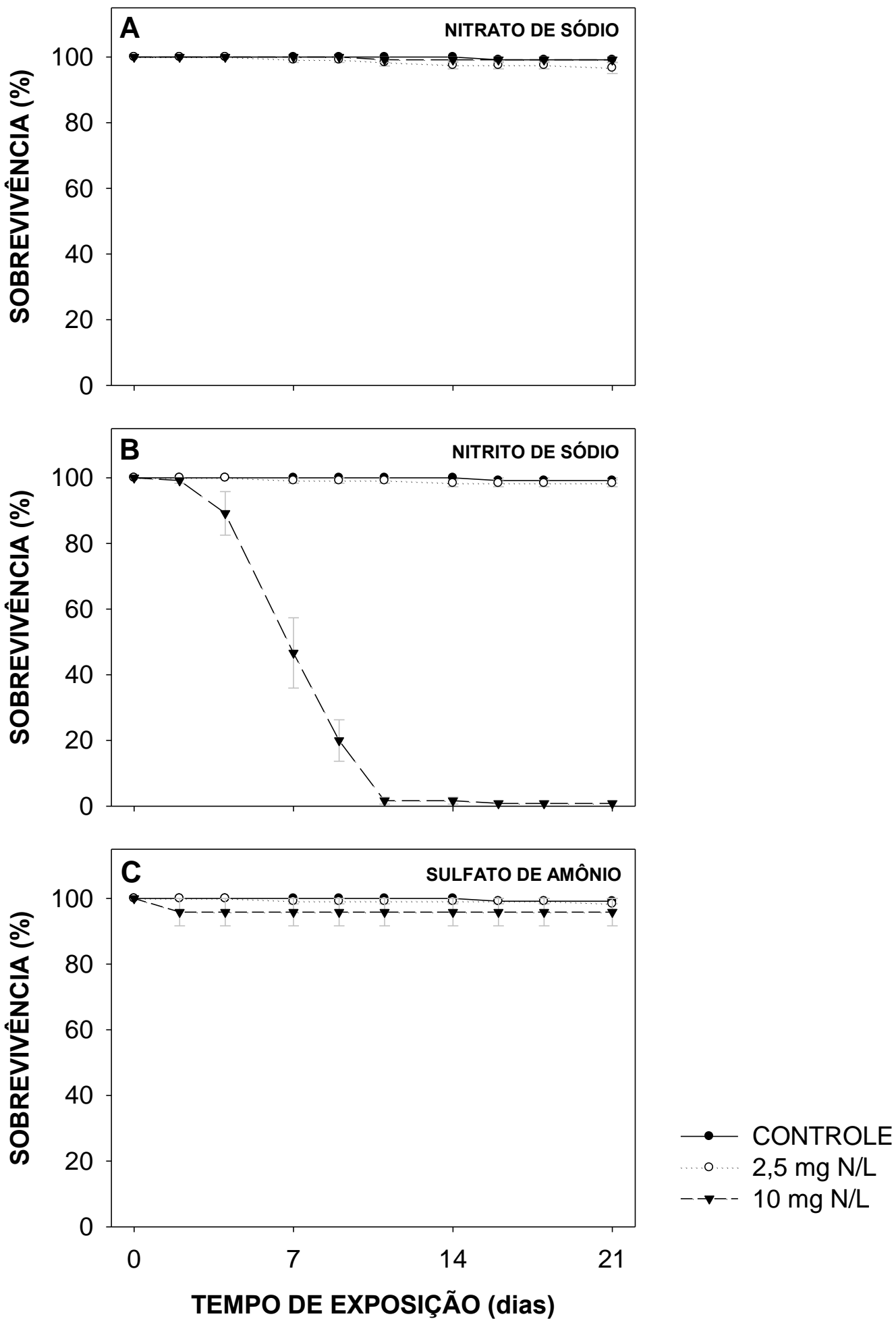

Figura 5. Sobrevivência de Rhinella ornata ao nitrato de sódio (A), nitrito de sódio (B) e sulfato de amônio $(C)$ ao longo do experimento de exposição crônica. Cada ponto representa a média \pm 1 erro padrão de seis réplicas. 

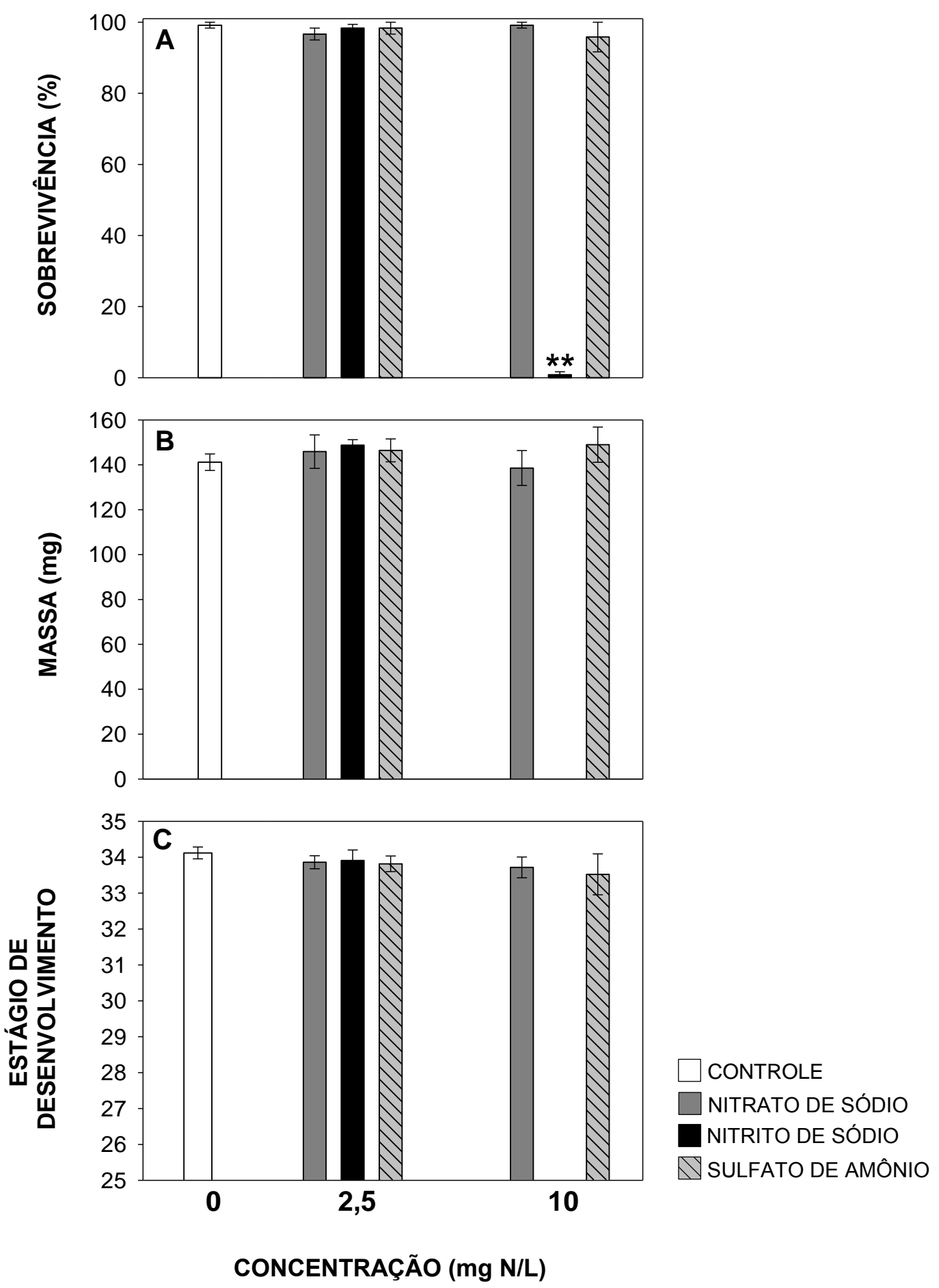

Figura 6. Sobrevivência (A), massa $(B)$ e estágio de desenvolvimento $(C)$ de girinos de Rhinella ornata em exposição crônica ao nitrato de sódio (cinza), nitrito de sódio (preto) e sulfato de amônio (hachurado) decorridos 21 dias de experimentos. $O$ controle está representado pela barra branca. Cada barra representa a média \pm 1 erro padrão de três réplicas. Diferença em relação ao controle com $p<0,01$ foi representada por **. Note que o eixo $X$ não está em escala linear, e que para efeitos de visualização as barras foram deslocadas ao redor da concentração manipulada, que foi igual para todos os três compostos. 

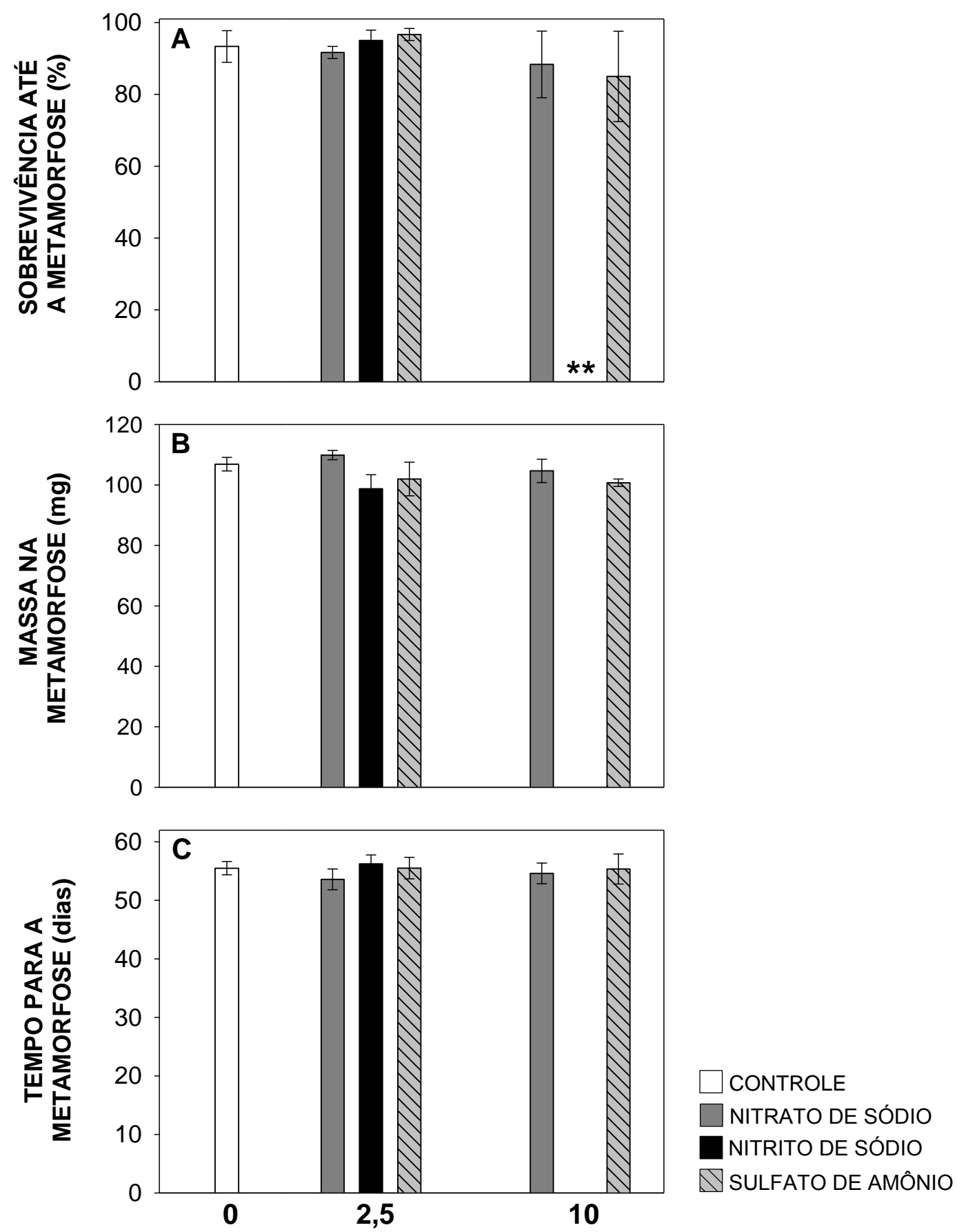

CONCENTRAÇÃO (mg N/L)

Figura 7. Sobrevivência até a metamorfose (A), massa na metamorfose (B) e tempo para completar a metamorfose $(\mathrm{C})$ de girinos de Rhinella ornata em exposição crônica ao nitrato de sódio (cinza), nitrito de sódio (preto) e sulfato de amônio (hachurado). O controle está representado pela barra branca. Cada barra representa a média \pm 1 erro padrão de três réplicas $e^{* *}$ representa diferença em relação ao controle com $p<0,01$. Note que o eixo $X$ não está em escala linear, e que para efeitos de visualização as barras foram deslocadas ao redor da concentração manipulada, que foi igual para todos os três compostos. 


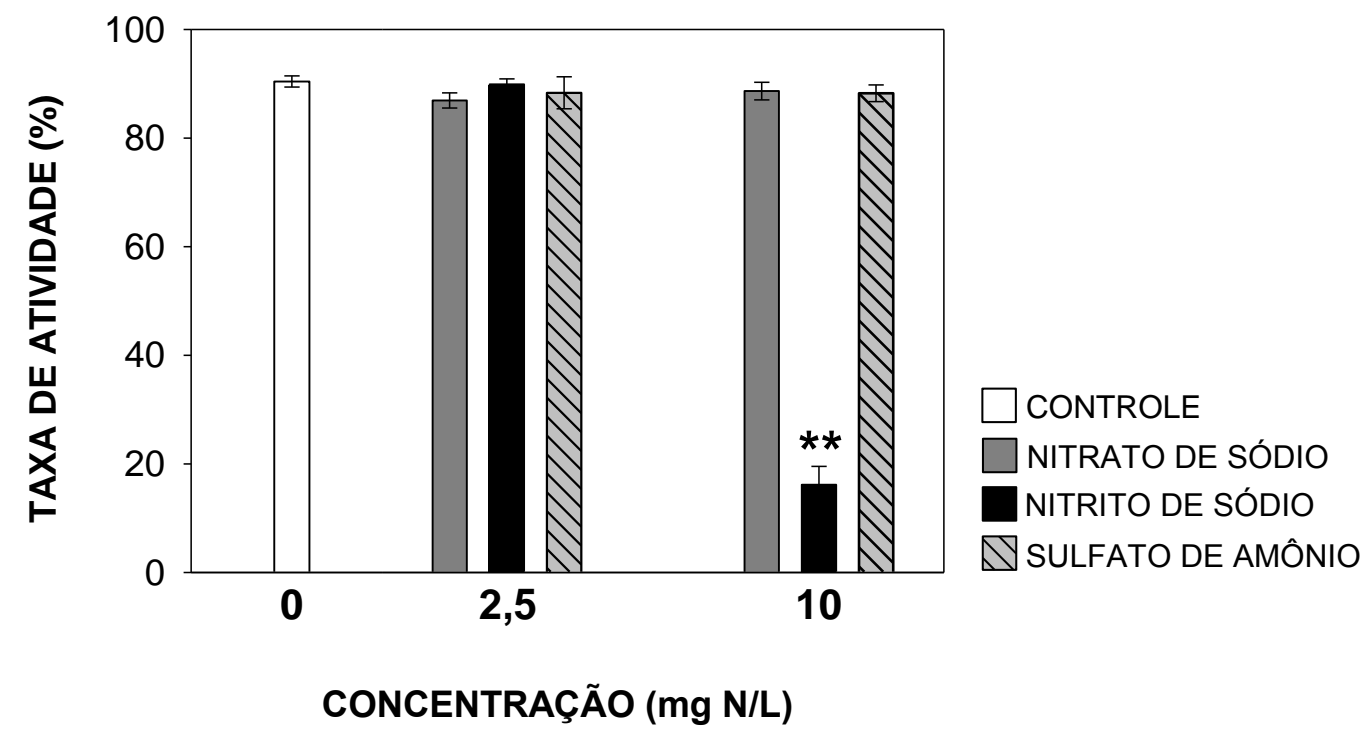

Figura 8. Taxa de atividade de girinos de Rhinella ornata em exposição crônica (21 dias) ao nitrato de sódio (cinza), nitrito de sódio (preto) e sulfato de amônio (hachurado). O controle está representado pela barra branca. Cada barra representa a média \pm 1 erro padrão de 8 observações realizadas em seis réplicas e ${ }^{* *}$ representa diferença em relação ao controle com $p$ menor que 0,01 . Note que o eixo $X$ não esta em escala linear, e que para efeitos de visualização as barras foram deslocadas ao redor da concentração manipulada, que foi igual para todos os três compostos. 
No experimento com Physalaemus cuvieri os girinos apresentaram baixa sobrevivência em todos aquários. Nos controles, a sobrevivência manteve-se superior a 95\% até o final da primeira semana, mas após 14 dias caiu para $56 \%$ e decorridos 21 dias atingiu 32,5\% (Figura 9). No final do experimento, as larvas dos controles pesaram em média 24mg e estavam no estágio de desenvolvimento 27 (Gosner 1960). As larvas expostas ao nitrato de sódio, nas duas concentrações manipuladas, apresentaram a mesma sobrevivência que os controles durante todo o experimento. Contudo, a sobrevivência em 2,5 mgN / L foi significativamente superior à registrada em $10 \mathrm{mgN} / \mathrm{L}$ após $14\left(\mathrm{ANOVA}_{2,23}=7,153 ; p=0,004\right) \mathrm{e}$ 21 dias (ANOVA $F_{2,23}=9,122 ; p=0,001$ ). Embora não tenha sido detectado nenhum efeito do nitrato de sódio sobre a massa dos girinos (Tabela 4; Figura 10; ANOVA $\left.F_{2,23}=2,411 ; p=0,115\right)$, os indivíduos expostos a $10 \mathrm{mgN}$-nitrato / $\mathrm{L}$ apresentaram em média estágios de desenvolvimento inferiores aos observados nos controles (Tabela 4; Figura 10; ANOVA $F_{2,23}=4,768 ; p=0,02$ ). O nitrito de sódio afetou a sobrevivência dos girinos desde a primeira semana de exposição (Tabela 4; Figura 9). A concentração de 2,5 mgN / L não afetou a sobrevivência dos girinos na primeira semana, mas reduziu para 32,5\% após 14 dias e para $15,8 \%$ após três semanas. Esses valores são a metade do registrado nos controles para os mesmos períodos. Já nitrito de sódio na concentração de $10 \mathrm{mgN} / \mathrm{L}$ reduziu a sobrevivência das larvas de $P$. cuvieri para $25,8 \%$ logo na primeira semana e após 14 e 21 dias atingiu respectivamente $2,5 \%$ e 1,6\%. Nenhum efeito do nitrito de

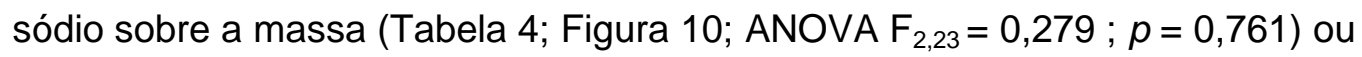
desenvolvimento dos girinos (Tabela 4; Figura 10; ANOVA $F_{2,23}=0,424 ; p=0,663$ ) foi detectado. A exposição ao sulfato de amônio não causou qualquer efeito letal ou subletal para as larvas de $P$. cuvieri nas duas concentrações testadas (Tabela 4; Figura 10). 

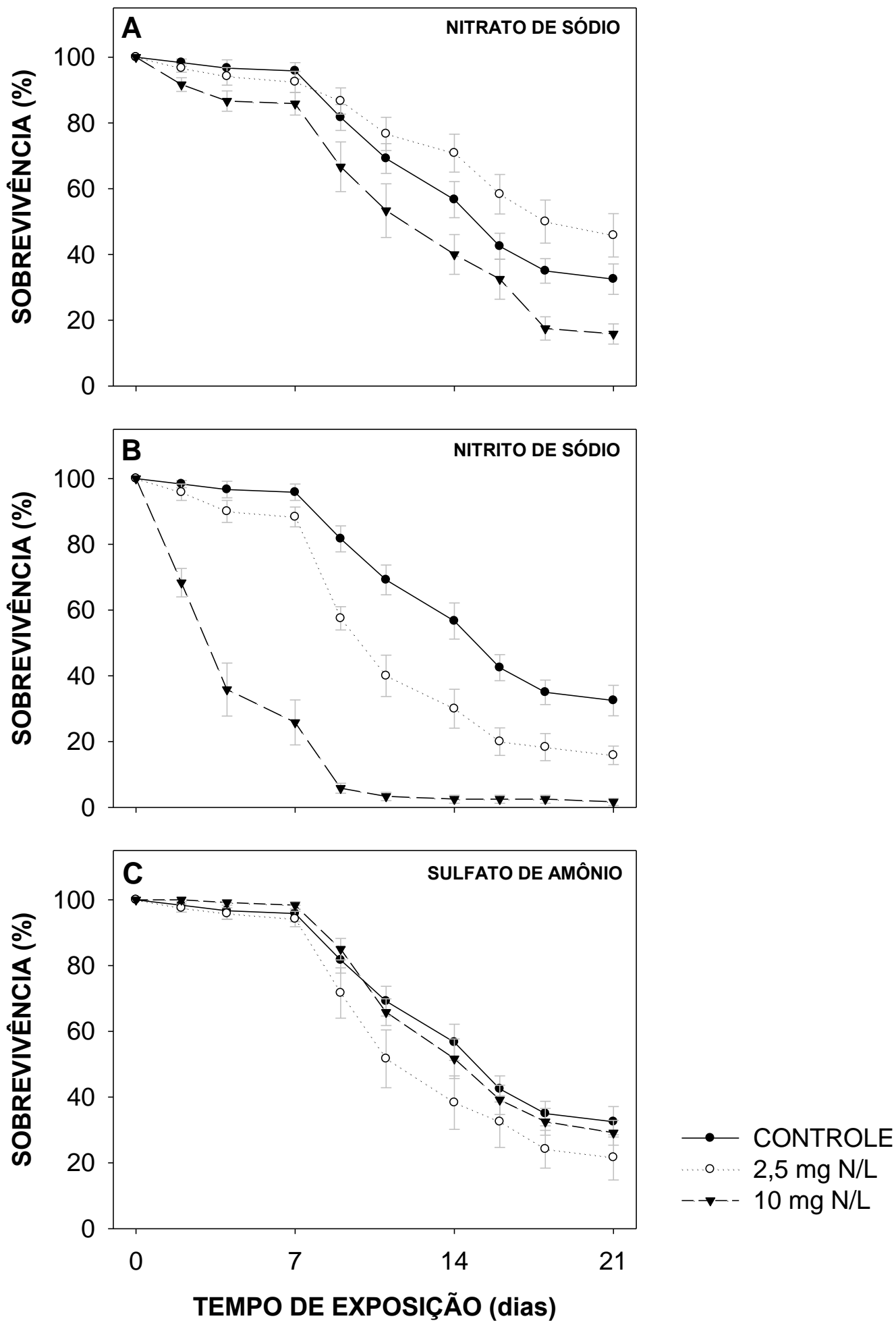

Figura 9. Sobrevivência de Physalaemus cuvieri ao longo do experimento de exposição crônica ao nitrato de sódio $(A)$, nitrito de sódio $(B)$ e sulfato de amônio (C). Cada ponto representa a média \pm 1 erro padrão de oito réplicas. 

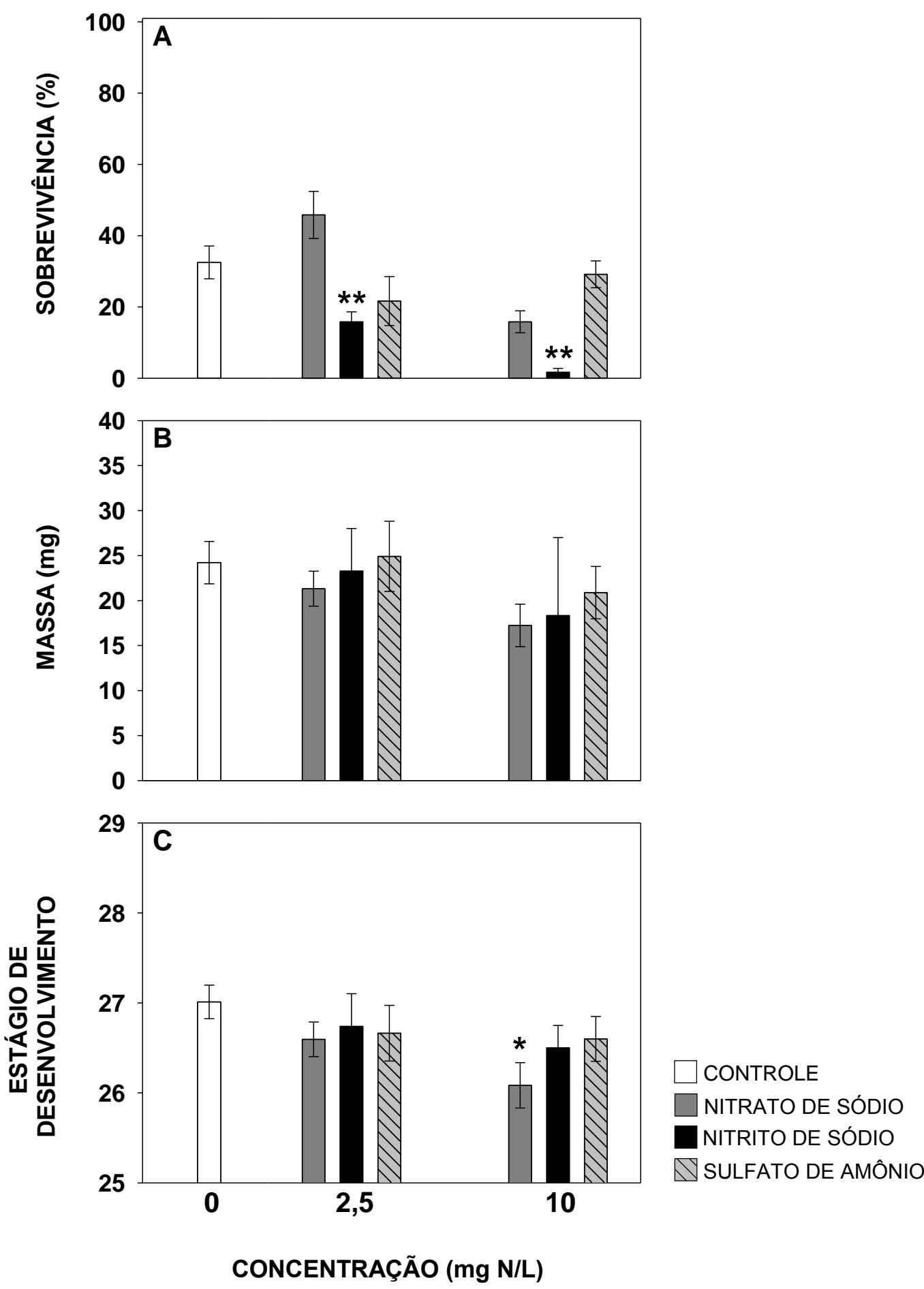

Figura 10. Sobrevivência $(A)$, massa $(B)$ e estágio de desenvolvimento $(C)$ de girinos de Physalaemus cuvieri após 21 dias de exposição ao nitrato de sódio (cinza), nitrito de sódio (preto) e sulfato de amônio (hachurado). O controle está representado pela barra branca. Cada barra representa a média \pm 1 erro padrão de oito réplicas, * $\mathrm{e}^{* *}$ representam diferenças em relação ao controle com $p$ menor que 0,05 e 0,01 , respectivamente. Note que o eixo $X$ não esta em escala linear, $e$ que para efeitos de visualização as barras foram deslocadas ao redor da concentração manipulada, que foi igual para todos os três compostos. 
No experimento com Hypsiboas faber os controles apresentaram 99\% de sobrevivência ao término do experimento. Neste momento os girinos pesaram em média 115mg e estavam no mesmo estágio de desenvolvimento de quando começaram o experimento (estágio 25; Gosner 1960). O nitrato de sódio não causou qualquer efeito letal ou subletal para as larvas de $H$. faber nas duas concentrações testadas (Tabela 4; Figuras 12 e 13). O nitrito de sódio na concentração de 2,5 mgN / L também não afetou nenhuma das variáveis medidas (Tabela 4; Figuras 12 e 13), enquanto que a concentração de $10 \mathrm{mgN} / \mathrm{L}$ afetou negativamente a sobrevivência e a massa dos girinos. Durante as duas primeiras semanas, a sobrevivência dos girinos expostos a $10 \mathrm{mgN}$-nitrito / $\mathrm{L}$ foi igual a dos controles, mas no final da terceira semana caiu para 79\% (Tabela 4; Figura 11; ANOVA $\left.F_{2,14}=34,636 ; p<0,001\right)$. Além disso, a massa dos girinos nesse tratamento foi em média 11,9\% menor que nos controles (Tabela 4; Figura 12; ANOVA $\left.F_{2,14}=7,817 ; p=0,007\right)$. O sulfato de amônio na concentração de $2,5 \mathrm{mgN}$ / L não causou qualquer efeito letal ou subletal para as larvas de $H$. faber, mas 10 mgN / L causou redução da sobrevivência e atividade dos girinos. Apenas na primeira semana a sobrevivência dos girinos expostos a $10 \mathrm{mgN}$-amonia total / $\mathrm{L}$ foi igual a dos controles (Tabela 4; Figura 11; ANOVA $F_{2,14}=1,2 ; p=0,335$ ). Após 14 dias já foi registrado redução para 92\% (Tabela 4; Figura 11; ANOVA $_{2,14}=6,615$; $p=0,012$ ) e até o final da terceira semana caiu para 89\% (Tabela 4; Figura 11; ANOVA $\left.F_{2,14}=15,167 ; p=0,001\right)$. A exposição a $10 \mathrm{mgN}$-amonia total $/ \mathrm{L}$ reduziu a taxa de atividade dos girinos de $H$. faber em $22 \%$ com relação ao controle (Tabela 4; Figura 13; ANOVA $\left.F_{2,14}=5,115 ; p=0,025\right)$. 

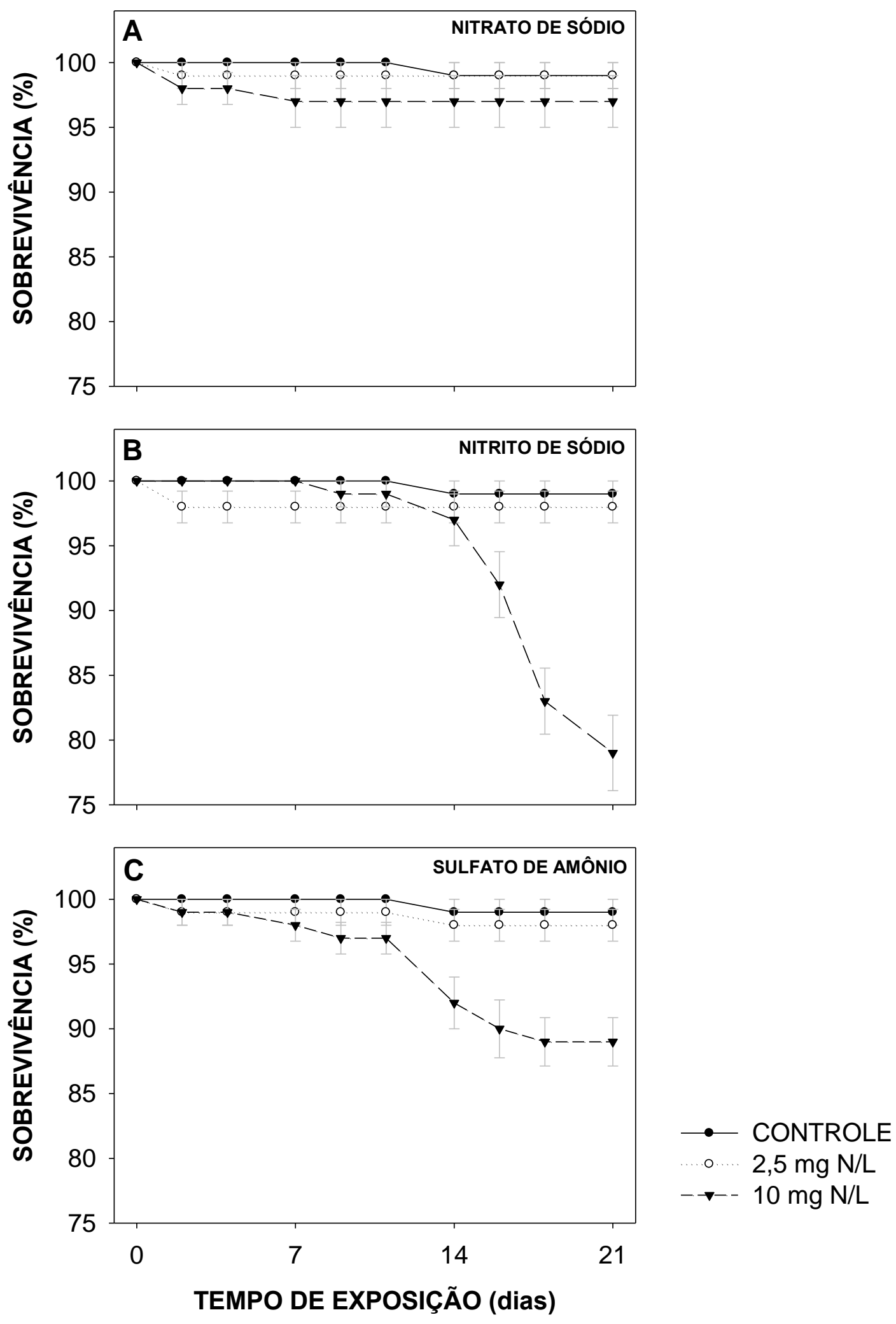

Figura 11. Sobrevivência de Hypsiboas faber ao longo do experimento de exposição crônica ao nitrato de sódio (A), nitrito de sódio (B) e sulfato de amônio (C). Cada ponto representa a média \pm 1 erro padrão de cinco réplicas. 

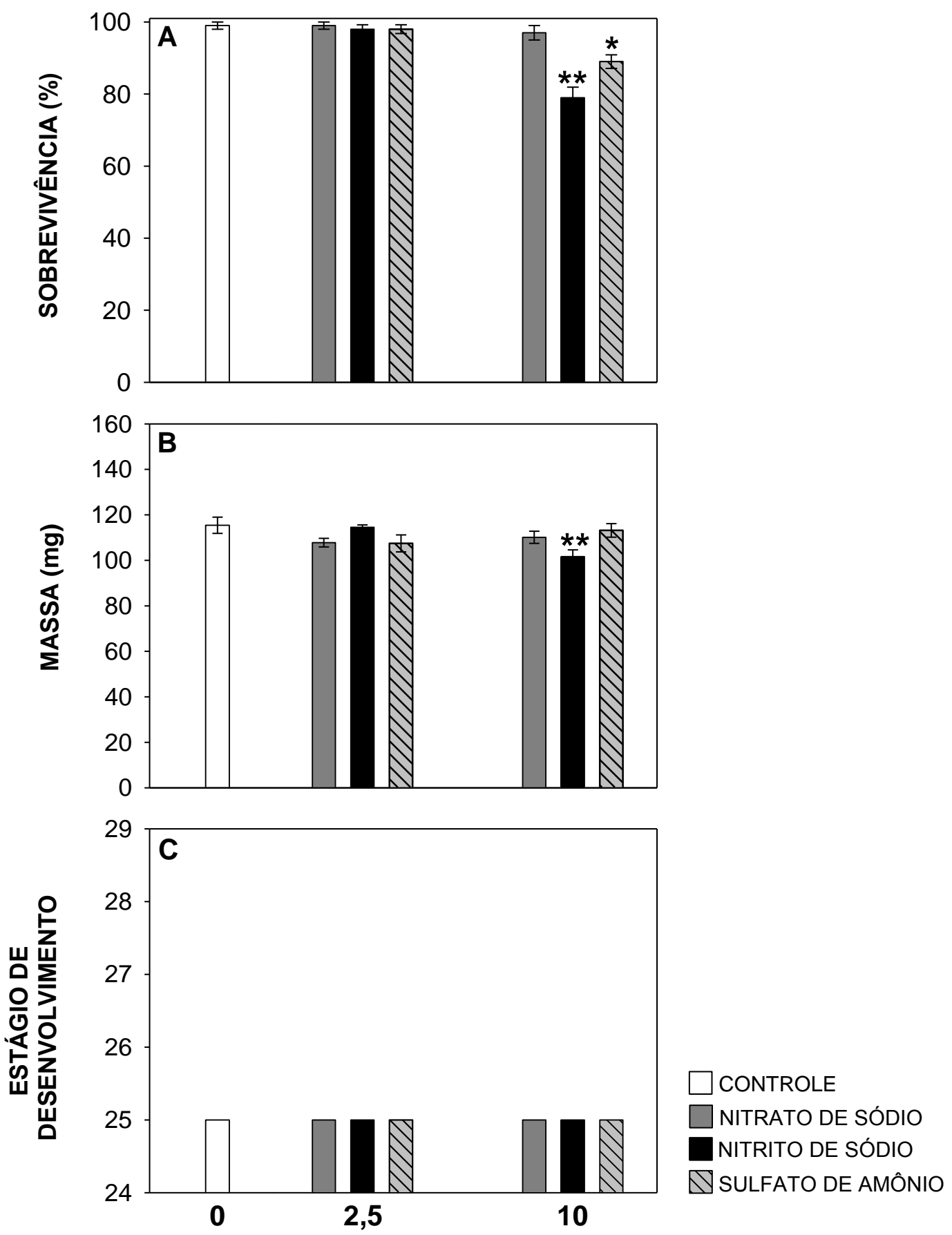

CONCENTRAÇÃO (mg N/L)

Figura 12. Sobrevivência (A), massa (B) e estágio de desenvolvimento (C) de girinos de Hypsiboas faber decorridos 21 dias de exposição ao nitrato de sódio (cinza), nitrito de sódio (preto) e sulfato de amônio (hachurado). O controle está representado pela barra branca. Cada barra representa a média \pm 1 erro padrão de cinco réplicas, ${ }^{*} \mathrm{e}^{* *}$ representam diferenças em relação ao controle com $p$ menor que 0,05 e 0,01 respectivamente. Note que o eixo $X$ não esta em escala linear, $e$ que para efeitos de visualização as barras foram deslocadas ao redor da concentração manipulada, que foi igual para todos os três compostos. 


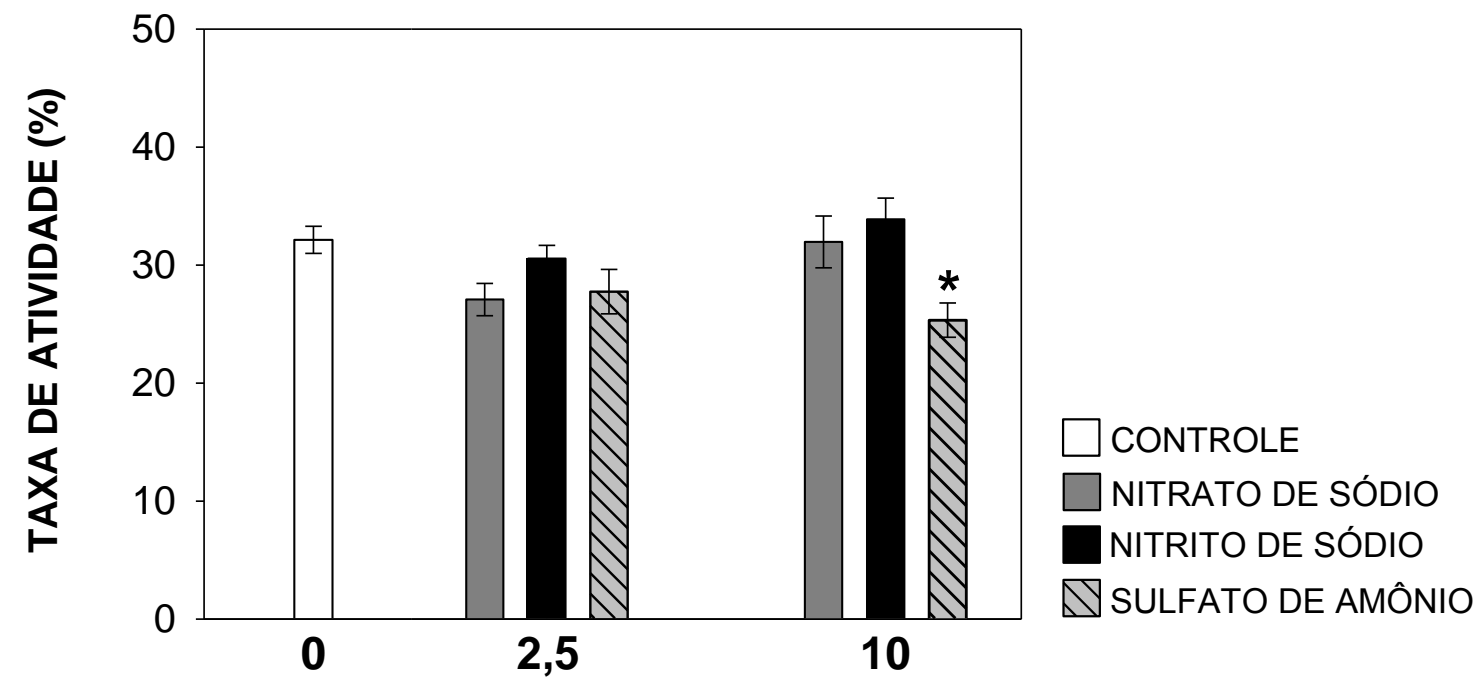

CONCENTRAÇÃO (mg N/L)

Figura 13. Taxa de atividade de girinos de Hypsiboas faber em exposição crônica (21 dias) ao nitrato de sódio (cinza), nitrito de sódio (preto) e sulfato de amônio (hachurado). O controle está representado pela barra branca. Cada barra representa a média \pm 1 erro padrão de 20 observações realizadas em cinco réplicas $e^{*}$ representa diferença em relação ao controle com $p$ menor que 0,05 . Note que o eixo $X$ não esta em escala linear, e que para efeitos de visualização as barras foram deslocadas ao redor da concentração manipulada, que foi igual para todos os três compostos. 


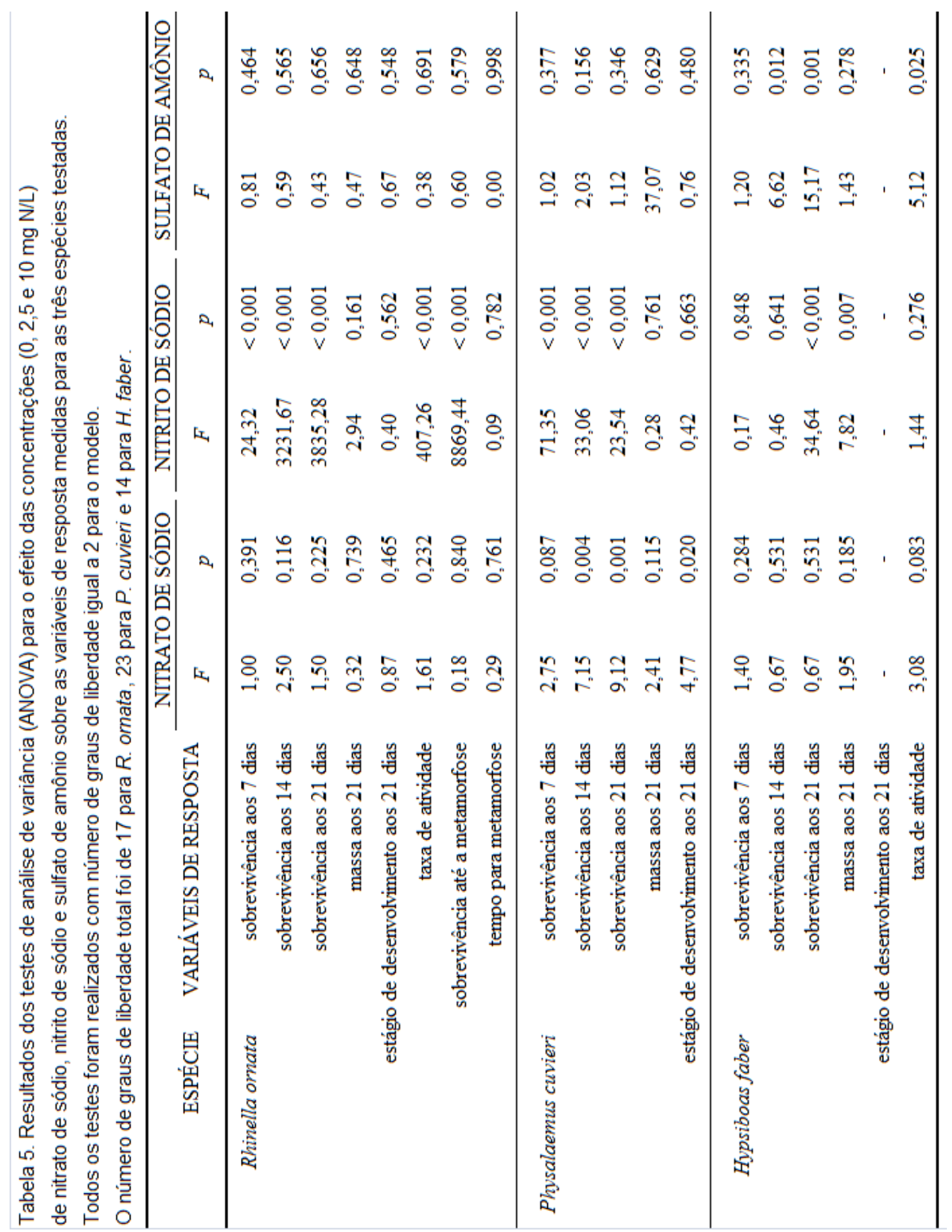




\section{Discussão}

Nesse trabalho, demonstrei que as larvas de anuros brasileiros podem sofrer efeitos letais e subletais se forem expostos de forma prolongada a concentrações relativamente baixas e ecologicamente relevantes de nitrogênio inorgânico. Demonstrei também que nitrito é mais tóxico que amônio, que esses dois íons são consideravelmente mais tóxicos que nitrato, e que existe grande variação interespecífica na sensibilidade a essas formas de nitrogênio. Além de avançar o conhecimento geral dos efeitos do nitrogênio inorgânico sobre larvas de anuros, que apenas muito recentemente incorporaram a comparação entre compostos e a investigação de efeitos subletais, esta é, até onde podemos avaliar (Schiesari et al. 2005, Schiesari et al. 2007, e pesquisas bibliográficas posteriores por mim realizadas), a primeira pesquisa ecotoxicológica no Brasil utilizando espécies nativas de anfíbios em bioensaios padronizados (ASTM, 2004). Portanto, a relevância desse trabalho vai além dos resultados apresentados, e inclui o estabelecimento das bases de uma metodologia e de um sistema experimental modelo pioneiro no país.

Com relação à toxicidade relativa das formas de nitrogênio, a observação de que o nitrato é pouco tóxico para as espécies testadas reflete o conhecimento disponível para anfíbios (veja na revisão feita por Marco \& Ortiz-Santaliestra, no prelo) e para organismos aquáticos de um modo geral (Camargo \& Alonso, 2006). Da mesma forma, a observação de que o nitrito é 2.5 vezes mais tóxico que o amônio (embora a diferença tenha sido detectada como não-significativa pela grande variação interespecífica) corresponde ao esperado pelo menos com relação aos anfíbios. Por exemplo, os de valores de CL50 em 96 horas de exposição ao nitrato foram quantificados em 16,5-3666 mg N/L para anfíbios (Schuytema \& Nebeker, 1999a; Schuytema \& Nebeker, 1999b), 62,5-1042 mg N/L para invertebrados e de 191-1975 mg N/L para peixes (Camargo et al., 2005; Camargo \& 
Alonso, 2006). Já para o amônio os valores de CL50 foram consideravelmente menores para anfíbios: 60-135 mg N/L (Schuytema \& Nebeker, 1999a; Schuytema \& Nebeker, 1999b). Finalmente, para o nitrito os valores de CL50 foram ainda menores: 5,5-6,82 mg N-nitrito/L para anfíbios (Marco et al., 1999), 1,03-10,9 mg $\mathrm{N} / \mathrm{L}$ para invertebrados e 0,1-3 mg N/L para peixes (Camargo \& Alonso, 2006). Apesar desses padrões gerais, diversos trabalhos sugerem que os organismos aquáticos apresentam grande variação interespecífica na sensibilidade aos compostos nitrogenados (Camargo \& Alonso, 2006; Marco \& Ortiz-Santaliestra, no prelo). Neste trabalho observei diferenças na sensibilidade das espécies de até duas vezes para nitrato (entre $H$. faber e $P$. olfersii), seis vezes para nitrito (entre $R$. ornata e $H$. pardalis) e de mais de três vezes e meia para amônio (entre $H$. faber e P. cuvieri). Diferenças como essas ou maiores já foram registradas em outros trabalhos. Por exemplo, segundo Smith et al. (2005) os girinos de Rana clamitans são três vezes mais sensíveis ao nitrato que os de Rana catesbeiana, e segundo Marco et al. (1999) Rana pretiosa é sete vezes mais sensível ao nitrito que Rana aurora e 20 vezes mais sensível que Pseudacris regilla. Essas variações na suscetibilidade das espécies podem ter importantes efeitos diretos e indiretos na estrutura das comunidades aquáticas, seja devido à modificação na forma como espécies respondem ao meio abiótico, seja na modificação dos resultados das interações competitivas e predador-presa (Griffis-Kyle \& Ritchie, 2007).

Vários são os artefatos que poderiam confundir o papel da identidade das espécies - e portanto a magnitude da variação interespecífica - na resposta a contaminantes, como por exemplo as condições experimentais, a qualidade da água, o tipo de composto químico utilizado, e o tamanho e estágio de desenvolvimento dos animais testados (Marco \& Ortiz-Santaliestra, no prelo). Nos bioensaios de exposição aguda que realizei pode-se descartar um efeito da qualidade da água e dos compostos químicos utilizados, pois esses fatores foram 
iguais para todas as espécies. Também pode-se descartar um papel para o estágio de desenvolvimento, uma vez que todas as espécies foram testadas ao redor do estágio 25 (Gosner, 1960). Por outro lado, fixando-se o estágio de desenvolvimento a ser testado, necessariamente tivemos diferenças no tamanho das larvas testadas para as diferentes espécies.

Larvas de $P$. cuvieri e $P$. olfersi são consideravelmente menores que os das outras três espécies, as quais possuem tamanhos bastante parecidos. Embora indivíduos maiores possuam maior tolerância a substâncias tóxicas em geral (Schuytema \& Nebeker, 1999b), este fator não parece ter influenciado os resultados, pois não houve padrão óbvio na posição destas duas espécies no ranqueamento de sensibilidade para os três íons; ou seja, as sensibilidades de $P$. cuvieri e $P$. olfersi foram maiores, iguais ou menores do que as das demais espécies dependendo do composto manipulado. Um fator de grande influência para a ecotoxicidade, e que diferiu entre bioensaios, foi a temperatura. Em geral, a solubilidade dos compostos na água e as taxas metabólicas dos organismos (inclusive taxas de absorção e circulação sanguínea) são maiores em temperaturas elevadas, o que pode acentuar os efeitos tóxicos (Cairns et al., 1975). Por outro lado, conforme as taxas metabólicas aumentam com a temperatura, a desintoxicação bioquímica também pode aumentar, reduzindo eventualmente a toxicidade dos compostos (Howe et al., 1994). Portanto a temperatura tem grande potencial de influenciar a toxicidade de contaminantes, especialmente para organismos ectotérmicos (Sprague, 1985). Por este motivo protocolos internacionais determinam $24 \pm 2{ }^{\circ} \mathrm{C}$ como temperatura padrão para os testes ecotoxicológicos (ASTM, 2004). Infelizmente, por questões logísticas não pude controlar a temperatura, que diferiu em média $4,5^{\circ} \mathrm{C}$ (amplitude de 2-8) entre os testes. De qualquer forma, não observei relação entre a temperatura na qual os bioensaios foram conduzidos e os valores de CL50 calculados para nitrato, nitrito e amônio o 
que sugere que a temperatura, mesmo que importante, não afetou de forma evidente os resultados experimentais.

O ranqueamento na sensibilidade das espécies às formas de nitrogênio inorgânico foi mantido entre nitrato e nitrito, mas não entre nitrato e amônio ou entre nitrito e amônio. Isto provavelmente se deu por conta dos mecanismos de ação tóxica característicos de cada um desses compostos. No interior do corpo dos animais o nitrato é reduzido a nitrito, e consequentemente a ação tóxica do nitrato converge para a do nitrito (Camargo \& Alonso, 2006). Após entrar na corrente sanguínea, o nitrito oxida as proteínas responsáveis pelo transporte de oxigênio (hemoglobina, hemocianina) convertendo-as em formas incapazes de transportar oxigênio para a respiração celular (metahemoglobina, metahemocianina) (Huey \& Beitinger, 1980). Já ação tóxica do amônio, pode envolver a redução da concentração de sódio no sangue para níveis possivelmente fatais, embora na realidade os feitos negativos mais graves sejam causados pela sua porção nãoionizada, a amônia (Russo, 1985). A ação tóxica da amônia sobre os organismos aquáticos envolve diversas alterações bioquímicas do metabolismo, mas o principal efeito negativo causado é a destruição dos tecidos, especialmente do epitélio branquial, o que prejudica a respiração e a osmorregulação (Camargo \& Alonso, 2006).

No que diz respeito à comparação da sensibilidade das espécies que manipulei com outras reportadas na literatura, é importante notar que mesmo com o esforço da comunidade científica no sentido de padronizar testes ecotoxicológicos, há algumas diferenças no delineamento experimental das pesquisas publicadas, principalmente com relação aos períodos de exposição, compostos manipulados e estágio de desenvolvimento dos animais testados, que prejudicam qualquer comparação (veja na revisão feita por Marco \& Ortiz-Santaliestra, no prelo). Por exemplo, em toda a (relativamente pequena; $\mathrm{N} \stackrel{\sim}{=} 80$ trabalhos publicados) literatura 
sobre efeitos ecotoxicológicos do nitrogênio inorgânico para larvas de anuros, existe apenas um único trabalho que calculou a CL50 em 96 horas de exposição ao nitrato de sódio e sulfato de amônio (Schuytema \& Nebeker, 1999a) e um único para nitrito de sódio (Marco et al., 1999). Outros estudos manipularam outros compostos (principalmente nitrato de amônio), larvas em outras estágios de desenvolvimento e diferentes períodos de exposição.

Segundo Schuytema \& Nebeker (1999a), as CL50 para girinos em estágio 26 das espécies Pseudacris regilla e Xenopus laevis são respectivamente 1750 e 3666 mg N-nitrato/L para nitrato de sódio, e 115 e 135 mg N-amônio/L para sulfato de amônio. Em comparação com este trabalho, todas as espécies que testei foram mais sensíveis ao nitrato, pois os valores de CL50 que calculei estiveram na faixa de 743-1546 mg N-nitrato/L. Esses valores são próximos a CL50 calculada para larvas de Rana aurora em estágio 11-12 (CL50 = 636 mg N-nitrato/L) que foram expostas por 16 dias ao nitrato de sódio (Schuytema \& Nebeker, 1999c). Logo, isso reforça a idéia de maior sensibilidade ao nitrato nas espécies que eu testei, pois larvas em estágios ontogenéticos inferiores são mais sensíveis e exposições maiores aumentam a toxicidade dos compostos (Camargo et al., 2005; Ortiz et al., 2006). Por outro lado, os valores de CL50 que calculei para amônio estiveram na faixa de $198-745 \mathrm{mg} \mathrm{N} / \mathrm{L}$, e portanto as espécies que eu testei foram mais resistentes a esse íon que as testadas por Schuytema \& Nebeker (1999a). Isso é contraintuitivo não só pelo fato de um mesmo grupo de espécies ser relativamente mais sensível a uma substância e ao mesmo tempo mais resistente a outro, mas também porque suspeita-se que $X$. laevis seja pouco sensível a compostos químicos em geral (Hoke \& Ankley, 2005).

Para nitrito de sódio, os valores de CL50 apresentados por Marco et al. (1999) estão na faixa de 5,5-6,82 mg N-nitrito/L ( $N=4$ spp), e são muito inferiores aos que eu calculei (32-192 mg N-nitrito/L). Contudo, Marco et al. (1999) utilizou 
embriões recém-eclodidos em seus experimentos, os quais são consideravelmente mais sensíveis aos efeitos negativos de substâncias tóxicas de uma forma geral (Ortiz-Santaliestra et al., 2006) em comparação com girinos em estágio 26 que utilizei. Portanto faz sentido que haja essa diferença. Mas principalmente, isso demonstra que os testes ecotoxicológicos que tradicionalmente avaliam apenas um estágio ontogenético, especialmente os que lidam com estágios tardios de desenvolvimento, podem subestimar enormemente as consequências da exposição a substâncias tóxicas (Griffis-Kyle, 2005).

Bioensaios padronizados foram desenvolvidos como ferramentas importantes para a avaliação da variação interespecífica da sensibilidade e do grau de ecotoxicidade de compostos aos organismos, e de forma a serem reconhecidos não só pela academia, mas também pela indústria e pelo governo. Por exemplo, o estabelecimento de valores de referência de qualidade da água e a regulamentação de substâncias despejadas em ecossistemas aquáticos são baseados predominantemente em dados derivados desses bioensaios (OECD, 1995). Em regiões tropicais, no entanto, a carência de dados para espécies nativas faz com que os critérios aplicados no controle de qualidade da água sejam derivados de dados obtidos com espécies da zona temperada (Kwok et al., 2007). O problema dessa estratégia é que ela assume que a sensibilidade das espécies tropicais é similar à das espécies temperadas.

No entanto, Kwok et al. (2007) demonstraram em um trabalho de revisão que não há padrão único para a sensibilidade relativa de espécies tropicais e temperadas. Esse trabalho comparou a sensibilidade de espécies temperadas e tropicais de peixes, anfíbios e diversos grupos de invertebrados à 18 substâncias tóxicas, e observou que, por exemplo, para a maioria dos metais as espécies temperadas tendem a ser mais sensíveis que as tropicais, enquanto que para pesticidas e amônia não-ionizada as espécies tropicais são provavelmente mais 
sensíveis. Birge et al. (2000) concorda que a sensibilidade relativa das espécies de anfíbios não segue um padrão consistente, e no presente estudo, também foi isso que observei: as espécies que testei foram todas mais resistentes ao amônio que $P$. regilla e X. laevis (Schuytema \& Nebeker, 1999a), e ao mesmo tempo foram todas mais sensíveis ao nitrato. É cedo para definir padrões gerais, mas uma vez que há limitada capacidade de extrapolação entre resultados obtidos para diferentes espécies, compostos ou ecossistemas (Schiesari et al., 2007) estudos ecotoxicológicos como os que aqui apresento talvez permitam futuramente desenvolver critérios de qualidade ambientais mais adequados à conservação dos ambientes aquáticos tropicais.

Os experimentos de longa duração que realizei confirmam o padrão geral de que mesmo concentrações relativamente baixas e ecologicamente relevantes de nitrogênio inorgânico podem causar efeitos letais e subletais para a biota se a exposição for longa o suficiente (Camargo et al., 2005). Neste trabalho, descobri que a exposição prolongada a apenas $10 \mathrm{mg} \mathrm{N}$-nitrito/L pode reduzir a sobrevivência de $H$. faber em mais de $10 \%$, e a de $R$. ornata (Figura 14) e $P$. cuvieri a praticamente zero. Mesmo 2,5 mg N-nitrito/L causou redução na sobrevivência de P. cuvieri, mas devido à elevada mortalidade que ocorreu nos controles desse experimento, é razoável pensar que os girinos testados não estavam saudáveis. Apesar disso, outros estudos mostram que a exposição por 15 dias a concentrações inferiores a apenas $1,75 \mathrm{mg} \mathrm{N}$-nitrito/L podem causar reduções de mais de $50 \%$ na sobrevivência de girinos de várias espécies de anfíbios (Marco et al., 1999; Shinn et al., 2008). 


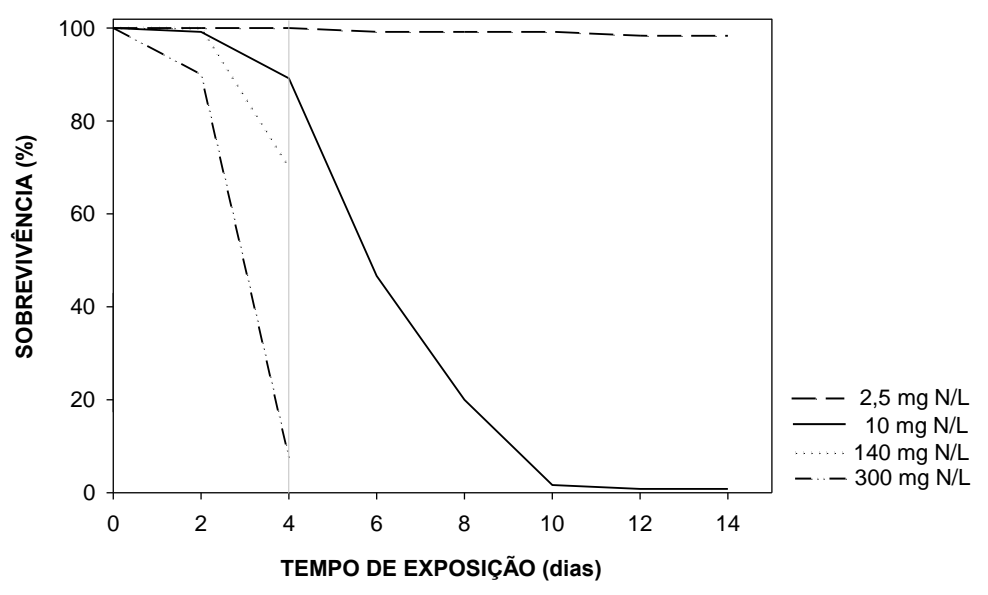

Figura 14. Sobrevivência de larvas de Rhinella ornata durante exposição a soluções de nitrito de sódio variando entre 2,5 e $300 \mathrm{mg} \mathrm{N} / \mathrm{L}$. Curvas referentes às concentrações de 2,5 e $10 \mathrm{mg} \mathrm{N} / \mathrm{L}$ foram obtidas no experimento de exposição crônica (21 dias) e curvas referentes às concentrações de 140 e 300 mg N/L foram obtidas no experimento de exposição aguda (4 dias).

Similarmente ao que ocorreu com nitrito, a exposição prolongada a $10 \mathrm{mg}$ N-amônio/L reduziu em mais de $10 \%$ a sobrevivência dos girinos de $H$. faber. Essa concentração é nada menos que 35 vezes inferior a maior concentração sem efeito observado para essa espécie nos bioensaios de 96 horas (350 mg N-amônio/L). E apesar das baixas concentrações de $\mathrm{N}$-amônio que manipulei não terem afetado as larvas de $R$. ornata e $P$. cuvieri, diversos trabalhos sugerem que concentrações iguais ou até mesmos inferiores dessa forma de nitrogênio podem ser prejudiciais aos anfíbios (Schuytema \& Nebeker, 1999b; Hamer et al., 2004; Marco \& OrtizSantaliestra, 2009). Por exemplo, Griffis-Kyle \& Ritchie (2007) demonstraram que 6,5 mg N-amônio/L podem causar 100\% de mortalidade em Rana sylvatica. E segundo Hamer et al. (2004) a exposição crônica a apenas 2,25 mg N-amônio/L reduz em $76 \%$ a sobrevivência de Litoria aurea.

Já para o nitrato, as baixas concentrações que manipulei não causaram efeitos letais em nenhuma das três espécies testadas. Da mesma forma, outros trabalhos que testaram concentrações iguais ou até mesmo maiores não encontram efeitos negativos causados por essa forma de nitrogênio. Por exemplo, para 15 dias 
de exposição, 10 mg N-nitrato/L não afetaram a sobrevivência larval de Rana catesbeiana (Smith et al., 2005), 25 mg N-nitrato/L não afetaram os girinos de Hyla regilla e Bufo boreas (Marco et al., 1999), e nem mesmo $30 \mathrm{mg} \mathrm{N}$-nitrato/L afetaram a sobrevivência de Bufo terrestris (Edwards et al., 2006). Não surpreende portanto que a toxicidade do íon nitrato seja tradicionalmente considerada irrelevante ecologicamente (Russo, 1985).

No entanto, sabe-se que algumas espécies mais sensíveis podem ser afetadas por esse íon (Camargo et al., 2005). Por exemplo, a exposição crônica a 9 mg N-nitrato/L causaram redução de $50 \%$ na sobrevivência de Litoria caerulea (Baker \& Waights, 1994), e apenas 6,5 mg N-nitrato/L reduziram a sobrevivência de Bufo bufo para quase 15\% (Baker \& Waights, 1993). Além disso, acredita-se que o nitrato, assim como o nitrito, possa atuar como disruptor endócrino em diversos grupos de vertebrados, inclusive nos anfíbios (Guillette \& Edwards, 2005). Esses íons podem influenciar o funcionamento da tireóide e o equilíbrio hormonal, consequentemente afetando o crescimento, desenvolvimento larval e a metamorfose (Guillette \& Edwards, 2005).

A exposição a substâncias tóxicas em geral também pode prejudicar o crescimento e desenvolvimento larval, pois mecanismos fisiológicos deslocam o balanço energético em favor do processo de desintoxicação bioquímica, o qual envolve elevado consumo de energia (Marco \& Ortiz-Santaliestra, no prelo). Para os girinos, a redução do crescimento pode ter sérios efeitos negativos, porque as capacidades competitivas são prejudicadas e porque indivíduos menores são mais vulneráveis à predação (Berven, 1990; Newman \& Dunham, 1994). Já a redução do desenvolvimento e, portanto o prolongamento do período larval pode reduzir a sobrevivência devido à dessecação em hábitats efêmeros e ao maior período de exposição aos predadores aquáticos (Griffis-Kyle, 2007). Da mesma forma, o tamanho corporal menor pode prejudicar a sobrevivência dos estágios pós- 
metamórficos e o sucesso reprodutivo dos adultos. Indivíduos menores possuem capacidade locomotora reduzida, o que aumenta a vulnerabilidade a predadores (Xu \& Oldham, 1997), e também possuem menor tolerância à desidratação, menor fertilidade, e menor probabilidade de sucesso na seleção de parceiros (Smith, 1987; Berven, 1990; Goater et al., 1993; Newman \& Dunham, 1994).

Neste trabalho, os girinos de P. cuvieri expostos a $10 \mathrm{mg} \mathrm{N}$-nitrato/L sofreram redução no desenvolvimento larval, e os girinos de $H$. faber expostos a 10 mg N-nitrito/L cresceram menos que os controles. Outros trabalhos também demonstram que o nitrogênio inorgânico pode afetar negativamente o crescimento e desenvolvimento larval dos anfíbios. Segundo Schuytema \& Nebeker (1999b), 10 dias de exposição a 11,7 mg N-amônio/L causaram redução na massa dos girinos de Pseudacris regilla e Xenopus laevis. As larvas de Rana temporaria, sofreram redução no crescimento e desenvolvimento devido a exposição crônica a 5 mg Nnitrato/L (Johansson et al., 2001). E segundo Shinn et al. (2008), apenas 0,5 mgNnitrito/L são suficientes para causarem redução no crescimento de Pelophylax perezi.

Embora neste trabalho eu não tenha detectado efeitos negativos sobre a massa na metamorfose ou no tempo para completar a metamorfose em $R$. ornata, outras pesquisas já demonstraram que os compostos nitrogenados podem não só afetar essas características, como também inibir o processo metamórfico como um todo (Marco \& Ortiz-Santaliestra, no prelo). Por exemplo, o sucesso metamórfico de Pseudacris triseriata foi praticamente nulo devido a exposição a baixas concentrações de nitrato de amônio (Hecnar, 1995), e 5 mg N-nitrato/L fizeram com que Rana temporaria demorasse mais tempo para completar a metamorfose e o fizesse com menor tamanho (Johansson et al., 2001).

A exposição ao nitrogênio inorgânico também pode alterar o comportamento das larvas de anuros causando redução dos níveis de atividade 
(Marco \& Ortiz-Santaliestra, no prelo). A ocorrência desse efeito indica que há uma ação tóxica sobre o sistema nervoso central dos girinos, o qual controla a atividade e a percepção das condições ambientais (Hecnar, 1995). A alteração na atividade tem potencialmente grandes implicações porque a atividade media o conflito que há entre forrageamento e evitação de predadores (Werner \& Anholt, 1993). Por um lado, a redução do nível de atividade pode ser benéfica por reduzir o risco de predação (Lefcort, 1996; Anholt et al., 2005). Mas por outro lado, a redução da atividade pode prejudicar o forrageamento, e consequentemente o crescimento larval (Skelly \& Werner, 1990; Relyea \& Werner, 1999), além de afetar negativamente as habilidades competitivas dos girinos (Semlitsch, 1993; Dayton \& Fitzgerald, 2001). Ou seja, sob a influência de um composto tóxico, a solução para o balanço entre evitar predadores e forragear pode ser deslocada, e a conseqüência pode depender do contexto ecológico da exposição (por exemplo, se competidores e/ou predadores estão presentes ou não).

Essas alterações comportamentais já foram observadas em várias espécies de anfíbios e podem ser causadas por diferentes compostos nitrogenados (Hecnar, 1995; Watt \& Oldham, 1995; Xu and Oldham, 1997; Marco et al., 1999; Marco \& Blaustein, 1999). Neste trabalho, a atividade dos girinos de $H$. faber foi reduzida em mais de 10\% devido a exposição a 10 mg N-amônio/L e os girinos de $R$. ornata tiveram seus níveis de atividade drasticamente reduzidos pela exposição a $10 \mathrm{mg} \mathrm{N}$-nitrito/L. Nesse experimento, as larvas de $R$. ornata permaneceram praticamente imóveis no fundo dos aquários durante toda a exposição, o que na natureza provavelmente significaria elevada redução da sobrevivência (Marco \& Ortiz-Santaliestra, no prelo).

Conclui-se portanto que o nitrogênio inorgânico pode ser tóxico para as larvas de anuros, e, através de efeitos letais e subletais, influenciar o sucesso dos indivíduos. Contudo, resta saber se o nitrogênio está de fato causando efeitos 
negativos sobre larvas de anfíbios na natureza, e em que situações isso ocorre com maior freqüência e intensidade.

Nos ecossistemas aquáticos, o nitrato é a forma de nitrogênio mais estável em condições aeróbicas (Halling-Sorensen \& Jorgensen, 1993) e costuma representar de dois terços a quatro quintos do total de $\mathrm{N}$ no ambiente (Crouzet et al., 1999). Por isso, ecossistemas aquáticos afetados pela agricultura e atividades urbanas no mundo todo frequentemente apresentam concentrações superiores a 25 mg N-nitrato/L (Bogardi et al., 1991). Por sua vez, ambientes aquáticos que recebam elevadas descargas de $\mathrm{N}$ e enfrentem condições anaeróbicas podem sofrer o acúmulo de nitrito e principalmente de amônia total (Marco \& OrtizSantaliestra, no prelo). Tais situações podem gerar concentrações de até $180 \mathrm{mg}$ N-nitrito/L (McCoy, 1972), e de até 5 mg N/L de amônia em ambientes não-poluídos ou mais de $10 \mathrm{mg} \mathrm{N} / \mathrm{L}$ em cenários de contaminação leve e moderada (Wetzel, 1983). Nestes cenários descritos, claramente efeitos deletérios sobre larvas de anfíbios seriam esperados.

No Brasil, as informações sobre concentrações de N inorgânico em ecossistemas aquáticos restringem-se basicamente a rios e reservatórios. Nesses ambientes, as concentrações de nitrogênio dissolvido se mantém geralmente na ordem de microgramas por litro (CETESB, 2009; Martinelli et al., no prelo), e portanto muito abaixo de níveis tóxicos para a maioria dos organismos aquáticos (Marco \& Ortiz-Santaliestra, no prelo). No entanto, brejos, poças e lagoas podem apresentar concentrações de nitrogênio elevadas o suficiente para afetar os anfíbios (Berger 1989; Hecnar 1995; Marco et al., 1999; Schuytema and Nebeker 1999a) porque possuem menor volume de água, e consequentemente menor capacidade de diluir grandes volumes de nitrogênio. Por exemplo, nos Estados Unidos, concentrações de até $78 \mathrm{mg} \mathrm{N}$-nitrato/L e $21 \mathrm{mg} \mathrm{N}$-amônia total/L já foram registradas em poças temporárias no Mississipi (McDowell \& McGregor, 1979), e 
de até 77,5 mg N-nitrato/L (Owens et al., 1983) e 42 mg N-amônia total/L em Ohio (Edwards \& Daniel, 1994). Embora não conheço dados na literatura para contaminação desse tipo de ambiente no Brasil, dados preliminares indicam que concentrações como 8,5 mg N-nitrato/L e 12 mg N-amônia-total/L podem ser facilmente atingidas em áreas agrícolas (observação pessoal).

Portanto, é muito plausivel que no Brasil, onde o consumo de fertilizantes é grande e a expansão agressiva da fronteira agrícola depara com excepcional biodiversidade, algumas populações naturais de anfíbios estejam sofrendo efeitos negativos semelhantes aos que observei no laboratório. Todavia, é importante ter em mente que é impossível avaliar com precisão os efeitos da poluição por $\mathrm{N}$ natureza a partir de experimentos de laboratório (Ortiz et al., 2004). Por exemplo, baixas concentrações de compostos nitrogenados na natureza podem ser benéficas para consumidores primários, como os girinos, devido ao aumento da produtividade primária (Smith et al., 2005). Por outro lado, concentrações consideradas inofensivas em testes de laboratório podem tornar-se prejudiciais na natureza devido a sinergismos com outros fatores físicos, químicos e/ou biológicos (veja na revisão feita por Marco \& Ortiz-Santaliestra, no prelo). Sabe-se por exemplo que a radiação UV-B pode aumentar os efeitos tóxicos do nitrato e do nitrito (Hatch \& Blaustein, 2003; Macías et al., 2007) e que a temperatura e o pH podem influenciar na toxicidade da amônia-total devido a alterações na proporção entre as formas ionizada e não-ionizada (Diamond et al., 1993; Hatch \& Blaustein, 2000). Baixas concentrações de oxigênio dissolvido também podem aumentar os efeitos negativos causados pelo nitrato, nitrito e amônia-total (Johnson et al., 1987; Allan et al., 1990) e uma vez que a exposição a essas formas de $\mathrm{N}$ causa depressão do sistema imunológico, a susceptibilidade a doenças e parasitas é consequentemente aumentada (Dappen, 1982; Camargo \& Alonso, 2006). Finalmente, estudos preliminares demonstram que a interação de compostos nitrogenados com outros 
contaminantes (pesticidas, PCBs, PAHs, dioxinas, etc) também pode potencializar os efeitos negativos sobre os anfíbios e contribuir decisivamente para o seu declínio global (Marco \& Ortiz-Santaliestra, no prelo).

Tais cenários de estresse múltiplo são particularmente prováveis de acontecer em corpos d'água lênticos e temporários, principalmente em poças e drenagens construídas em sistemas agrícolas, onde diversas espécies de anuros se reproduzem (Babbitt \& Tanner, 2000; Vasconcelos \& Rossa-Feres, 2005). Devido as dimensões relativamente pequenas desses corpos hídricos, os contaminantes podem atingir grandes concentrações, e o impacto de fatores moduladores da sensibilidade ecotoxicológica (por exemplo temperatura, pH e oxigênio dissolvido) é fortemente aumentado.

Portanto, trabalhos futuros que testem as consequências das interações sinérgicas entre nitrogênio inorgânico e outros estressores físicos, químicos ou biológicos terão grande utilidade na avaliação do risco ambiental da contaminação por nitrogênio. Além disso, é de fundamental importância que as concentrações de nitrogênio inorgânico sejam monitoradas em campo. Com isso, saberemos a que concentrações os girinos são de fato expostos na natureza, e principalmente, poderemos detectar o local e a grandeza das contaminações. Consequentemente poderemos avaliar como as atividades humanas estão afetando a qualidade ambiental, bem como os efeitos dessa degradação sobre a biodiversidade. Recentemente, a poluição por nitrogênio foi considerada uma das três maiores ameaças a biodiversidade do mundo (Townsend \& Howarth, 2010), e tudo indica que as descargas de nitrogênio no meio ambiente aumentarão ainda mais no futuro (Camargo \& Alonso, 2006). Logo, é imperativo que a sociedade maneje esse elemento de forma mais eficiente (Townsend \& Howarth, 2010).

Primeiramente, a utilização dos fertilizantes na agricultura pode e deve ser feita de forma mais eficiente, pois cerca de $50 \%$ do $\mathrm{N}$ aplicado não é absorvido 
pelas culturas (Galloway, 1998) e acaba sendo transportado e depositado nos corpos d'água da bacia de drenagem (Marco \& Ortiz-Santaliestra, no prelo). A conservação de áreas com vegetação no entorno dos habitats aquáticos utilizados pelos anfíbios também pode reduzir significativamente a quantidade de compostos nitrogenados que entrariam nesses ambientes (Muscutt et al., 1993). A manutenção de áreas ripárias é considerada a melhor prática de manejo em muitas áreas dos EUA e Europa, pois a absorção pelos vegetais e a denitrificação que ocorrem nessas áreas removem tipicamente 85\% do nitrogênio dissolvido na água, preservando assim a qualidade do ecossistema aquático (Matson et al., 1999). Outra estratégia que poderia reduzir pela metade o consumo de fertilizantes nitrogenados seria a redução do consumo de carne, pois grande parte da produção agrícola destina-se a alimentação de rebanhos (Townsend \& Howarth, 2010). Claramente, nenhuma dessas soluções é simples de ser aplicada, mas se almejamos a manutenção da qualidade e integridade ambiental, é imprescindível que essas estratégias sejam empregadas e gerenciadas corretamente.

\section{Conclusões}

1. O nitrato, a forma de nitrogênio mais abundante na natureza, é de baixa toxicidade quando comparada a nitrito e amônio.

2. Há significativa variação interespecífica na sensibilidade das larvas de anuros ao nitrogênio inorgânico.

3. O ranqueamento de sensibilidade das espécies ao nitrato e ao nitrito são similares, possivelmente por conta de mecanismos comuns de ação tóxica. 
4. Se houver exposição prolongada, mesmo concentrações relativamente baixas de nitrogênio inorgânico podem afetar às larvas de anuros reduzindo suas chances de sobrevivência e sucesso reprodutivo.

\section{Referências Bibliográficas}

AGREN, G.I. \& E. BOSATTA. 1988. Nitrogen saturation of terrestrial ecosystems.

Environmental Pollution 54: 185-197.

ALLAN, G.L.; MAGUIRE, G.B. \& HOPKINS, S.J. 1990. Acute and chornic toxicity of ammonia to juvenile Metapenaeus macleayi and Penaeus monodon and the influence of low dissolved-oxygen levels. Aquaculture 92: 277-288.

ALONSO, A. \& CAMARGO, J.A. 2003. Short-term toxicity of ammonia, nitrite, and nitrate to the aquatic snail Potamopyrgus antipodarum (Hydrobiidae, Mollusca). Bulletin of Environmental Contamination and Toxicology 70: 1006-12.

ALONSO, A. \& CAMARGO, J.A. 2004. Toxic effects of unionized ammonia on survival and feeding activity of the freshwater amphipod Eulimnogammarus toletanus 
(Gammaridae, Crustacea). Bulletin of Environmental Contamination and Toxicology 72: 1052-8.

ANDA. Associação Nacional para Difusão de Adubos. 2003. Anuário estatístico do setor de fertilizantes - 2002. São Paulo, SP, Brazil. 158 pp.

ANHOLT, B.R.; SKELLY, D.K. \& WERNER, E.E. 1996. Factors modifying antipredator behaviour in larval toads. Herpetologica 52: 301-313.

ASTM. 2004. American Society for Testing and Materials. Active standard: E1439-98(2004) Standard Guide for Conducting the Frog Embryo Teratogenesis Assay-Xenopus (FETAX).

BABIKER, I.S.; MOHAMED, M.A.A.; TERAO. H.; KATO, K. \& OHTA, K. 2004. Assessment of groundwater contamination by nitrate leaching from intensive vegetable cultivation using geographical information system. Environment International 29: 1009-1017.

Blaustein, A.R.; Romansic, J.M.; Kiesecker, J.M. \& Hatch, A.C. 2003. Ultraviolet radiation, toxic chemicals and amphibian population declines. Diversity \& Distributions 9: 123140.

BAKER, J.M.R. \& WAIGHTS, V. 1993. The effect of sodium nitrate on the growth and survival of toad tadpoles (Bufo bufo) in the laboratory. Herpetological Journal 3: 147-148.

BAKER, J.M.R. \& WAIGHTS, V. 1994. The effects of nitrate on tadpoles of the tree frog (Litoria caerulea). Herpetological Journal 4: 106-108.

BARINAGA, M. 1990. Where have all the frogs gone? Science 247: 1033-1034.

BLAUSTEIN, A.R. \& WAKE, D.B. 1995. The puzzle of declining amphibian populations. Scientific American 272: 52-57.

Berger, L. 1987. Impact of agriculture intensification on Amphibia. Pp. 79-82. In van Gelder, J.J., H. Strijbosh and P.J.M. Bergers (Eds.), Proceedings of the Fourth Ordinary General Meeting of the Societas Europaea Herpetologica. Nijmegen, Netherlands.

BERGER, L. 1989. Disappearance of amphibian larvae in the agricultural landscape. Ecology International Bulletin 17: 65-73.

BERVEN, K., 1990. Factors affecting population fluctuations in larval and adult stages of the wood frog (Rana sylvatica). Ecology 71: 1599-1608.

BERTOLUCI, J. 1997. Fenologia e seleção de hábitat em girinos da Mata Atlântica em Boracéia (Amphibia, Anura). Tese de Doutorado. Universidade de São Paulo.

BIRGE, W. J., A. G. WESTERMAN, AND J. A. SPROMBERG. 2000. Comparative toxicology and risk assessment of amphibians. Pp 727-791. In Sparling, D.W.; Linder, G. \& Bishop, C.A. (eds), Ecotoxicology of amphibians and reptiles. Society of Environmental Toxicology and Chemistry Press, Pensacola, Florida.

BOGARDI, I.; KUZELKA, R.D. \& ENNENGA, W.G. 1991. Nitrate Contamination: Exposure, Consequence, and Control. NATO ASI series G - Ecological Sciences, Vol 30. Springer-Verlag, New York.

BOKERMANN, W.C.A. 1962. Observações biológicas sobre Physalaemus cuvieri Fitz.,1826 (Amphibia, Salientia). Revista Brasileira de Biologia 22(4): 391-399. 
CAIRNS, J.Jr.; HEATH, A.G. \& PARKER, B.C. 1975. The effects of temperature upon the toxicity of chemicals to aquatic organisms. Hydrobiologia 47: 135-171.

CAMARGO, J.A.; ALONSO, A. \& SALAMANCA, A. 2005. Nitrate toxicity to aquatic animals: A review with new data for freshwater invertebrates. Chemosphere 58: 1255-1267.

CAMARGO, J.A. \& ALONSO, A. 2006. Ecological and toxicological effects of inorganic nitrogen pollution in aquatic ecosystems: A global assessment. Environment International 32: 831-849.

CAMARGO, J.A. \& J.V. WARD. 1992. Short-term toxicity of sodium nitrate $\left(\mathrm{NaNO}_{3}\right)$ to nontarget freshwater invertebrates. Chemosphere 24: 23-28.

CETESB. 2009. Relatório de qualidade das águas superficiais no estado de São Paulo. Disponível em: <http://www.cetesb.sp.gov.br/publicacoes/publicacoes.asp>. Acessado em 29/07/2010

COOKE, A.S. 1972. Indications of recent changes in status in the British Isles of the frog (Rana temporaria) and the toad (Bufo bufo). Journal of Zoology 167: 161-178.

CROUZET, P.; J. LEONARD, S. NIXON, Y. REES, W. PARR, L. LAFFON, J. BØGESTRAND, P. KRISTENSEN, C. LALLANA, G. IZZO, T. BOKN, J. BAK, 1999. Nutrients in European Ecosystems. European Environment pp. 1-155.

CRUMP, M.L., F.R. HENSLEY, K.L. CLARK.1992. Apparent Decline of the Golden Toad Underground or Extinct? Copeia: 413-420.

DAPPEN, G. E., 1982. Effects of nitrates upon hemopoietic, lymphoid and vascular tissues of tadpoles and frogs. Proceedings of the Nebraska Academy of Sciences and Affiliated Societies 92: 23.

DAYTON, G.H., \& FITZGERALD, L.A. 2001. Competition, predation, and the distributions of four desert anurans. Oecologia 129: 430-435.

DIAMOND, J.M.; MACKLER, D.G.; RASNAKE, W.J. \& GRUBER, D. 1993. Derivation of sitespecific ammonia criteria for an effluent-dominated headwater stream. Environmental Toxicology and Chemistry 12(4): 649-658.

ECKERT, R.; RANDALL, D. \& AUGUSTINE, G. 1988. Animal physiology, mechanisms and adaptations, $3^{\text {rd }}$ ed. W.H. Freeman and Company, New York.

EDWARDS, D.R. \& DANIEL, T. C., 1994. Quality of runoff from fescue grass plots treated with poultry litter and inorganic fertilizer. Journal of Environmental Quality 25: 579584.

EDWARDS, T.M., MCCOY, K.A., BARBEAU, T., MCCOY, M.W., THRO, J.M. \& GUILLETE JR., L.J. 2006. Environmental context determines nitrate toxicity in Southern toad (Bufo terrestris) tadpoles. Aquatic Toxicology 78: 50-58.

EGEA-SERRANO, A., TEJEDO, M. \& TORRALVA, M. 2008. Analysis of the Avoidance of Nitrogen Fertilizers in the Water Column by Juvenile Iberian Water Frog, Pelophylax perezi (Seoane, 1885), in Laboratory Conditions. Bulletin of Environmental Contamination and Toxicology 80: 178-183. 
EIAFAC. 1984. Water quality criteria and criteria for european freshwater fish. European Inland Advisory Commission Tech, FAO, Roma.

EMERSON, K.; RUSSO, R.C.; LUND, R.E. \& THURSTON, R.V. 1975. Aqueous ammonia equilibrium calculations: effect of $\mathrm{pH}$ and temperature. Journal of Fisheries Research Board of Canada 32: 2379-2383.

ENVIRONMENT CANADA. 2003. Canadian Water Quality Guildelines for the Protection of Aquatic Life: Nitrate Ion. Ecosystem Health: Science-based Solutions Report No. 16. National Guidelines and Standards Office, Water Policy and Coordination Directorate, Environment Canada. 115pp.

ESTEVES, F.A. 1998. Fundamentos de Limnologia. $2^{\text {a }}$ ed. Editora Interciência, Rio de Janeiro.

FERRO, V.G. \& DINIZ, I.R. 2007. Arctiidae (Insecta: Lepidoptera) da Estação Biológica de Boracéia (Salesópolis, São Paulo, Brasil). Biota Neotropica 7(3): 1-8.

FILOSO, S.; MARTINELLI, L.A.; HOWARTH, R.W.; BOYER, E.W. \& DENTENER. F. 2006. Human activities changing the nitrogen cycle in Brazil. Biogeochemistry 79: 61-89

GALLOWAY, J.N. 1998. The global nitrogen-cycle: Changes and consequences. In Van der Hoek, K.W.; Erisman, J.W.; Smeulders, S.; Wisniewski, J.R. \& Wisniewski, J. (Eds.), Nitrogen, the Confer-N-s: First International Nitrogen Conference. 23-27 March 1998 Noordwijkerhout, Netherlands. Elsevier, Amsterdam., pp. 15-24.

GOATER, C.P.; SEMLITSCH, R.D. \& BERNASCONI, M. 1993. Effects of body size and parasite infection on the locomotory performance of juvenile toads, Bufo bufo. Oikos 66: 129-136.

GOSNER, K. L. 1960. A simplified table for staging anuran embryos and larvae with notes on identification. Herpetologica 16:183-190.

GRIFFIS-KYLE, K.L. 2007. Sublethal effects of nitrite on eastern tiger salamander (Ambystoma tigrinum tigrinum) and wood frog (Rana sylvatica) embryos and larvae: implications for field populations. Aquatic Ecology 41: 119-127.

GRIFFISKYLE, K.L. \& RITCHIE, M.E. 2007. Amphibian survival, growth an development in response to mineral nitrogen exposure and predator cues in the field: an experimental approach. Oecologia 152:633-642.

GRIME, J.P. 1979. Plant Strategies and Vegetation Processes. John Wiley, London, England.

GUILLETTE, L. J. \& EDWARDS, T.M. 2005. Is Nitrate an Ecologically Relevant Endocrine Disruptor in Vertebrates? Integrative and Comparative Biology 45: 19-27.

HADDAD, C. F. B. \& SAZIMA, I. 1992. Anfíbios anuros da Serra do Japi. In Morellato, L.P.C. (Org.), História natural da Serra do Japi: ecologia e preservação de uma área florestal no Sudeste do Brasil, pp. 188-211. Editora da UNICAMP/FAPESP, Campinas.

HALLING-SORENSEN, B. \& JORGENSEN, S.E. 1993. The Removal of Nitrogen Compounds From Wastewater. Elsevier Science Publishers. Amsterdam, Netherlands, 443pp. 
HAMER, A.J.; MAKINGS, J.A.; LANE, S.J \& MAHONY, M.J. 2004. Amphibian decline and fertilizers used on agricultural land in south-eastern Australia. Agriculture Ecosystems \& Environment 102(3): 299-305.

HATCH, A.C. \& BLAUSTEIN, A.R. 2000. Combined effects of UV-B, nitrate and low pH reduce the survival and activity level of larval Cascades Frogs (Rana cascadae). Archives of Environmental Contamination and Toxicology 39(4): 494-499.

HEYER, W.R.; RAND, A.S.; CRUZ, C.A.G.; PEIXOTO, O.L. \& NELSON, C.E. 1990. Frogs of Boracéia. Arquivos de Zoologia 31(4): 231-410.

HEYER, W.R.; MCDIARMID, R.W. \& WEIGMANN, D. 1975. Tadpoles predation an pond habitats in the tropics. Biotropica 7: 100-111.

HECNAR, S.J. 1995. Acute and chronic toxicity of ammonium nitrate fertilizer to amphibians from southern Ontario. Environmental Toxicology and Chemistry 14: 2131-2137.

HENRIKSEN, A. \& BRAKKE, F. 1988. Increasing contributions of nitrogen to the acidity of surface warters in Norway. Water, Air, and Soil Pollution 42: 83-201.

HOKE, R. A., \& ANKLEY, G.T. 2005. Application of frog embryo teratogenesis assay-xenopus to ecological risk assessment. Environmental Toxicology and Chemistry 24:26772690.

HORNE, A.J. \& GOLDMAN, C.R. 1994. Limnology. 2 Ed. McGraw Hill, New York, 576 pp.

HOWE, G.E.; MARKING, L.L.; BILLS, T.D.; RACH, J.J. \& MAYER, F.L. 1994. Effects of water temperature and $\mathrm{pH}$ on toxicity of terbufos, trichlorfon, 4-nitrophenol and 2,4dinitrophenol to the amphipod Gammarus pseudolimnaeus and rainbow trout Oncorhynchus mykiss. . Environmental Toxicology and Chemistry 13:51-66.

HUEY, D.W. \& BEITINGER, T.L. 1980. Hematological responses of larval Rana catesbeiana to sublethal nitrite exposures. Bulletin of Environmental Contamination and Toxicology. 25: 574-577.

IFA. Internationa Fertilizer industry Association. 2008. Assesment of Fertilizer Use by Crop at the Global Level. Paris, França.

IUCN. International Union for Conservation of Nature. 2006. Global Amphibian Assessment. http://www.globalamphibians.org. Acesso em 29 Setembro 2006.

JOFRE, M.B. \& KARASOV, W.H. 1999. Direct effect of ammonia on three species of north american anuran amphibians. Environmental Toxicology and Chemistry 18: 18061812.

JOHANSSON, M.; RA"SA"NEN, K. \& MERILA, J. 2001. Comparison of nitrate tolerance between different populations of the common frog, Rana temporaria. Aquatic Toxicology 54: 1-14

JOHNSON, C.J.; BONRUD, P.A.; DOSCH, T.L.; KILNESS, A.W.; SENGER, K.A.; BUSCH, D.C. \& MEYER, M.R. 1987. Fatal outcome of methemoglobinemia in an infant. Journal of the American Medical Association. 257: 2796-2797. 
JUSTIE, N.; RABALAIS, N.N.; TURNER, R.E. \& DORTCH, Q. 1995. Changes in nutrient structure of river dominated coastal waters: stoichiometric nutrient balance and its consequences. Estuarine, Coastal and Shelf Science 40: 339-356.

KALFF, J. 2002. Limnology. Prentice Hall, New Jersey, EUA.

KELSO, B.H.L.; GLASS, D.M. \& SMITH, R.V. 1999. Toxicity of nitrite in freshwater invertebrates. In Wilson, W.S.; Ball, A.S. \& Hinton, R.H. (Eds), Managing risks of nitrites to human and the environment. Royal Society of Chemistry, Cambridge, Pp175-88.

KWOK, K.W.H.; LEUNG, K.M.Y.; LUI, G.S.G.; CHU, V.K.H.; LAM, P.K.S.; MORRITT, D.; MALTBY, L.; BROCK, T.C.M.; BRINK, P.J.V.; WARNE, M.ST. \& CRANE, M. 2007. Comparison of Tropical and Temperate Freshwater Animal Species' Acute Sensitivities to Chemicals: Implications for Deriving Safe Extrapolation Factors. Integrated Environmental Assessment and Management 3(1): 49-67.

LARSSON, U., ELMGREN, R. \& WULF, F. 1985. Eutrophication and the Baltic Sea: causes and consequences. Ambio 14: 9-14.

LEFCORT, H. 1996. Adaptive, chemically mediated fright response in tadpoles of the Southern Leopard Frog, Rana utricularia. Copeia 2:455-459.

LIPS, K.R. 2000. Decline of a tropical amphibian fauna. In 166th National Meeting of the American Association for the Advancement of Science (AAAS) and Science Innovation Exposition. Washington, 17-22 Fevereiro 2000.

MACÍAS, G.; MARCO, A. \& BLAUSTEIN, A.R. 2007. Combined exposure to ambient UVB radiation and nitrite negatively affects survival of amphibian early life stages. Science of the Total Environment 385: 55-65.

MARCO, A. \& BLAUSTEIN, A.R. 1999. The effects of nitrite on behavior and metamorphosis in cascades frogs (Rana cascadae). Environmental Toxicology and Chemistry 18 : 946-949.

MARCO, A.; QUILCHANO, C. \& BLAUSTEIN, A.R. 1999. Sensitivity to nitrate and nitrite in pond-breeding amphibians from the Pacific Northwest. Environmental Toxicology and Chemistry 18: 2836-2839.

MARCO, A. \& ORTIZ-SANTALIESTRA, M. No prelo. Pollution: Impact of Reactive Nitrogen on Amphibians (NITROGEN POLLUTION).

MARTINELLI, L.A.; COLETTA, L.D.; RAVAGNANI, E.C.; DE CAMARGO, P.B.; J OMETTO, P.H.B.; FILOSO, S. \& VICTORIA, R.L. no prelo. Dissolved nitrogen in rivers: comparing pristine and impacted regions of Brazil.

MARTINS, M. 1993. Observations on the reproductive behaviour in the Smith Frog, Hyla faber. Herpetological Journal 3: 31-34.

MATSON, P.A.; MCDOWELL, W.H.; TOWNSEND, A.R. \& VITOUSEK, P.M. 1999. The globalization of $\mathrm{N}$ deposition: ecosystem consequences in tropical environments. Biogeochemistry 46: 67-83. 
MATTHEWS, E. 1994. Nitrogenous fertilizers: Global distribution of consumption and associated emissions of nitrous oxide and ammonia. Global Biogeochemical Cycles 8: $411-439$.

McCOY, E. F. 1972. Role of bacteria in the nitrogen cycle in lakes. 16010, EHR 03/72. Environmental Protection Agency, Water Pollution Control Service, Washington, DC.

McDOWELL, L.L. \& McGREGOR, K.C. 1979. Nitrogen and phosphorus losses in runoff from no-till soybeans. Transactions of the ASAE 23(3): 643-648.

MORIN, P.J. 1983. Predation, competition, and the composition of larval anuran guilds. Ecological Monographs 53(2): 119-138.

MUIR, P.R.; SUTTON, D.C. \& OWENS, L. 1991. Nitrate toxicity to Penaeus monodon protozoea. Marine Ecology 108: 67-71.

MUMMERT, A.K.; NEVES, R.J.; NEWCOMB, T.J. \& CHERRY, D.S. 2003. Sensitivity of juvenile freshwater mussels (Lampsilis fasciola, Villosa iris) to total and unionized ammonia. Environmental Toxicology and Chemistry 22: 2545-53.

MUSCUTT, A.D.; HARRIS, G.L.; BAILEY, S.W. \& DAVIES, D.B. 1993. Buffer zones to improve water-quality. A review of their potential use in UK agriculture. Agriculture Ecosystems \& Environment 45: 59-77.

NEWMAN, R.A. \& A.E. DUNHAM. 1994. Size at metamorphosis and water loss in a desert anuran (Scaphiopus couchii). Copeia 2: 372-381.

NUGENT, M.; KAMRIM, M.A.; WOLFSON, L. \& D'ITRI,.F.M. 2001. Nitrate: a drinking water concern. Michigam State University Extension Service, Extension bulletin WQ-19. Disponível em: < http://www.gem.msu.edu/pubs/msue >. Acesso em 18 Setembro 2006.

OECD. Organization for Economic Cooperation and Development. 1995. Guidance document for aquatic effects assessment. Paris (FR): OECD Environment Monograph 92, Environment Directorate.

OLDHAM, R.S.; LATHAN, D.M.; HILTON-BROWN, D.; TOWNS, M. COOKE, A.S. \& BURN, A. 1997. The effect of ammonium nitrate fertilizer on frog (Rana temporaria) survival. Agriculture, Ecosystems and Environment 61: 69-74.

ORTIZ, M.E.; MARCO, A.; SAIZ, N. \& LIZANA, M. 2004. Impact of ammonium nitrate on growth and survival of six european amphibians. Archives of Environmental Contamination and Toxicology 47: 234-239.

ORTIZ-SANTALIESTRA, M.E.; MARCO, A.; FERNANDEZ, M.J. \& LIZANA, M. 2006. Influence of developmental stage on sensitivity to ammonium nitrate of aquatic stages of amphibians. Environmental Toxicology and Chemistry 25: 105-111.

OWENS, L.B.; VANKEUREN, R.W. \& EDWARDS, W.M. 1983. Nitrogen loss from a highfertility, rotational pasture program. Journal of Environmental Quality 12(3): 346350 . 
PACES, T. 1982. Natural and anthropogenic flux of major elements from central Europe. Ambio 11: 206-208.

RAMOS, A.D. \& GASPARINI, J.L. 2004. Anfíbios do Goiapaba-Açu, Fundão, Estado do Espírito Santo. Gráfica Santo Antonio, Vitória.

RELYEA, R.A. \& WERNER, E.E. 1999. Quantifying the relation between predator-induced behavior and growth performance in larval anurans. Ecology 80: 2117-2124.

RESENDE, A.V. 2002. Agricultura e qualidade da água: contaminação por nitrato. Planaltina, Brasília: Embrapa Cerrados. 29p.

ROUSE, J.D.; BISHOP, C.A. \& STRUGER, J. 1999. Nitrogen pollution: An assessment of its threat to amphibian survival. Environmental Health Perspectives 107: 799-803.

RUBIN, A.J. \& ELMARAGHY, G.A. 1977. Studies on the toxicity of ammonia, nitrate and their mixtures to guppy fry. Water Research 11: 927-935.

RUSSO, R.C. 1985. Ammonia, nitrite and nitrate. In Fundamentals of aquatic toxicology (Rand,.M.G. \& Petrochelli, S.R. (Eds), Hemisphere Publishing Corporation, Washington, Pp.455-471.

SBH. Sociedade Brasileira de Herpetologia. 2010. Lista de espécies de anfíbios do Brasil. http://www.sbherpetologia.org.br/checklist/anfibios.htm. Acesso em 29 Julho 2010.

SCHIESARI, L.C. 2004. Performance tradeoffs across resource gradients in anuran larvae. PhD Dissertation. University of Michigan, Ann Arbor, Michigan, USA.

SCHIESARI, L.; GRILLITSCH, B. \& GRILLITSCH, H. 2007. Biogeographic biases in ecotoxicological research and their consequences for linking amphibian declines to pollution. Conservation Biology 21(2): 465-471.

SCHINDLER, W.D. 1990. Experimental perturbations of whole lakes as tests of hypotheses concerning ecossystem structure and function. Oikos 57: 25-41.

SCHUYTEMA, G.S. \& NEBEKER, A.V. 1999a. Comparative toxicity of ammonium and nitrate compounds to Pacific treefrog and African clawed frog tadpoles. Environmental Toxicology and Chemistry 18: 2251-2257.

SCHUYTEMA, G.S. \& NEBEKER, A.V. 1999b. Comparative effects of ammonium and nitrate compounds on Pacific treefrog and African clawed frog embryos. Archives of Environmental Contamination and Toxicology 36: 200-206.

SCHUYTEMA, G.S. \& NEBEKER, A.V. 1999c. Effects of Ammonium Nitrate, Sodium Nitrate and Urea on Red-legged Frogs, Pacific Treefrogs, and African Clawed Frogs. Bulletin of Environmental Contamination and Toxicology 63: 357-364.

SMITH, D.C. 1987. Adult recruitment in chorus frogs: effects of size and date at metamorphosis. Ecology 68: 344-350.

SKELLY, D.K. \& WERNER, E.E. 1990. Behavioral and life-historical responses of larval American toads to an odonate predator. Ecology 71:2313-2322.

SEMLITSCH, R.D. 1993. Asymmetric competition in mixed populations of tadpoles of the hybridogenetic Rana esculenta complex. evoution 47(2): 510-519. 
SHINN, C.; MARCO, A. \& SERRANO, L. 2008. Inter- and intra-specific variation on sensitivity of larval amphibians to nitrite. Chemosphere 71:507-514.

SMITH, D.C. 1987. Adult recruitment in chorus frogs: effects of size and date at metamorphosis. Ecology 68:344-350.

SMITH, G.R.; TEMPLE, K.G.; VAALA, D.A. \& DINGFELDER, H.A. 2005. Effects of Nitrate on the tadpoles of two ranids (Rana catesbeiana and $R$. clamitans). Archives of Environmental Contamination and Toxicology 49: 559-562.

SPRAGUE, J.B. 1985. Factors that modify toxicity. In: Rand, G.M. \& Petrocelli, S.R. (Eds), Fundamentals of aquatic toxicology. Bristol (UK): Taylor \& Francis. p 124-163.

STERNER, R.W. \& ELSER, J.J. 2002. Ecological stoichiometry: the biology of elements from molecules to the biosphere. Princeton Univ. Press, 439p.

STODDARD, J.L. 1994. Long-term changes in watershed retention of nitrogen: its causes and aquatic consequences. In Baker, L.A. (Eds), Environmental chemistry of lakes and reservoirs. American Chemical Society, Washington, Pp.223-284.

THOMANN, R.V. \& MUELLER, J.A. 1987. Principles of Surface Water Quality Modeling and Control. Harper \& Row, New York.

TOMASSO, J.R. \& CARMICHAEL, G.J. 1986. Acute toxicity of ammonia, nitrite and nitrate to the Guadeloupe bass, Micropterus treculi. Bulletin of Environmental Contamination and Toxicology 36: 866-870.

TOWNSEND, A.R.; BRASWELL, B.H.; HOLLAND, E.A. \& PENNER. J.E. 1996. Spatial and Temporal Patterns in Terrestrial Carbon Storage Due to Deposition of Fossil Fuel Nitrogen. Ecological Applications 6: 806-814.

TOWNSEND, A.R. \& HOWARTH, R.W. 2010. Fixing the Global Nitrogen Problem. Scientific American 302(2): 64-71.

TURNER, R.E. \& RABALAIS, N.N. 1991. Changes in Mississippi River water quality this century. BioScience 41: 140-147.

VERDADE, V.K.; CARNAVAL, A.C.; RODRIGUES, M.T.; SCHIESARI, L.C.; PAVAN, D. \& BERTOLUCI, J.A. no prelo. Decline of amphibians in Brazil. In Heatwole, H. \& Wilkinson, J.W. (Eds), Amphibian conservation. Surrey Beatty \& Sons, Chipping Norton.

VERDADE, V.K. ; RODRIGUES, M.T. \& PAVAN, D. 2009. Anfíbios Anuros da região da Estação Biológica do Alto da Serra de Paranapiacaba. In Lopes, M.I.M.S.; Kirizawa, M. \& MELO, M.M.R.F. (Eds), Patrimônio da Reserva Biológica do Alto da Serra de Paranapiacaba. A antiga Estação Biológica do Alto da Serra. São Paulo: Editora Secretaria do Meio Ambiente do Estado de São Paulo, Pp. 579-604.

VITOUSEK, P.M.; ABER, J.D.; HOWARTH, R.W.; LIKENS, G.E.; MATSON, P.A.; SCHINDLER, D.W.; SCHLESINGER, W.H. \& TILMAN, D. 1997. Human alteration of the global nitrogen cycle: sources and consequences. Ecological Applications 7: 737-750. 
XU, Q. \& OLDHAM, R.S. 1997. Lethal and sublethal effects of nitrogen fertilizer ammonium nitrate in common toad (Bufo bufo) tadpoles. Archives of Environmental Contamination and Toxicology 32: 298-303.

WAKE, D.B. 1991. Declining Amphibian Populations. Science 253: 860.

WAKE, D.B. \& H.J. MOROWITZ. 1991. Declining amphibian populations: a global phenomenon? Findings and recommendations. Alytes 9: 33-42.

WASSERSUG, R. 1971. On the comparative palatability of some dry-season tadpoles from Costa Rica. American Midland Naturalist 86: 101-109.

WATT, P.J. \& OLDHAM, R.S. 1995. The effect of ammonium nitrate on the feeding and development of larvae of the smooth newt, Triturus vulgaris $(L)$, and on the behaviour of its food source, Daphnia. Freshwater Biology 33(2): 319-324.

WERNER, E.E. 1992. Individual behavior and higher-order species interactions. American Naturalist 140: 5-32.

WERNER, E.E. \& ANHOLT, B.R. 1993. Ecological consequences of the trade-off between growth and mortality rates mediated by foraging activity. American Naturalist 142 : 242-272.

WERNER, E.E. \& PEACOR, S.D. 2003. A review of trait-mediated indirect interactions in ecological communities. Ecology 84(5): 1083-1100.

WESTIN, D.T. 1974. Nitrate and nitrite toxicity to salmonoid fishes. Proguessive Fish-Culturist 36: 86-89.

WETZEL, R.G. 2001. Limnology. Lake and River Ecosystems. 3th Ed. Academic Press, San Diego, 1006pp.

WETZEL, R.G. 1983. Limnology. 2nd Ed. Saunders College Publishing, New York, 767p.

WILBUR, H.M. 1976. Density-dependent aspects of metamorphosis in Ambystoma and Rana sylvatica. Ecology 57: 1289-1296.

WILBUR, H. M. 1987. Regulation of structure in complex systems: experimental temporary pond communities. Ecology 68:1437-1452.

WILBUR, H.M. 1997. experimental ecology of food webs: complex systems in temporary ponds. The Robert H. MacArthur Award Lecture. Ecology 78: 2279-2302.

WOOTTON, J.T. \& POWER, M.E. 1993. Productivity, consumers, and the structure of a river food chain. Proceedings of the National Academy of Sciences of the United States of America 90: 1384-1387.

YOUNG, J.P.W. 1992. Phylogenic classification of nitrogen-fixing organisms. Pp 43-86. In Stacey, G.; Burris, R.H. \& Evans, H. (Eds.), Biological Nitrogen Fixation. Chapman and Hall, New York.

ZAR , J. 1999. Biostatiscal analysis. Upper Saddle River Prentice Hall, New Jersey. 663p. 